\title{
Financial fragility
}

Citation for published version (APA):

Benink, H. A. (1996). Financial fragility. [Doctoral Thesis, Maastricht University]. Universiteit Maastricht. https://doi.org/10.26481/dis.19961213hb

Document status and date:

Published: 01/01/1996

DOI:

10.26481/dis.19961213hb

Document Version:

Publisher's PDF, also known as Version of record

\section{Please check the document version of this publication:}

- A submitted manuscript is the version of the article upon submission and before peer-review. There can be important differences between the submitted version and the official published version of record.

People interested in the research are advised to contact the author for the final version of the publication, or visit the DOI to the publisher's website.

- The final author version and the galley proof are versions of the publication after peer review.

- The final published version features the final layout of the paper including the volume, issue and page numbers.

Link to publication

\footnotetext{
General rights rights.

- You may freely distribute the URL identifying the publication in the public portal. please follow below link for the End User Agreement:

www.umlib.nl/taverne-license

Take down policy

If you believe that this document breaches copyright please contact us at:

repository@maastrichtuniversity.nl

providing details and we will investigate your claim.
}

Copyright and moral rights for the publications made accessible in the public portal are retained by the authors and/or other copyright owners and it is a condition of accessing publications that users recognise and abide by the legal requirements associated with these

- Users may download and print one copy of any publication from the public portal for the purpose of private study or research.

- You may not further distribute the material or use it for any profit-making activity or commercial gain

If the publication is distributed under the terms of Article $25 \mathrm{fa}$ of the Dutch Copyright Act, indicated by the "Taverne" license above, 


\section{Financial Fragility}




\section{Financial Fragility}

\section{PROEFSCHRIFT}

ter verkrijging van de graad van doctor aan de Universiteit Maastricht

op gezag van de Rector Magnificus, Prof.mr. M.J. Cohen, volgens het besluit van het College van Decanen, in het openbaar te verdedigen op vrijdag 13 december 1996 om 16.00 uur

door

Harald Alexander Benink

geboren te Geldrop 
Promotores:

Prof.dr. C.C.P. Wolff

Prof.dr. J.J. Sijben (Katholieke Universiteit Brabant)

Beoordelingscommissie:

Prof.dr. W.F.J. Buijink (voorzitter)

Prof.dr. C.G. Koedijk

Prof.dr. L.M. van Leeuwen (Katholieke Universiteit Brabant) 


\section{Acknowledgement}

When writing a thesis about financial fragility one cannot prevent being confronted with one's own fragility. During the years I have been working on this dissertation I often had the feeling that my research was focusing on both types of fragility at the same time.

Many persons have played an inspiring role during my 'dissertation period'. First of all, I would like to thank my supervisors: Professors Jacques Sijben and Christian Wolff. Jacques Sijben, with his everlasting inspiring and extravert style, interested me for monetary and financial economics when I was still a student at Tilburg University. Actually, the subject of this thesis is strongly linked to his lectures and research. Christian Wolff showed me the importance of (empirical) research that can also be published in international journals. Moreover, influenced strongly by the period he worked in the U.S. and the U.K., he pleasantly made clear the advantages of going to international conferences and of networking with professors working in the same field. Many thanks to both of them.

Next, I would like to acknowledge the members of my dissertation committee: Professors Willem Buijink, Kees Koedijk, and Luck van Leeuwen. Each of them has been a different source of inspiration and interaction. Willem Buijink, with whom I have worked for several years in the board of the department of accounting and finance, always surprises me with his distinctly mixed Dutch/Belgian style of communication. Kees Koedijk has been a support in many ways and circumstances, both inside and outside LIFE. Luck van Leeuwen has always intrigued me with his relaxed style of moving around in the financial, political, and academic circles. Many thanks for the pleasant contacts and interaction.

My colleagues at the Finance Department of Maastricht University have contributed to an inspiring atmosphere. I would like to mention especially Professor Peter Schotman, who with his remarks on the (im)possibilities of econometrics has given me an introduction in this magical world. Also special thanks to the 'old club' at the Finance Department: Professors Piet Eichholtz, Arthur Herst, and Alireza Tourani Rad. Finally, I thank Nathalie Jansen and Carina Wijnands for their kind secretarial support. 
My parents, brothers, and sister are acknowledged for their interest and support. Especially, I would like to thank my father and mother for their support and their patience when waiting for this dissertation to be finalized.

Finally, my friends are credited for the many non-academic things we have experienced together. Titus van Heur and Bart Rubbens have been around for many years. Special thanks to Hans van den Braak, Hans Hattink, and Anneke de Knegt for their never-ending support. Anneke de Knegt is also thanked for her design of the cover of this thesis.

Harald Benink

November 1996 


\section{Preface}

Most chapters in this thesis are based on previously written papers and articles. Chapter 2 is based on Benink (1993b). Chapter 3 originates from Benink, Koedijk and Nieuwland (1995). Chapter 4 draws on Benink (1994). Chapter 5 is based on Benink and Llewellyn (1994b). Chapter 6 is based on Benink and Llewellyn (1995). Finally, chapter 7 originates from Benink and Wolff (1996). 


\section{Table of Contents}

1 Introduction 1

2 Theories of Financial Fragility 9

2.1 Risk and Uncertainty in Economics 10

2.2 Financial Fragility in a Risk/Uncertainty Framework 11

2.3 Banking Fragility 22

2.4 Banking Fragility: Private Sector Solutions 25

2.5 Banking Fragility: Regulatory Solutions 27

2.6 Conclusion 29

3 Extreme Value Theory and Market Assessments of the Riskiness of U.S. Banks 33

3.1 Deregulation and the U.S. Banking Sector 34

3.2 Extreme Value Theory and the Tail Index Estimator 36

3.3 Data Description and Empirical Results 37

3.4 Conclusion 55

4 The U.S. Banking Crisis $\quad 57$

4.1 Wolfson's Empirical Analysis $\quad 58$

4.2 Sectoral Analysis for 1946-1987 63

4.3 Update for the Period 1988-1992 75

$\begin{array}{ll}4.4 \text { Conclusion } & 80\end{array}$ 
5.1 Financial Deregulation 83

5.2 Data and Methodology 88

5.3 Empirical Results 90

5.4 Interpretation 93

5.5 Conclusion 94

6 Systemic Stability and Competitive Neutrality Issues in the International Regulation of Banks

6.1 International Dimension to Regulation 98

6.2 Systemic Stability and Competitive Neutrality 101

6.3 Banking and Securities Business 107

6.4 Conclusion 113

7 Survey Data and the Interest Rate Sensitivity of U.S. Bank Stock Returns

7.1 Model and Data Selection 119

7.2 The Period 1974-1993 Using ARIMA Processes 123

7.3 The Period 1980-1993 Using Survey Data 125

7.4 Interpretation and Conclusion 126

8 Summary and Conclusion $\quad 129$

$\begin{array}{lll}8.1 \text { Summary } & 129\end{array}$

8.2 Conclusion 134

$\begin{array}{ll}\text { References } & 137\end{array}$

$\begin{array}{ll}\text { Nederlandse Samenvatting } & 147\end{array}$

$\begin{array}{ll}\text { Curriculum Vitae } & 155\end{array}$ 


\section{Chapter 1 \\ Introduction}

Recent events of financial disorder (international debt crisis, junk bond crisis, stock market crashes, bank failures) have caused renewed interest in the subject of financial fragility. Davis (1992) defines financial fragility as a state of balance sheets offering heightened vulnerability to default in a wide variety of circumstances. Heffernan (1996) notes that this heightened probability of default implied by the term financial fragility can be used for the fragility of households, businesses, or banks themselves. However, many authors specifically use financial fragility focusing their analyses on banks.

Minsky was one of the first authors to introduce the term 'financial fragility'. Minsky (1977) discusses financial fragility as the opposite of financial robustness. In a fragile financial system continued normal functioning can be disrupted by some not unusual event. In this sense such a fragile system is more susceptible to future outbreaks of financial disorder.

David Mullins, vice chairman of the Federal Reserve Board in the United States (U.S.), was quoted in The Economist (1993) in the following way:

"The 1970s was a period of instability which brought down the regulatory structures of an earlier area; in the 1980s traditional banking went out of the window".

Furthermore, The Economist (1996) states:

"Since the Bretton Woods system of fixed exchange rates was abandoned in the early 1970 s, the banking industry seems to have jumped from one drama to another, including the Latin American debt crisis, the $\$ 150$ billion American savings and loan fiasco and, more recently, a property-related lending binge that forced several Scandinavian governments to bail out large chunks of their banking systems".

On top of this, the U.S. was also confronted with failures of its commercial banks, Japan encountered major banking problems, Britain's Barings Bank collapsed, Crédit Lyonnais in France was confronted with spectacular losses, 
and Banco di Napoli had to be supported by an emergency rescue plan of the Italian government.

The aim of this thesis is to analyze the recent banking problems from a theoretical (chapter 2), empirical (chapters 3, 4, 5, and 7) and institutionalregulatory (chapter 6) point of view. The empirical chapters 3, 4, and 7 focus on the U.S., while chapter 5 deals with Norway, Sweden, and Finland.

In chapter 2 we present an overview of the various theories of financial fragility and disorder. In the first part of this chapter we will argue that the crucial difference between these theories lies in the assumed framework on risk and uncertainty. In the second part of the chapter, and in the other chapters of this thesis, we will focus our analysis of financial fragility on the fragility of the banking system, the so-called banking fragility.

Chapter 2 starts with an analysis of the use of the concepts of risk and uncertainty in economics. Next, we put the various theories of financial fragility in a risk/uncertainty framework. The 'pure' case of rational expectations and efficient markets is only conceivable in a risk framework, i.e. uncertainty can be reduced to the 'correct and objective' probability distribution. We proceed by discussing the possibility of rational bubbles and rational runs as a rationalization for turbulent periods of financial disorder. The concept of genuine uncertainty is the cornerstone of two other theories of financial disorder, namely unanticipated credit rationing and irrational bubbles and euphoria. Finally, we discuss the asymmetric information literature with respect to financial fragility. This literature focuses on information asymmetries between borrowers and lenders causing uncertainty about the quality of borrowers.

During the 1980s and first part of the 1990s the banking sector in many countries experienced a process of rapid deregulation, increased risk taking, and major banking crises. This banking fragility will be the subject of the second part of chapter 2. We will discuss private sector (market-based) and regulatory solutions in order to cope with banking fragility.

Chapter 3 deals with extreme value theory and market assessments of the riskiness of banks in the U.S. Since the 1970s the U.S. banking system has experienced major changes in terms of new financial products, deregulation, increasing competition, lower margins and changing risk attitudes. To a large extent the prevailing banking regulations at the beginning of the 1970 s mirrored the legislation adopted after the banking crisis of 1929-1933. The banking 
failures of 1929-1933 induced the Banking (Glass-Steagall) Act of 1933 which changed fundamentally the parameters of the functioning of the U.S. banking system. Federal deposit insurance was introduced in order to avoid new bank runs. The activities of banks were restricted with a view to the perceived excessive competition of the previous period. Commercial and investment banking were separated, each type of bank was restricted to a specific type of lending and interstate banking was discouraged. Furthermore, payment of interest on demand deposits was prohibited and interest rates on time deposits were restricted to a maximum.

By the late 1970 s, the regulations were widely viewed as excessively restrictive on the ability of banks to respond to changes in the environment that showed advances in telecommunications and information processing technology, financial innovation, increases in interest rates and higher volatility. As a result, the profitability of banks was reduced and non-bank competitors grew rapidly. The U.S. Congress reacted by adopting two major deregulation acts.

The Depository Institutions Deregulation and Monetary Control Act (DIDMCA) of 1980 and the Garn-St.Germain Depository Institutions Act (DIA) of 1982 reduced the governmental restrictions on depository institutions. The Act of 1980 phased out interest rate ceilings and permitted all depository institutions to offer NOW (negotiable order of withdrawal) accounts, allowing greater competition for deposits among banks. Loan rate ceilings were weakened. This Act, in combination with the Act of 1982, also increased competition between banks and S\&Ls by expanding the realm of the S\&L business. Furthermore, federal deposit insurance was increased from $\$ 40,000$ to $\$ 100,000$ in 1980 .

The movement towards a more deregulated and competitive equilibrium increased the efficiency of the U.S. banking system: it expanded the choices for savers and investors, reduced the cost of financial transactions, and improved the allocation of saving and investment nationally and internationally (Corrigan 1990). On the other hand, however, deregulation could be responsible for the deterioration of bank asset quality during the 1980 s and the substantial increase in bank failures.

We contribute to the empirical literature by assessing the degree of riskiness of the twenty largest U.S. bank holding companies between 1973 and 1993. More specifically, we investigate the extent to which developments in the 1980s, in particular deregulation, have led to significantly higher risk for U.S. banks. Since the efficient market hypothesis indicates that there is a direct and continuous relationship between information on the fundamental value of financial assets and their market price. we will use stock returns of the twenty largest 
U.S. bank holding companies as our information variable. Most studies on risk measurement of banks have used average properties like expected retum or volatility (see for instance Bruni and Patemo 1995), while relatively little attention has been paid to the use of extreme movements. Rothschild and Stiglitz (1970) underline the importance of the tails of the statistical distribution for asset prices. They stress that the weights in the tails of random variables give a better definition of increasing risk than a standard one, like for instance the usual variance. In this chapter we will concentrate on the tail of the distribution as our measure of risk. In order to get accurate measures of the tails of distribution we will make use of extreme value theory. This provides us with an effective measure of the degree of riskiness of the underlying stock.

The organizing principle of extreme value theory is the fatness in the tails of the distribution. Extremal analysis investigates the distribution of the maximum (minimum) in large samples, thereby determining the shape of the tails of a distribution. In fact, the limit law for the maximum is characterized by the socalled tail index $\alpha$, which happens to be equal to the number of moments that exists. Ihus, the tail index is a good indicator for the thickness of the tails. The important point to note is that alternatives like the stable and student $t$ distribution are nested within the limit law for extremes. The idea then is to estimate this tail index directly and use the known distribution of the tail estimator to test for possible regime switches affecting the type of distribution, i.e. as a result of the deregulation measures in the 1980s. The loss of this procedure consists of information about the center characteristics of the distribution. Given the predominance of outliers in asset return series, one may benefit from this trade-off. Moreover, given an estimate for the tail index, one can establish the sizes of the extremely low or high returns that would be rarely exceeded.

In chapter 4 we analyze banking crises in the U.S. during the period 1946-1992. Starting point for our analysis is Wolfson (1990) who presents an empirical analyis aimed at explaining so-called 'financial instability' in the U.S. banking sector during the period 1946-1987. Wolfson's approach is an aggregate analysis of all U.S. commercial banks and savings \& loan associations (S\&Ls). Using the standard OLS regression technique Wolfson estimates a regression equation in which 'financial instability' is regressed as a dependent variable upon four independent variables. These four independent variables are indicators of tinancial fragility in the commercial banking or S\&L sector. 'Financial instability' is taken to be the actual outbreak of problems in the financial system whereas the term 'financial fragility' is designed to measure the vulnerability of 
the system to the future outbreak of these problems.

The aim of this chapter is twofold. First, since Wolfson provides an aggregate analysis for the commercial banks and savings \& loan associations together, we disaggregate the analysis in order to look for differences among the two sectors. Second, we present an update of Wolfson's analysis including the turbulent period 1988-1992 during which the U.S. experienced a lot of banking problems.

In chapter 5 we present an empirical analysis of the Scandinavian banking crisis at the end of the 1980s and the beginning of the 1990s. Up to the early 1980s the banking system in the Nordic countries (Norway, Sweden, and Finland) can be characterized as a highly regulated regime consisting of controls on interest rates, credit controls and capital controls. The rapid process of financial liberalization and deregulation intensified dramatically competition between financial institutions. This led to an unprecedented growth in bank lending. Although in the early phase of the expansion banking appeared to be very profitable, developments towards the end of the decade indicated that profitability had been over-estimated and risks under-rated. Massive rescue and support operations (state ownership, capital injections, guarantees etc.) were mounted in Norway, Sweden and Finland. Atle-Berg (1993) calculates that the volume of official support operations by 1992 amounted to 2.8 per cent, 3.1 per cent and 7.2 per cent of GNP in Norway, Sweden and Finland respectively. The interesting point about Norway, Sweden and Finland is that the transition from a regulated and uncompetitive banking sector to a less regulated and more competitive regime went together with a banking crisis of unprecendented scale. This could suggest, that at least during the transitional phase, risk awareness and risk pricing were not adequate.

In this chapter we present maximum likelihood estimates for pooled banking data of Norway, Sweden and Finland during the period 1980-1992. Our main focus is upon the question whether the failures and solvencies of commercial and savings banks in the Nordic countries were significantly related to mounting credit losses or to a deterioration of net interest margins. If the empirical analysis shows that mounting credit losses played a significant role in the banking crises of Norway, Sweden and Finland and that, at the same time, the bank failures and insolvencies were not caused by a significant deterioration of net interest margins, then a logical interpretation could be that banks have not been able to charge adequate risk premia in order to be compensated for the higher lending risks after deregulation had taken effect. This would result in 
built-up capital reserves being too small in order to be able to bear the credit losses and, consequently, in massive bank failures and insolvencies.

In chapter 6 we analyze systemic stability and competitive neutrality issues in the international regulation of banks. The increasing globalization of banking and finance means that autarky (self-sufficiency at the national level) is no longer a feasible strategy in financial regulation: there is the potential for regulation determined at the national level to be undermined by developments in other regulatory jurisdictions, and regulatory requirements in one country have impacts in others. This creates a standard case for international regulatory cooperation as, given the externalities involved, co-operative strategies have the potential to increase the effectiveness of regulation, and limit the scope for regulatory arbitrage.

The focus of this chapter is upon the international dimension to regulation in two areas (banking and securities business) which, while they have common considerations, also raise different issues. The focus is upon two issues in internationally co-operative regulatory strategies: systemic stability and competitive neutrality.

Chapter 7 presents an empirical analysis of the interest rate sensitivity of U.S. bank stock returns. The interest rate sensitivity of U.S. bank stock returns has been the research topic of many academic papers. Most papers start from the two-index model developed by Stone (1974). This asset pricing model expands the standard market model of asset returns by adding an interest-rate index. The function of this interest rate factor is to account for the influence of unexpected interest rate changes on the stock returns of banks. Empirical research by, among others, Fama and Schwert (1977) and Folger, Kose and Tipton (1981) has shown that the inclusion of an interest-rate factor adds substantial explanatory power to the single-factor market model.

The contribution of this chapter to the literature is twofold. First, using weekly data for the period 1974-1993 and using the forecast errors of autoregressive integrated moving average (ARIMA) processes in order to model the unexpected interest rate, we provide empirical evidence on the interest rate sensitivity of the stock returns of the twenty largest U.S. bank holding companies during a long period of twenty years incorporating recent data.

The second contribution of this chapter is to use survey data in order to model the unexpected interest rate variable. This is an alternative approach compared to the existing literature. Flannery and James (1984) and Robinson 
(1995) use the forecast errors of an autoregressive (AR) model as a proxy for unexpected interest rate movements. Scott and Peterson (1986), Sweeney and Warga (1986) and Kane and Unal (1988) use changes in the yield on a given maturity of long-term government bonds to capture unanticipated changes in interest rates. Finally, Mishkin (1982) and Brewer and Lee (1985) proxy unanticipated changes in interest rates by the difference between the spot threemonth Treasury bill rate at time $t$ and the forward three-month Treasury bill rate imbedded in the yield curve at time $t$-1. In this chapter we use weekly survey data on the U.S. federal funds rate for the period April 29, 1980 until December 22, 1993. The survey was conducted by Money Market Services (MMS) International (part of Standard \& Poor's) in Belmont, California. The weekly surveys generate a market expectation for the federal funds rate for a certain survey period which is then confronted with the realized value of the federal funds rate during the same survey period. This enables us to calculate an unexpected change in the federal funds rate for the relevant survey period which is then used for estimating the interest rate sensitivity in the two-index model.

Chapter 8 summarizes and concludes this thesis. 



\section{Chapter 2}

\section{Theories of Financial Fragility}

Recent events of financial disorder (international debt crisis, junk bond crisis, stock market crashes, bank failures) have caused renewed interest in the subject of financial fragility. Davis (1992) defines financial fragility as a state of balance sheets offering heightened vulnerability to default in a wide variety of circumstances. Heffernan (1996) notes that this heightened probability of default implied by the term financial fragility can be used for the fragility of households, businesses, or banks themselves. However, many authors specifically use financial fragility focusing their analyses on banks.

Minsky was one of the first authors to introduce the term 'financial fragility'. Minsky (1977) discusses financial fragility as the opposite of financial robustness. In a fragile financial system continued normal functioning can be disrupted by some not unusual event. In this sense such a fragile system is more susceptible to future outbreaks of financial disorder.

In the first part of this chapter we will present an overview of the various theories of financial fragility and disorder. We will argue that the crucial difference between these theories lies in the assumed framework on risk and uncertainty. In the second part of this chapter, and in the other chapters of this thesis, we will focus our analysis of financial fragility on the fragility of the banking system, the so-called banking fragility.

Section 2.1 presents an analysis of the use of the concepts of risk and uncertainty in economics. In section 2.2 we put the various theories of financial fragility in a risk/uncertainty framework. We first present theories of financial fragility characterized by a full understanding of risk, i.e. uncertainty can be reduced to the 'correct and objective' probability distribution. These theories, being the rational expectations and efficient markets literature (subsection 2.2.1) and the literature on rational bubbles and runs (subsection 2.2.2), contain a postive view on periods of financial disorder. Basically, these periods of financial disruption are not causing serious damage to financial markets and the economy since agents are fully risk aware. In this context such periods are nonevents. Section 2.2 continues by discussing other theories of financial fragility, comprised of the literature on unanticipated credit rationing (subsection 2.2.3), 
irrational bubbles and euphoria (subsection 2.2.4), and asymmetric information (subsection 2.2.5). The common element of these theories is that they all analyze a financial system characterized by an incomplete understanding of risk, thereby leaving room for uncertainty. However, they differ from each other in the way they model uncertainty. The irrational bubbles and euphoria literature is extreme in the sense that uncertainty is completely untractable and invincible. The other theories take positions somewhere in between the polar cases of uncertainty and risk.

During the 1980s and first part of the 1990s the banking sector in many countries experienced a process of rapid deregulation, increased risk taking, and major banking crises. This banking fragility will be the subject of section 2.3 . In section 2.4 we will discuss private sector (market-based) solutions in order to cope with banking fragility. In section 2.5 we focus on regulatory solutions. Section 2.6 concludes the chapter.

\subsection{Risk and Uncertainty in Economics}

With respect to the measurability of probability Knight (1921) distinguishes three types of probability:

* A priori probability.

This probability is derived mathematically. An example is the probability that a coin toss will produce a particular value.

* Statistical probability.

This probability rests on an empirical classification of instances and can not be derived from mathematical laws or principles.

* Estimates or judgements.

The distinguishing characteristic is that there is no valid basis of any kind for classifying instances. The essential and outstanding fact is that the instance in question is so entirely unique that there are no others or not a sufficient number to make it possible to tabulate enough like it to form a basis for any inference of value about any real probability.

The first two cases of probability are called 'risk' by Knight. The third case embodies non-measurable probability and is referred to as '(true) uncertainty'. 
Forty years later, in 1961, Muth presented the concept of rational expectations. He postulates that economic agents form their expectations on the basis of the 'true' structural model of the economy: "Expectations, since they are informed predictions of future events, are essentially the same as the predictions of the relevant economic theory". The hypothesis of rational expectations asserts that the subjective expectations of individuals are exactly the true mathematical conditional expectations implied by the model itself.

In a rational expectations world economic agents make optimal forecasts, i.e. no systematic predictions or expectations errors. Put more technically: the expectations errors conditional on the available information set have zero means and the expectations errors are uncorrelated with the values of all the variables in the information set and therefore with their own past values (Pesaran 1987). The notion of optimal forecasts crucially depends on knowledge of the objective distribution implied by the true model, i.e. uncertainty is reduced to objective risk. The optimality properties of rational expectations will follow only if agents know, or are capable of learning, the true model of the economy. Meltzer (1982) observes that the stochastic process used in standard rational expectations models misses some of the principal uncertainties that most of us face as consumers and producers.

\subsection{Financial Fragility in a Risk/Uncertainty Framework}

In this section we put the various theories of financial fragility in a risk/uncertainty framework. Attention will be paid to rational expectations and efficient markets (subsection 2.2.1), rational bubbles and rational runs (subsection 2.2.2), unanticipated credit rationing (subsection 2.2.3), irrational bubbles and euphoria (subsection 2.2.4), and to asymmetric information (subsection 2.2.5).

\subsubsection{Rational Expectations and Efficient Markets}

In a rational expectations world economic agents know the correct and objective probability distribution, which enables them to price correctly financial assets (efficient market hypothesis). In such a world defaults represent bad outcomes ex post, rather than systematic misperception of the true ex ante odds. Applying this reasoning to the market for junk bonds, Miller (1991) argues: 
"The yields expected (in the Markowitz sense of yield outcomes weighted by probability of occurrence) on junk bonds, were below the nominal or promised yields. The high promised yields that might be earned during the good years were understood as compensation for the possible bad years in time and bad bonds in the total junk bond portfolio. The high nominal yields, in short, were essentially risk premiums. And in 1989, for many of the junk bonds issued earlier, the risk happened".

The above world can be characterized by the existence of a stable, competitive equilibrium in which financial firms make normal profits, risks are adequately covered in loan pricing, underwriting margins and capitalization. Although the system may be subject to shocks, these do not generate systemic crises. In such an equilibrium, risk premia are sufficient to cover losses over the economic cycle. The shift to such an equilibrium from an imperfectly competitive or oligopolistic market (where insufficient credit was advanced and intermediaries gained monopoly profits) should not be a cause for vigilance, but instead a pure welfare gain (Davis 1990). The financial innovation process of the 1970s and 1980 s is viewed as very positive, since as a result of this process financial markets have become more competitive, complete, and operationally efficient (Van Horne 1985). Miller (1986) reasons:

"By the middle and late 1960 s, the recovery in world wealth (and trade) had proceeded so far that the taxes, interest rate ceilings, foreign exchange restrictions, security sales regulations, and other competitive controls slapped on in the 1930 s and 1940s were becoming increasingly onerous. It was not so much that new tax and regulatory burdens were being imposed, but more that the existing burdens were increasingly binding, particularly so given the surges in the level and volatility of prices, interest rates, and exchange rates that were erupting in those years. Many of the inefficient tax and regulatory structures inherited from the 1930s and 1940s will have been driven at last from the scene along with so many of the obsolete economic and political doctrines that gave rise to them".

Although the financial innovation and deregulation process went together with a rise in debt ratios during the 1980s (see section 2.3), this does not necessarily imply overleveraging. The increase in the aggregate debt/equity ratio reflects, seen from a macroeconomic perspective, changing preferences of households for holding wealth (Miller 1988). Higher debt ratios and increased financial fragility can be considered as a rational choice of risk aware agents on financial markets. 
The increased financial fragility may increase the likelihood of periods of financial disorder, but it should not be considered automatically as an undesirable thing and as a rationale for increased regulation by international supervisory authorities. If risks are known and correctly priced by market participants, then these periods of financial disorder are unlucky, but calculated events.

\subsubsection{Rational Bubbles and Rational Runs}

In a world of rational expectations and efficient markets one would expect asset prices to reflect market fundamentals. However, there can be rational deviations of the price from this value. These deviations are called rational speculative bubbles (Blanchard and Watson 1982).

Standard rational expectations models relate the price variable $\mathrm{p}(\mathrm{t})$ to fundamentals $f(t)$, which are determined by a linear combination of exogenous variables (intrinsic information, i.e. information incorporated in the fundamentals). The possibility of a rational bubble arises by adding the bubble term $b(t)$ to the above equation, so that $p(t)=f(t)+b(t)$. This bubble term $b(t)$ follows a stochastic time path imposed on the system. Crucial is that this bubble term is determined arbitrarily by extrinsic information (not incorporated in the market fundamentals) and refers neither directly nor indirectly to any observable phenomena (Mullineux 1990).

According to Flood and Garber (1982) a bubble can arise when the actual market price depends positively on its own expected rate of change, as normally occurs in asset markets. Since agents forming rational expectations do not make systematic prediction errors, the positive relationship between price and its expected rate of change implies a similar relationship between price and its actual rate of change. In such conditions, the arbitrary, self-fulfilling expectations of price changes may drive actual price changes independently of market fundamentals. This movement away from market fundamentals is caused by rational speculation.

The concept of arbitrary, self-fulfilling expectations can be metaphorized by the 'beauty contest' described by Keynes in his General Theory (1936):

"Professional investment may be likened to those newspaper competitions in which the competitors have to pick out the six prettiest faces from a hundred photographs, the prize being awarded to the competitor whose choice most nearly corresponds to the average preferences of the competitors as a whole; so 
that each competitor has to pick, not those faces which he himself finds prettiest, but those which he thinks likeliest to catch the fancy of the other competitors, all of whom are looking at the problem from the same point of view. It is not a case of choosing those which, to the best of one's judgement, are really the prettiest, nor even those which average opinion genuinely thinks the prettiest. We have reached the third degree where we devote our intelligences to anticipating what average opinion expects the average opinion to be. And there are some, I believe, who practice the fourth, fifth and higher degrees".

An often cited example of a bubble is the appreciation of the U.S. dollar in the 1980s (see for instance Krugman 1985). At a certain moment many people argued that the dollar was overvalued and should decrease in value back to market fundamentals. However, the dollar appreciated even further before finally falling down. Apparently, if market participants have the arbitrary, i.e. not based on market fundamentals, expectation that the dollar will further appreciate, then a rational speculator will buy dollars. Since many speculators are doing so, the arbritrary expectation will become self-fulfilling with the result of an appreciating dollar. Our rational speculator has made a profit, which he would not have made with a strategy of selling dollars based on the perception of market fundamentals. Naturally, at a certain moment in time the bubble may burst. The essential difference between a rational and an irrational speculator is that the former is living in a world of risk and is capable of calculating this probability of a bursting bubble, while the latter is not because of uncertainty.

Not only bubbles, but also runs may be seen in a rational context (Flood and Garber 1982). A run is an event that terminates a price-fixing scheme. Some economic agents (perhaps the government) may stand ready to buy or sell a particular item at a fixed price. The viability of such a price-fixing scheme depends on the agent's maintaining a stock of the item. If other agents perceive that the price-fixing regime is temporary, that is, that the price will rise eventually, then anticipating capital gains, these agents draw down the stock that back the price-fixing scheme. If the stock is depleted entirely in one final discrete withdrawal, this event is categorized as a run.

Bank collapses can be caused by a run. A bank fixes the price of its deposits in terms of government currency. If the depositors fear a capital loss on their deposits, then they will deplete bank reserves of government currency, possibly with one final massive withdrawal, forcing the bank to cease fixing the price of its deposits. 
Another example of a rational run indicated by Flood and Garber (1982) may be the currency crisis prevalent in the 1960s and early 1970s. In the case of fixed exchange rates a government announces a fixed price for its currency in terms of the currency of another country and holds foreign currency reserves of this other country. However, the government's stock of foreign currency reserves may be depleted through balance-of-payments deficits. If rational speculators can see no end to the deficits, then they anticipate the eventual demise of the fixed rate regime and may draw down government foreign exchange reserves in one final massive withdrawal - a rational run.

Reasoning from the rational framework, periods of financial disorder associated with rational (bursting) bubbles and rational runs are not undesirable events. Moreover, these so-called 'finance-driven' events cannot be blamed for causing depressions.

On the subject of the Great Depression in the early 1930s Miller (1991) remarks:

"Contrary to wide-held folk beliefs, bankruptcies did not bring on the Gireat Depression. The direction of causation runs from depression to bankruptcies, not the other way around. The collapse of the stock market in 1929 and of the U.S. banking system during 1931-1932 may well have created the appearance of a finance-driven disaster. But that disaster was not just the inevitable bursting of another overleveraged tulip bubble as some have suggested. Responsibility for turning an ordinary downturn into a depression of unprecedented severity lies primarily with the managers of the Federal Reserve System".

Hamilton (1987) presents evidence for this view that the Great Depression was caused by monetary factors. At the beginning of 1928 the Federal Reserve embarked on a highly contractionary monetary policy. Two reasons motivated this policy:

"While one factor in the initial decision may well have been a desire to stem the gold outflows, this cannot explain why the U.S. continued with this tight monetary policy even after higher interest rates were generating significant gold inflows by 1929. Instead, the major factor influencing monetary policy during 1928-1929 was surely the stock market. Despite repeated public assertions by Fed officials that the System did not regard itself as an arbiter of security prices, the consensus of most researchers who have studied Fed policy during this era 
is that the primary purpose of the monetary contraction was to curb the stock market boom".

In the monetary view the Fed succeeded in bringing the stock market down: in October 1929 the New York Stock Exchange collapsed. The crash was followed up by banking panics beginning in 1930. Friedman and Schwartz (1963) argue in their Monetary History that the banking panics led to a frightening away of the public from checking accounts, just as banks felt forced to increase their holdings of reserves relative to deposits. These increases in the currency-deposit ratio and reserve-deposit ratio account for the simultaneous rise in the monetary base and drop in the money supply (M1 and M2) during 1931-1933. The inability of the Federal Reserve to avert these banking panics and runs and the related drop in the money supply led to an even more severe contractionary regime compared with the period 1928-1930.

Summarizing, one could say that the monetary view of the Great Depression blames the Federal Reserve for two reasons. In the first place the monetary contraction of 1928-1929 to bring the stock market down, and in the second place the failure to prevent the banking panics and the drop in the money supply as from 1930. Miller (1991) notes that the U.S. money supply imploded by 30 percent between 1930 and 1932, dragging the economy and the price level down with it (deflation process).

Furthermore, as Bernanke (1983) argues, the deflation process may be reinforced by the fact that the banking failures undermined the ability of the financial sector to perform its intermediation services of evaluating and providing loans. More and more borrowers found credit to be expensive and difficult to obtain. The resulting credit squeeze had a negative influence on aggregate demand.

Miller (1991) sees as further confirmation of the monetary view that, because of the prompt action by the Federal Reserve to support the liquidity of the banking system after the stock market crash of October 19, 1987 (and again after the mini-crash of October 13, 1989), these crashes did not have a real impact. 


\subsubsection{Unanticipated Credit Rationing}

Guttentag and Herring (1984) develop a hybrid model of financial fragility and financial disorder, applying both the concepts of risk and uncertainty.

Bankers lend money to borrowers undertaking real investment projects with some probability distribution. Concerning the probability of an unfavourable outcome from this project-specific distribution, Guttentag and Herring assume that the subjective probabilities of market participants converge to the objective probabilities (rational expectations and risk in the sense of Knight). The reason for this convergence is that unfavourable outcomes are sufficiently frequent, so that participants who stubbornly cling to subjective probability distributions which differ from the objective distribution, will suffer losses and be forced to withdraw from the market.

However, 'nature' may draw from a disastrous distribution causing an unfavourable shift in the project-specific distribution of investment returns. Guttentag and Herring refer to infrequent shocks that have less-than-catastrophic direct consequences on real economic activity, but which, if not anticipated by lenders, may have serious financial consequences that substantially exacerbate the impact of the shock on real economic activity. The state of knowledge surrounding this disastrous distribution is less complete than in the case of the projectspecific distribution. There is a small but finite probability that disasters can happen. Market participants do not have a priori knowledge of the parameters of the distribution that governs whether nature draws from the disastrous distribution, nor do they have sufficient evidence to infer the parameters of the distribution from the historical record. This limited knowledge or ignorance can be qualified as true uncertainty in the sense of Knight.

Since the rational expectations and efficient market axioms do not apply in situations of uncertainty, Guttentag and Herring use the work of cognitive psychologists and decision scientists in order to formulate a hypothesis regarding the subjective probability of a disaster. This hypothesis is the 'disaster myopia' hypothesis. It consists of two components, namely the 'availability heuristic' and the 'threshold heuristic'. The availability heuristic implies that estimates of frequency or probability are influenced by the ease with which instances or associations can be brought to mind. Frequent events are usually easier to recall than infrequent events. The probability of an infrequent event is likely to be underestimated, particularly as time elapses since the last occurrence 
of the infrequent, disastrous event. The availability heuristic argues that, with the passage of time, the subjective probability of a disaster falls until it reaches a certain threshold where it drops to zero (threshold heuristic).

The disaster myopia hypothesis predicts a tendency for subjective probabilities to fall below actual probabilities of disaster during periods in which no major shocks occur. In an expanding economy with the absence of major shocks such a process may develop. Bankers will lend to borrowers against interest rates incorporating risk premia based on the subjective probabilities being lower than the objective, but unknown probabilities of disaster. Furthermore, bankers will decline their capital positions because of the lower perceived probabilities. This process of qualitative decline in credit and capital positions makes the financial system more fragile and increases the magnitude of periods of financial disorder.

When a shock occurs, the perceived probability will jump very quickly in the direction of the objective probability. The result will be bankers reconsidering their lending portfolios: prime borrowers start paying risk premia, risky borrowers will have to pay extra risk premia or get rationed, and borrowers already rationed before the shock will be rationed extra or cut off completely from bank credit. This adaptation process towards more market-conform risk premia and a higher level of credit rationing will enable lenders to improve their capital positions. Guttentag and Herring see as relevant examples of such shocks leading to financial disorder the failure of the Herstatt Bank and the collapse of the Franklin National Bank in 1974, and the Mexican debt crisis in 1982.

\subsubsection{Irrational Bubbles and Euphoria}

The 'irrational bubbles and euphoria' approach to financial disorder covers all the subjects of the previous subparagraphs, but interprets most of them in a different way. The heart of the argument lies in a different perception of the world: uncertainty instead of risk, which precludes the framework of rational expectations and efficient markets.

According to Minsky (1980) an economic theory that is relevant to a capitalist economy cannot evade the issues involved in unidirectional historical time by assuming recontracting and the existence of universal systems of future, or contingent, contracts. The essence of capitalism is that units have to take positions in an uncertain world. 
Minsky's so-called 'financial instability hypothesis' is grounded in an alternative interpretation of Keynes' General Theory (see Minsky 1975). The essential element of this interpretation, which is an alternative to the standard HicksHansen and Klein-Patinkin view, is untractable uncertainty: agents base their portfolio decisions on a very imprecise and shaky foresight of future developments, so that unexpected behavior of the economy can lead to a large change in the relative prices of assets, which is the root of a financial crisis (Delli Gatti and Gallegati 1995).

In the theories of Fisher and Minsky periods of financial disorder are an essential component of the turning point of the business cycle - a response to finance-driven excesses.

Fisher (1933) argues that during the upswing investment increases as well as speculation in asset markets for capital gain. The process is debt-financed, mainly by bank loans, increasing deposits, the money supply and the price level. Rising prices during the upswing reduce the real value of outstanding debt, offsetting the increase in nominal debt and encouraging further borrowing. The indebtedness of economic agents increases, and hence their chances of becoming insolvent (in modern terms we would say that financial fragility increases). However, essential is that Fisher perceives this indebtedness as an 'overindebtedness'. Apparently, increased indebtedness is not the outcome of a rational choice reflected in risk premia. If this is the case, a financial crisis can easily develop: debtors unable to pay debts and refinance positions can be forced by creditors to liquidate assets ('distress selling'). If this is widespread, and in the absence of lender-of-last-resort interventions by the monetary authorities, it can trigger further crises and a deep depression (debt-deflation process). Deflation increases the real value of outstanding debt. At the same time creditors see the nominal value of collateral declining with prices. The consequence of the two phenomena is that banks start calling loans, which reinforces the process of liquidating assets. Output and employment fall until bankruptcy has eliminated overindebtedness.

Minsky (1982 and 1986) further develops the concept of financial fragility in order to clarify the problem of overindebtedness. An important factor determining the degree of fragility is the changing mix of hedge, speculative and Ponzi finance during the upswing. In the case of hedge finance expected cash flows are sufficient to meet contractual payment commitments now and in the future. Speculative finance involves expected cash flows being lower than the 
cash payment commitments in some, typically near-term, periods. Cash flow deficiencies arise because there are commitments to pay cash on the account of principal that are greater than the receipts on principal account during these periods. Speculative financing involves the rolling over of maturing debt. Ponzi finance goes further: the amount of outstanding debt increases in some, nearterm, periods in order to be able to meet cash payment commitments. Minsky's point is that during the upswing there is a shift from hedge to speculative and Ponzi finance caused by an excess demand for finance and an insufficient perception of the risks involved ('euphoric expectations'). As the proportion of hedge units in the population of borrowers decreases, financial fragility increases. When it becomes clear that the aggregate cash flows do not validate debt any more (for instance a stream of overextended borrowers goes bankrupt), the network of financial relations collapses and a financial crisis sets in. This is the moment that fragility translates into financial instability and that, as in Fisher's analysis, a debt-deflation process starts'.

Carter (1989) notes that the volatility in this boom-bust cycle depends critically on the assumption that for quite some time during the upswing lenders (and borrowers too) systematically underestimate the increase in risk as borrowers' leverage rises and as near-term debt payments balloon in relation to near-term expected income flows. If lenders smoothly raised their lending rates to compensate for increased risk because of higher corporate leverage and lower balance sheet liquidity, and if borrowers smoothly raised the risk premia they added on to borrowing rates when discounting expected cash flows from highly leveraged investment, then the growth of investment and speculative credit arrangements would be slowed.

According to Minsky modern capitalism is prone to the recurrence of financially determined booms and busts: the financial instability hypothesis implies that instability is a systemic property of economies with complex financial structures. This instability of the financial system is caused by the fact that Minsky rejects the representative agent paradigm, in which no meaningful distinction can be drawn between banks and firms and where homogeneous agents are utility or profit maximizers in a world of certainty or certainty equivalence. Both firms and banks are conceptualized by Minsky as profit seeking agents trying to do their best in a world of untractable uncertainty (Delli Gatti and Gallegati 1995).

1 Sijben (1993 and 1994) discusses in detail the macroeconomic effects of financial fragility. 


\subsubsection{Asymmetric Information}

The theories discussed in the last two subparagraphs dealt with genuine uncertainty. This uncertainty is caused by incomplete information as a result of an inability to know all of the possible states of nature or the probabilities of their occurrence. However, information can also be incomplete in the sense that it is distributed asymmetrically so that some people know more than others and can exploit this informational advantage (Hester 1994). In this way a special type of uncertainty is created.

Akerlof (1970) argued that if one side of the market knows the quality of the good better than the other, then the number of exchanges is much lower than in a context of perfect information. Under certain circumstances there will not be a market at all. Akerlof illustrates his ideas with the market for used cars where asymmetric information exists between buyers and sellers in the sense that the seller has more information about the quality of the cars than the buyer. However, good cars and bad cars ('lemons') must still sell at the same price since it is impossible for a buyer to tell the difference between a good and a bad car. Because of the uniform price for all qualities, the owners of low quality cars receive a 'lemon premium' at the cost of those who supply high quality cars at the same price. The result is that the owners of good cars will prefer not to sell and that the market for used cars is reduced to a market on which only low quality cars are traded. Moreover, it is quite conceivable that the market for used cars ceases to exist.

The aymmetric information framwork has been extended to capital markets by Stiglitz and Weiss (1981). Information asymmetries exist between borrowers and lenders (banks) causing uncertainty about the quality of borrowers. Borrowers are better informed about their own credit risk than lenders. Consequently, lenders cannot differentiate between high-risk and low-risk borrowers causing them to charge an interest rate incorporating a lemon premium: highrisk borrowers are subsidized by low-risk borrowers. This creates an incentive for low-risk borrowers to leave the market and look for alternative sources of finance such as direct external financing on the capital market. The high-risk borrowers will stay. Because of this adverse selection effect the average quality of bank loans will deteriorate, thereby increasing the vulnerability of the banking system (Sijben 1993). 


\subsection{Banking Fragility}

In a number of recent publications the International Monetary Fund (IMF 1992a, 1992b, 1993a, and 1993b) analyzes the phenomenon that during the 1980 s and first part of the 1990s the banking sector in many countries experienced a process of rapid deregulation, increased risk taking, and major banking crises. The crucial question is why after a long postwar period of stability banking problems became so widespread.

Before the financial liberalization and deregulation of the 1980 s cartelized banking markets, in concert with a host of regulations, served to restrict competition in the financial services industry. Banks and other financial institutions thus enjoyed a financial cushion in the form of excess profits. Government-led deregulation and liberalization, with the related market-driven financial innovation process, lowered barriers to new domestic and foreign entrants, eliminated interest rate regulations, and weakened restrictions on bank activities. The resulting new financial environment can be characterized as a process of competition-driven disintermediation from banking systems - particularly from wholesale banking systems - into securitized money and capital markets. The securitization process implies a decline in the special role of banking: the need for customers to have direct access to bank-provided liquidity has diminished because many of the larger customers now have direct access to the money and capital markets. Increased competition led both to a weakening of the profitability of banks' traditional activities (price effect) and to a shift of many of the larger clients to direct finance on the money and capital markets (quantity effect). Both effects weakened the traditional sources of banks' income.

Faced with a potential downsizing of their operations, many banks responded to this new, less friendly environment by increasing the riskiness of their portfolios. This behavioral response of increased risk taking has been modelled in the theoretical literature. Park (1994), analyzing how deregulation increased the riskiness of U.S. banks in the 1980s. divides the literature into two main parts: the literature emphasizing the moral hazard of bank stockholders and the literature focusing on the incentives of bank managers. Both explanations are probably relevant and mutually reinforcing.

Proponents of the moral hazard view (Marcus 1984 and Keeley 1990) argue that banks had increased incentives to take risk in the 1980s for two main reasons: losses that impaired capital and reduced charter values due to greater competition. Lower capital reduces the exposure of stockholders and, thereby, 
their concern about probable losses resulting from increased risk taking. In addition to tangible capital, firms have charter values, which may be defined as the economic value deriving from the opportunity to do business in the future.

Keeley (1990) analyzes under a fixed-rate deposit insurance system the influence of increased competition on bank charter values, risk taking and capital ratios. Following Merton (1977) he views deposit insurance as a put option on the value of a bank's assets at a strike price equal to the promised maturity value of its debt. In the case of no banking regulation, banks seeking to maximize the value of their equity will maximize the value of the put by increasing asset risk and/or minimizing invested capital relative to assets. At the same time, however, regulation limits competition which endowes banks with market power and makes bank charters valuable. In this way the potential loss of a charter in the event of bankruptcy can counterbalance the incentive for excessive risk taking due to fixed-rate deposit insurance. Deregulation changes the subtle balance between these two effects. Because deregulation increases competition, bank charter values will decline and, consequently, banks reach earlier the point that increased risk taking becomes attractive: the expected gain to bank stockholders of the enhanced value of the deposit insurance put option exceeds the expected loss of the charter value.

Keeley's argument starts from the assumption of a fixed-rate deposit insurance which implies that increased risk taking does not lead to higher deposit insurance premiums that banks have to pay to the deposit insurance fund. In the case of risk-based deposit insurance premiums the incentive effect for increased risk taking would be mitigated because of the fact that higher expected returns in that case would have to be adjusted for the higher deposit insurance premiums.

The literature on the incentives of managers focuses on the possibility that bank managers have an incentive to take excessive risk when they are incompetent and profits are declining (Gorton and Rosen 1992). Until the early 1980s banking was a tightly regulated industry in which incompetent managers were able to make sufficient profits without taking excessive risk. Deregulation increased competition and decreased profitability in the 1980s. This made managerial ability more important. For incompetent managers not being able to prove their ability in the new competitive environment, taking excessive risk may have been a rational strategy for the sake of survival. 
The IMF mentions several dimensions in which the increased tolerance for risk showed up. The first dimension is the rapid expansion of bank balance sheets in many countries, particularly in the countries that were highly regulated until the first part of the 1980s. Bank lending as a percentage of GDP expanded in Japan from 61 to 94 percent between 1980 and 1990; in Norway from 64 to 85 percent between 1983 and 1986; in Sweden from 43 to 68 percent from 1986 to 1990; in Finland from 55 to 76 percent between 1986 and 1990; and in the U.S. from 30 to 34 percent between 1984 and 1986. The expansion in credit was generally accommodated during the 1980 s by the monetary authorities. The huge credit expansion led to an acceleration of prices in asset markets, concentrated in the residential and commercial real estate markets. The result was a growing concentration of bank lending in the real estate sector. Another dimension of increased risk taking is that, because of the decline of their traditional business, banks increased the share of their assets held in highly leveraged transactions, leveraged buyouts, developing country debt, and off-balance-sheet derivative products.

The higher risk business made banks more vulnerable to cyclical developments, particularly asset price adjustments. In the late 1980s and early 1990s the increased risks were exposed and turned into bank losses by a significant shift in economic conditions - whether a tightening of monetary policy, a large sectoral shock, a decline in asset prices, a prolonged period of slow economic activity, or a combination of these factors. Major banking crises of unprecedented scale since the Great Depression of the 1930s took place in the U.S., Norway, Sweden. Finland, and $\operatorname{Japan}^{2}$.

In its 1991/1992 annual report the Bank for International Settlements (BIS 1992) evaluates deregulation and financial innovation. The BIS notes that there is a widespread perception that deregulation and financial innovation have gone hand in hand with greater financial instability, be it in the form of 'excessive' fluctuations in asset prices or distress among financial institutions. According to the BIS, with hindsight, it is clear that the observed instability has involved an element of collective bad judgement. For instance, the real estate lending crisis resulted from "misplaced optimism regarding property values and hence the soundness of collateral". Furthermore, the BIS states:

\footnotetext{
'In chapters 3 and 4 of this thesis we present an empirical analysis of increased risk taking and the banking crisis in the United States. Chapter 5 contains an empirical study of the banking crises in Norway, Sweden, and Finland.
} 
"Moreover, the general euphoria which underlay many of these excesses was in part a by-product of the vigorous and long-lasting economic expansion of the 1980s. At the same time, the changes in the financial environment helped to make such collective errors of judgement more likely and their implications more serious and widespread internationally".

With its view that the banking crises involved an element of collective bad judgement, the BIS takes the position that financial markets cannot be characterized by fully risk aware agents. Bringing back into mind our discussion in section 2.2 of the various theories of financial fragility in a risk/uncertainty framework, this implies that the BIS identifies itself with the theories analyzing a financial system characterized by an incomplete understanding of risk, thereby leaving room for uncertainty ${ }^{3}$.

\subsection{Banking Fragility: Private Sector Solutions}

In the previous section we discussed recent episodes of banking fragility. In order to cope with this banking fragility, we can distinguish between private sector (market-based) solutions and regulatory solutions. This section focuses on private sector solutions and section 2.5 on regulatory solutions.

Horvitz (1995) notes that "the invisible hand that most economists believe in is not inconsistent with financial fragility". Most economists do have a strong preference for market solutions, though attitudes differ. The extreme view would be a belief in market efficiency and stability to the extent that we need to do nothing more to deal with the potential problem of financial fragility than rely on market forces (see also our discussion in section 2.2 on risk and uncertainty). A notable proponent of such a view is Schwartz (1995) by making the following statement:

\footnotetext{
${ }^{3}$ From our empirical analysis of the U.S. and Scandinavian banking crises in chapters 4 and 5 , it follows that a logical interpretation of the occurrence of these crises is that banks' risk awareness and risk pricing were not taking account of the increased riskiness of banking.
} 
"I believe instability of the financial services industry is attributable to destabilizing actions of monetary authorities and regulators; that the financial services industry is not inherently unstable; that the distress and failure of individual financial firms, whether owing to poor management or bad luck, is no threat to the system as a whole; that declines in asset prices indicate wealth losses, not financial crises; that a genuine financial crisis occurs only when the payments system is impaired".

Moreover, Schwartz states that there has been no genuine financial crisis during the past 15 years in the U.S. or globally despite stock market crashes, wide swings in prices of real estate, distress affecting individual commercial banks or banking systems, collapse of the U.S. savings and loans, failure of BCCI and the Maxwell conglomerate, and distressed insurance companies.

Horvitz (1995) notes that, even if the extreme view is rejected, the preference among most economists is for private sector solutions that minimize regulatory interference with the market and maximize so-called 'market discipline'.

Bruni and Paterno (1995) hold the view that private sector and regulatory solutions to the problem of financial fragility are deeply connected. To some extent market discipline can replace government supervision and regulation but, according to Bruni and Paternò, the main influence of market forces is to complement the efforts of supervisors and regulators: an adequate regulatory setting is needed for market disciplining mechanisms to be effective.

Market discipline means that financial markets provide signals that lead borrowers to behave in a manner consistent with their solvency. It implies that borrowers are led to pursue sustainable policies. Effective market discipline requires that capital markets be open, that information on the borrowers' existing liabilities be readily available, that no bailout be anticipated, and that the borrowers respond to market signals (Lane 1993).

In a situation of enhanced market discipline as a device for coping with banking fragility, banks will be under pressure to provide appropriate external disclosure on their various risk exposures and on the way they handle these risks. A professionalization of banks' internal risk management and control systems will be the result (Taylor 1995).

Referring to Citibank's internal risk management and control systems with respect to derivatives trading, Ruding (1995) remarks that these systems include independent risk managers overseeing all trading businessses; marking the 
derivatives portfolio to market on a daily basis; placing strict potential loss limitations on derivatives business relative to forecasted revenues; employing independent audit and operational control units; utilizing rigorous qualification standards with potential derivatives customers; and putting into place comprehensive tracking and record-keeping functions.

\subsection{Banking Fragility: Regulatory Solutions}

Financial markets are characterized by informational asymmetries and frictions, thereby creating a role for financial intermediaries such as banks. At the same time, however, these informational uncertainties also generate potential instability in the form of unanticipated deposit withdrawals and premature asset liquidations. Therefore, deposit-funded banks are vulnerable to runs, and the entire banking system may be vulnerable to panics. Many banking regulations, such as a lender of last resort facility and/or deposit insurance, can then be understood as measures to reduce this form of instability (Bhattacharya and Thakor 1993).

However, these regulatory interventions create problems of their own. In section 2.3, following the argument made by Merton (1977), we observed that fixed-rate deposit insurance is a put option which encourages excessive risk taking. This then necessitates a regulatory response. As Merton and Bodie (1992) note, this response may include monitoring, risk-based deposit insurance premiums, cash/asset reserve and capital requirements, portfolio restrictions, and limits on discount window borrowing.

Government regulation with respect to banking fragility aims at preventing two types of bank failures. First, the failures of individual banks, especially when these banks are large and perceived to be 'too big to fail'. Second, and more importantly, the focus is on the prevention of individual bank failures causing other banks to fail, thereby creating a collapse of the banking and financial system ('systemic failure') that spreads to the real sector of the economy (Horvitz 1995). This aspect of regulation pursues the achievement of systemic stability.

\footnotetext{
${ }^{4}$ In chapter 6 we will make the point that, while in some cases there is a potential case for international co-ordination to increase the effectiveness of regulation for systemic stability reasons, issues of competitive neutrality might be dominant, and at times, in conflict with the requirements of prudential regulation for systemic stability.
} 
Most of the banking crises during the 1980s and first part of the 1990s were related to credit risk, being the risk that a counterparty defaults on its position. One of the ways international regulators try to prevent new credit risk related banking problems is by strengthening credit risk solvency requirements. Within the context of the Bank for International Settlements the Basle Committee on Banking Regulations and Supervisory Practices reached in December 1987 an agreement which was published in its final form in July 1988. The agreement implies a strengthening and harmonization of solveny requirements for most banks in the industrialized countries. The harmonization comes down to the relating of uniformly defined own funds through uniform solvency ratios, to the uniformly defined risk-weighted value of assets and off-balance-sheet activities. The 1988 Basle Accord was implemented at the end of 1992.

Another way of preventing new banking problems is to set up a clear regulatory rule for closing an institution whose problems cannot be resolved before it becomes insolvent. If it is decided to let a bank with insufficient capital continue to operate in the hope that it may earn its way out of predicament, then regulatory scrutiny of its activities should be increased (IMF 1995a). In the U.S. the Federal Deposit Insurance Corporation Improvement Act (FDICIA) of 1991 puts into place a system of 'prompt corrective action' and is based, among others, on what Benston and Kaufman call 'structured early intervention and resolution'. FDICIA strengthens the ability of regulatory agencies to take early action with respect to banks whose capital ratios are declining.

During the $1980 \mathrm{~s}$, with the rapid development of securities and derivative markets as well as foreign exchange contracts, banks have become much more exposed to market risk (IMF 1995b). Market risk can be defined as the potential loss due to unexpected general market price and interest rate changes ${ }^{5}$. In order to introduce capital requirements for market risk, in April 1995 the Basle Committee announced a new proposal. The proposal allows banks to use their own internal risk management models to estimate the so-called 'value-at-risk' which is at the heart of determining the market risk capital requirements. Value-at-risk is an estimate of the maximum loss that a portfolio could generate with a given level of confidence and during a given period into the future. After finalizing the consultative phase with the international banking community, the proposal is due to be implemented at the end of December 1997.

s In chapter 7 we present an empirical study on the sensitivity of the stock returns of the twenty largest U.S. bank holding companies to unexpected interest rate changes. 


\subsection{Conclusion}

Corrigan (1990) summarizes the trade-off between efficiency and stability as follows:

"The globalization, innovativeness, and deregulation of financial markets have proven to be very much a two-edged sword. On the one hand, there is little doubt that these developments have expanded the choices for savers and investors, reduced the cost of financial transactions, and improved the allocation of saving and investment nationally and internationally. But, and this is a very large but, there is also no doubt - at least in my mind - that these same forces have also increased volatility in financial markets and introduced new and highly complex elements of risk - possibly even increasing systemic risk".

The central argument of this chapter is that globalization of financial markets, financial innovation and financial deregulation can work out in three ways (see also Sijben 1995):

* Imperfectly competitive or oligopolistic financial markets are opened to the forces of national and international competition and are becoming more operationally efficient, thereby generating welfare gains.

* The innovation process may increase debt ratios and volatility in asset prices and as a result financial fragility in the sense of vulnerability of the financial system to future outbreaks of financial disorder. If, however, the risks involved are known and correctly priced by market participants, then these periods of financial disorder are unlucky, but calculated events. Increased financial fragility may lead to more frequent periods of financial disorder without causing serious damage to the functioning of financial markets and the economy.

* If increased financial innovation and financial fragility go together with a lack of understanding of the risks involved, then underpricing and lack of risk awareness by financial agents will aggravate the consequences of a period of financial disorder: not fully calculated events may trigger shifts in confidence, affecting markets more than appears warranted by their significance and leading to a financial crisis. 
This chapter first presented theories of financial fragility characterized by a full understanding of risk, i.e. uncertainty can be reduced to the 'correct and objective' probability distribution. These theories, being the rational expectations and efficient markets literature and the literature on rational bubbles and runs, contain a postive view on periods of financial disorder. Basically, these periods of financial disruption are not causing serious damage to financial markets and the economy since agents are fully risk aware. In this context such periods are nonevents. The chapter continued by discussing other theories of financial fragility, comprised of the literature on unanticipated credit rationing, irrational bubbles and euphoria, and asymmetric information. The common element of these theories is that they all analyze a financial system characterized by an incomplete understanding of risk, thereby leaving room for uncertainty. However, they differ from each other in the way they model uncertainty. The irrational bubbles and euphoria literature is extreme in the sense that uncertainty is completely untractable and invincible. The other theories take positions somewhere in between the polar cases of uncertainty and risk.

Taking into account the remarks made above, the financial fragility debate boils down to the debate on risk and uncertainty. Based upon their subjective perception of the applicability of risk, uncertainty, or something in between, academics, regulators, and practitioners will come to different conclusions with respect to the functioning of financial markets and the desirability of regulation. Recently, two well known regulators delivering speeches at the same conference, reached different conclusions with respect to the potential dangers of derivatives. Jordan (1995), president of the Federal Reserve Bank of Cleveland and member of the U.S. Federal Open Market Committee, stated:

"The point is that there seems to be no reason to believe that the potential externality of increasingly complex financial relationships has outdistanced an increasingly powerful ability to internalize that potential externality. As long as economic agents are able to estimate compound probabilities of failures, systemic risk is indistinguishable from normal credit risk. Knowing your counterparty and your counterparty's counterparties, and even your counterparty's counterparties' counterparties, should lead to quality spreads in market prices, to prudent loan loss reserves and capital from which to absorb losses, and to equality of the private and social cost of risk". 
During the same conference Crockett (1995), general manager of the Bank for International Settlements, came to the following conclusion:

"The ability of some derivative products to significantly increase the leverage of market participants may increase aggregate uncertainty. I would also conjecture that because of the fundamental lack of transparency of some financial products and the difficulty of evaluating risk associated with them, the resulting concentration in some derivatives markets creates uncertainty externalities in other closely related markets. As a result of the close cross-market linkages, the uncertainty externalities cannot easily be segmented in periods of market volatility and stress. As participants seek to shield themselves against the impact of an event whose timing or probability of occurrence cannot be estimated, markets may at times experience an erosion of liquidity possibly leading to difficulties in other markets".

Davis (1989) calls for a synthesis of the different theories of financial fragility. Financial markets are probably more rational than they sometimes appear. However, a fundamental uncertainty will always be prevalent, casting doubts on "the indiscriminate use of superrationality as the foundation for models of financial behavior" (Modigliani 1988). This spirit is well expressed by Corrigan (1990):

"The first lesson of the 1980s could probably apply to almost any decade but may be especially relevant for the 1980s and that is the utmost need to be cautious about the extremes of economic doctrine and theory. Indeed, whether we are speaking of the Keynesian, the monetarist, the supply sider, the rational expectationalist, or any other school of thought, single-minded approaches to public policy can be very misleading, if not dangerous". 

Chapter 3

\section{Extreme Value Theory and Market Assessments of the Riskiness of U.S. Banks}

In the 1980s the U.S. banking sector experienced a period of great turmoil. During the past decade the number of bank failures increased sharply and banks in general had to cope with an increasing number of problem loans. In the literature several theoretical reasons, ranging from increased incentives for risktaking behavior to unexpected economic shocks, have been put forward for the deterioration of the bank asset quality. Empirically, however, the evidence is scarce.

In this chapter we contribute to the empirical literature by assessing the degree of riskiness of the twenty largest U.S. bank holding companies between 1973 and 1993. More specifically, we investigate the extent to which developments in the 1980s have led to significantly higher risk for U.S. banks. Since the efficient market hypothesis indicates that there is a direct and continuous relationship between information on the fundamental value of financial assets and their market price, we will use stock returns of the twenty largest U.S. bank holding companies as our information variable. Most studies on risk measurement of banks have used average properties like expected return or volatility (see for instance Bruni and Paterno 1995), while relatively little attention has been paid to the use of extreme movements. Exceptions are Rothschild and Stiglitz (1970), Parkinson (1980), Friedman and Laibson (1989), and Longin (1996) who recognize that extremes contain useful information. Rothschild and Stiglitz (1970) particularly underline the importance of the tails of the statistical distribution for asset prices. They stress that the weights in the tails of random variables give a better definition of increasing risk than a standard one, like for instance the usual variance. In this study we will concentrate on the tail of the distribution as our measure of risk. In order to get accurate measures of the tails of distribution we will make use of extreme value theory. This provides us with an effective measure of the degree of riskiness of the underlying stock.

The organizing principle of extreme value theory is the fatness in the tails of the distribution. Extremal analysis investigates the distribution of the maximum (minimum) in large samples, thereby determining the shape of the tails of a 
distribution. In fact, the limit law for the maximum is characterized by the socalled tail index $\alpha$, which happens to be equal to the number of moments that exists. Thus, the tail index is a good indicator for the thickness of the tails. The important point to note is that alternatives like the stable and student $t$ distribution are nested within the limit law for extremes. The idea then is to estimate this tail index directly and use the known distribution of the tail estimator to test for possible regime switches affecting the type of distribution, i.e. as a result of the deregulation measures in the 1980s. The loss of this procedure consists of information about the center characteristics of the distribution. Given the predominance of outliers in asset return series, one may benefit from this trade-off. Moreover, given an estimate for the tail index, one can establish the sizes of the extremely low or high returns that would be rarely exceeded'.

The plan of this chapter is as follows. In section 3.1 we discuss the deregulation process of the 1980s and its likely effects on the riskiness of the U.S. banking sector. In section 3.2 we introduce the tail index estimator, based on extreme value theory. In section 3.3 we present the data description and empirical results on the riskiness of the U.S. banking sector. The conclusion is in section 3.4 .

\subsection{Deregulation and the U.S. Banking Sector}

Since the 1970s the U.S. banking system has experienced major changes in terms of new financial products, deregulation, increasing competition, lower margins and changing risk attitudes. To a large extent the prevailing banking regulations at the beginning of the 1970s mirrored the legislation adopted after the banking crisis of 1929-1933. The banking failures of 1929-1933 induced the Banking (Glass-Steagall) Act of 1933 which changed fundamentally the parameters of the functioning of the U.S. banking system. Federal deposit insurance was introduced in order to avoid new bank runs. The activities of banks were restricted with a view to the perceived excessive competition of the previous period. Commercial and investment banking were separated, each type of bank was restricted to a specific type of lending and interstate banking was discouraged. Furthermore, payment of interest on demand deposits was prohibited and interest rates on time deposits were restricted to a maximum.

\footnotetext{
' McCulloch (1981) calculates bankruptcy probabilities for banks. However, these probabilities are based on a specific distribution model.
} 
By the late 1970 s, the regulations were widely viewed as excessively restrictive on the ability of banks to respond to changes in the environment that showed advances in telecommunications and information processing technology, financial innovation, increases in interest rates and higher volatility ${ }^{2}$. As a result, the profitability of banks was reduced and non-bank competitors grew rapidly. The U.S. Congress reacted by adopting two major deregulation acts.

The Depository Institutions Deregulation and Monetary Control Act (DIDMCA) of 1980 and the Garn-St.Germain Depository Institutions Act (DIA) of 1982 reduced the governmental restrictions on depository institutions. The Act of 1980 phased out interest rate ceilings and permitted all depository institutions to offer NOW (negotiable order of withdrawal) accounts, allowing greater competition for deposits among banks. Loan rate ceilings were weakened. This Act, in combination with the Act of 1982 , also increased competition between banks and S\&Ls by expanding the realm of the S\&L business. Furthermore, federal deposit insurance was increased from $\$ 40,000$ to $\$ 100,000$ in 1980 .

The movement towards a more deregulated and competitive equilibrium increased the efficiency of the U.S. banking system: it expanded the choices for savers and investors, reduced the cost of financial transactions, and improved the allocation of saving and investment nationally and internationally (Corrigan 1990). On the other hand, however, deregulation could be responsible for the deterioration of bank asset quality during the 1980s and the substantial increase in bank failures. In chapter 2 we discussed a recent contribution by Park (1994) in which he analyzes how deregulation increased the riskiness of U.S. banks in the 1980s. Two explanations were offered: moral hazard of bank stockholders and incentives of bank managers.

In section 3.3 we will present empirical evidence on the increased riskiness of U.S. banks using a tail index estimator which will be introduced in the next section.

${ }^{2}$ See for an overview of the literature Kaufman (1992). 


\subsection{Extreme Value Theory and the Tail Index Estimator}

Consider $X_{1}, X_{2}, \ldots, X_{n}$ to be a random stationary sequence of independently and identically distributed (i.i.d.) stock returns with distribution function $F(\cdot)$. Define $M_{n}$ as the maximum of this sequence of returns:

$$
M_{n}:=\max \left(X_{1}, X_{2}, \ldots, X_{n}\right)
$$

It may then be shown that the distribution function $F^{n}(x)$ of $M_{n}$ for large $n$ converges towards the same limiting distribution $G(x)$, independent of whether the stock returns were generated by a student $t$ or sum-stable distribution. As the competing distributions are thus nested within the same limit law $G(x)$, no maintained hypothesis about the correct $F(x)$ is required.

The limiting distribution $G(x)$ is of the following form, with $\gamma>0$ and the tail index $\alpha$ equal to $1 / \gamma$ :

$$
\begin{aligned}
G(x) & =0 & & x<0 \\
& =\exp (-x)^{-1 / \gamma} & & x \geq 0
\end{aligned}
$$

Relevant references on this result are Mood, Graybill and Boes (1974), and Leadbetter, Lindgren and Rootzen (1983). Leadbetter, et al. (1983) have shown that the theory also holds in case the assumption of independence for the stock returns is inappropriate, provided the dependency is not too strong.

For the family of symmetric stable Paretian distributions the tail index $\alpha$ in (3.2) may be interpreted as the characteristic exponent of the stable distribution, which ranges between 0 and 2 . For the class of student $t$ distributions the tail index $\alpha$ in (3.2) equals the number of degrees of freedom of the distribution, ranging from zero to infinity. Roughly speaking, the lower the value of $\alpha$ the thicker are the tails of the distribution, all other things equal.

Recently, the following simple and efficient estimator of the tail index has been proposed:

$$
\hat{\gamma}=1 / \hat{\alpha}=\frac{1}{m} \sum_{i=1}^{m}\left[\log \phi_{(n+1-i)}-\log \phi_{(n-m)}\right]
$$

Here, $n$ represents the total number of return observations, $m$ the number of tail observations used to estimate $\alpha$, and $\phi_{1}, \ldots, \phi_{n}$ represents the sample ordered from lowest to highest value. The statistic $\hat{\gamma}$ first appears in Hill (1975). Mason (1982) proves that under some regularity conditions $\hat{y}$ is a consistent estimator 
for $\gamma$. Goldie and Smith (1987) show that $(\hat{\gamma}-\gamma) m^{1 / 2}$ is asymptotically normal with mean zero and variance $\gamma^{2}$. An empirical application of this estimator may be found in Koedijk, Schafgans and De Vries (1990).

As is clear from (3.3), the above estimator only uses the positive (right) tail of stock returns to estimate $\alpha$ and neglects the information content of the large negative observations in the other tail. Conditional on the right and left tail having the same tail index, for which we test explicitly, we combine the information in the right and left tail by taking absolute values of the stock returns $\phi$ before ordering them and applying (3.3). In this way the precision of our tail index estimates may be significantly improved. The number of tail observations $m$ to be used is determined through Monte Carlo simulations.

\subsection{Data Description and Empirical Results}

\section{Data Description}

In our empirical analysis we use continuously compounded weekly stock returns for the twenty largest U.S. bank holding companies. The sample period stretches from January 1973 to December 1993, and the ranking is based on total stock market capitalization as of December 1993. The data have been corrected for stock-splits, quite a common phenomenon for bank shares. Furthermore, for comparison reasons, we have included weekly returns on the S\&P 500.

Since deregulation started in 1980 , we have divided the sample period into two subperiods with January 1980 as the breakpoint. Tables 3.1a to 3.1c contain the summary statistics for our whole sample and subsamples. We present the first four central moments plus two distributional tests. One can see that the sample moments of the empirical return distributions do not support normality. In all periods the data are characterized by excess kurtosis and moderate skewness, and precisely this excess kurtosis is an indicator of tail fatness. Furthermore, we can observe that the majority of banks saw their share prices fall during the 1970 s followed by a recovery in the 1980s. The standard deviations of returns for all bank shares are considerably larger than the standard deviation of the S\&P 500. Moreover, 13 out of 20 banks experienced an increase in volatility (as measured by the standard deviation) from the first to the second subperiod. Finally, the S-test, which is a symmetry test, and the BJ (Bera-Jarque) test on overall normality, indicate that normality is dismissed. 
Table 3.1a: Empirical Distribution Characteristics, Jan. 1973 to Dec. $1993(n=1095)$

\begin{tabular}{lcccccc}
\hline Bank & Mean & Std.dev. & $\begin{array}{l}\text { Skew- } \\
\text { ness }\end{array}$ & Kurtosis & S-test $^{\text {t }}$ & BJ-test $^{2}$ \\
& & & & & & \\
\hline Banc One & 0.0023 & 0.0353 & 0.46 & 7.56 & 4.98 & 987.6 \\
BankAmerica & 0.0006 & 0.0447 & 0.34 & 5.72 & 2.93 & 360.3 \\
Bankers Trust & 0.0014 & 0.0395 & -0.00 & 5.00 & -0.03 & 182.2 \\
Bank of Boston & 0.0008 & 0.0490 & 0.33 & 7.00 & 2.02 & 750.1 \\
Bank of NY & 0.0013 & 0.0396 & -0.14 & 8.69 & 1.54 & 1479.0 \\
Bamett Bank & 0.0010 & 0.0486 & -0.28 & 7.09 & 1.90 & 777.8 \\
Chase Manhattan & 0.0002 & 0.0444 & -0.20 & 5.21 & 1.12 & 229.7 \\
Chemical Bank & 0.0005 & 0.0437 & -0.07 & 6.59 & 1.42 & 587.8 \\
Citicorp & 0.0006 & 0.0479 & 0.42 & 7.22 & 2.21 & 845.3 \\
First Chicago & 0.0003 & 0.0497 & -0.08 & 5.73 & 2.75 & 340.5 \\
First Fidelity & 0.0009 & 0.0381 & -0.23 & 9.18 & 2.02 & 1751.9 \\
First Interstate & 0.0009 & 0.0447 & 0.02 & 6.87 & 1.00 & 682.1 \\
First Union & 0.0012 & 0.0406 & 0.45 & 7.55 & 3.35 & 981.9 \\
Fleet Financial & 0.0011 & 0.0419 & 0.48 & 7.58 & 2.57 & 997.8 \\
JP Morgan & 0.0015 & 0.0365 & 0.10 & 3.79 & 0.94 & 30.4 \\
Mellon Bank & 0.0007 & 0.0370 & -0.09 & 6.54 & 2.02 & 573.1 \\
Nationsbank & 0.0009 & 0.0483 & -0.04 & 7.73 & 2.21 & 1021.4 \\
PNC Financial & 0.0017 & 0.0385 & 0.37 & 6.89 & 3.66 & 717.3 \\
Republic NY & 0.0017 & 0.0381 & 0.42 & 6.03 & 2.87 & 450.7 \\
Wells Fur:ov & 0.0020 & 0.0447 & 0.03 & 5.75 & 0.33 & 345.0 \\
S\&P 500 & 0.0013 & 0.0220 & -0.59 & 6.86 & -1.84 & 745.2 \\
\hline & & & & & & \\
\hline
\end{tabular}

S-test: $2 *$ (\# observations below mean $-n / 2$ ) $/ \sqrt{ } n-\mathrm{N}(0,1)$ for $n \rightarrow \infty$

${ }^{2}$ BJ-test: $n *\left(\left(\right.\right.$ skewness $\left.\left.^{2}\right) / 6+(\text { kurtosis }-3)^{2} / 24\right) \sim \chi^{2}(2)$ 
Table 3.1b: Empirical Distribution Characteristics, Jan. 1973 to Dec. $1979(n=364)$

\begin{tabular}{|c|c|c|c|c|c|c|}
\hline Bank & Mean & Std.dev. & $\begin{array}{l}\text { Skew- } \\
\text { ness }\end{array}$ & Kurtosis & S-test ${ }^{\prime}$ & BJ-test ${ }^{2}$ \\
\hline Banc One & 0.0001 & 0.0259 & 0.58 & 8.92 & 6.39 & 551.8 \\
\hline BankAmerica & 0.0003 & 0.0396 & -0.01 & 5.61 & 1.99 & 103.4 \\
\hline Bankers Trust & -0.0014 & 0.0357 & 0.01 & 4.98 & -1.26 & 59.3 \\
\hline Bank of Boston & -0.0013 & 0.0400 & -0.02 & 4.49 & 0.10 & 33.8 \\
\hline Bank of NY & -0.0003 & 0.0305 & 0.94 & 7.19 & -0.84 & 319.5 \\
\hline Barnett Bank & -0.0024 & 0.0541 & -0.81 & 6.90 & -1.99 & 271.0 \\
\hline Chase Manhattan & -0.0011 & 0.0403 & -0.25 & 4.41 & -0.21 & 34.1 \\
\hline Chemical Bank & -0.0011 & 0.0352 & 0.06 & 3.60 & -0.31 & 5.7 \\
\hline Citicorp & -0.0014 & 0.0470 & 0.04 & 4.04 & 0.63 & 16.5 \\
\hline Firs: Chicago & -0.0019 & 0.0511 & -0.10 & 6.41 & -0.42 & 177.5 \\
\hline First Fidelity & -0.0014 & 0.0278 & 0.82 & 6.21 & -0.52 & 197.0 \\
\hline First Interstate & 0.0008 & 0.0379 & -0.09 & 3.71 & 1.47 & 8.1 \\
\hline First Union & -0.0025 & 0.0466 & 0.80 & 8.88 & -0.73 & 563.5 \\
\hline Fleet Financial & -0.0023 & 0.0425 & 0.93 & 10.10 & 0.73 & 816.7 \\
\hline JP Morgan & -0.0005 & 0.0372 & -0.15 & 3.79 & -0.73 & 10.7 \\
\hline Mellon Bank & 0.0003 & 0.0298 & 0.15 & 5.72 & 1.57 & 113.6 \\
\hline Nationsbank & -0.0026 & 0.0561 & -0.21 & 8.56 & -1.68 & 471.7 \\
\hline PNC Financial & -0.0012 & 0.0357 & 0.67 & 7.80 & -2.20 & 377.2 \\
\hline Republic NY & -0.0006 & 0.0396 & 0.31 & 4.58 & $-I .05$ & 43.5 \\
\hline Wells Fargo & -0.0001 & 0.0445 & -0.16 & 4.65 & -1.78 & 42.6 \\
\hline S\&P 500 & -0.0003 & 0.0225 & -0.20 & 3.61 & -0.73 & 8.1 \\
\hline
\end{tabular}

'S-test: 2 * (\# observations below mean - n/2)/ $\sqrt{ }-\mathrm{N}(0,1)$ for $n \rightarrow \infty$

${ }^{2}$ BJ-test: $n *\left(\left(\right.\right.$ skewness $\left.\left.{ }^{2}\right) / 6+(\text { kurtosis }-3)^{2} / 24\right) \sim \chi^{2}(2)$ 
Table 3.1c: Empirical Distribution Characteristics, Jan. 1980 to Dec. $1993(n=731)$

\begin{tabular}{|c|c|c|c|c|c|c|}
\hline Bank & Mean & Std.dev. & $\begin{array}{l}\text { Skew- } \\
\text { ness }\end{array}$ & Kurtosis & S-test ${ }^{t}$ & $\mathrm{BJ}$-test ${ }^{2}$ \\
\hline Banc One & 0.0034 & 0.0391 & 0.38 & 6.63 & 1.96 & 419.6 \\
\hline BankAmerica & 0.0007 & 0.0470 & 0.45 & 5.59 & 2.18 & 228.1 \\
\hline Bankers Trust & 0.0028 & 0.0413 & -0.03 & 4.92 & 0.63 & 112.5 \\
\hline Bank of Boston & 0.0018 & 0.0529 & 0.37 & 6.96 & 0.78 & 493.5 \\
\hline Bank of NY & 0.0032 & 0.0434 & -0.35 & 8.18 & 0.48 & 832.4 \\
\hline Barnett Bank & 0.0027 & 0.0456 & 0.21 & 6.69 & 0.92 & 419.9 \\
\hline Chase Manhattan & 0.0008 & 0.0463 & -0.19 & 5.34 & 0.63 & 171.0 \\
\hline Chemical Bank & 0.0013 & 0.0473 & -0.12 & 6.61 & 1.07 & 399.1 \\
\hline Citicorp & 0.0016 & 0.0483 & 0.59 & 8.61 & 0.71 & 1000.5 \\
\hline First Chicago & 0.0014 & 0.0489 & -0.05 & 5.31 & 2.11 & 163.0 \\
\hline First Fidelity & 0.0021 & 0.0423 & -0.42 & 8.57 & -0.18 & 965.6 \\
\hline First Interstate & 0.0010 & 0.0477 & 0.05 & 7.19 & 0.18 & 533.8 \\
\hline First Union & 0.0030 & 0.0371 & 0.18 & 5.42 & 1.37 & 182.1 \\
\hline Fleet Financial & 0.0028 & 0.0416 & 0.25 & 6.38 & 0.55 & 355.1 \\
\hline JP Morgan & 0.0025 & 0.0361 & 0.24 & 3.75 & 1.29 & 24.1 \\
\hline Mellon Bank & 0.0009 & 0.0401 & -0.14 & 6.23 & 1.37 & 320.5 \\
\hline Nationsbank & 0.0027 & 0.0438 & 0.22 & 5.51 & 0.56 & 197.4 \\
\hline PNC Financial & 0.0031 & 0.0398 & 0.25 & 6.58 & 1.81 & 397.5 \\
\hline Republic NY & 0.0029 & 0.0373 & 0.50 & 6.91 & 2.70 & 496.7 \\
\hline Wells Fargo & 0.0031 & 0.0448 & 0.11 & 6.27 & 0.33 & 326.4 \\
\hline S\&P 500 & 0.0020 & 0.0216 & -0.81 & 8.86 & -1.22 & 1124.5 \\
\hline
\end{tabular}

'S-test: 2 * ( observations below mean $\left.-n^{\prime} 2\right) / \sqrt{ } n \sim \mathrm{N}(0,1)$ for $n \rightarrow \infty$

B B-test: $n^{*}\left(\left(\right.\right.$ skewness $\left.\left.{ }^{2}\right) / 6+(\text { kurtosis }-3)^{2} / 24\right)=\chi^{2}(2)$ 
Given the observed excess kurtosis, and given the notion that this kurtosis value increases from the first to the second subperiod in half of the cases, a natural question to ask is whether the tail behavior of bank shares is fundamentally different from a normal tail, and whether the degree of fat-tailedness increases over time. One caveat applies here. The calculated kurtosis values we obtain are only meaningful statistics when the fourth moment is indeed defined, which is the case when the value of the tail index is larger than 4 . When the tail index has a value of 4 or below 4 , then these statistics are meaningless, and consequently are misleading with respect to tail behavior. Therefore, hereafter we will apply a more direct approach by estimating $\alpha$ values and analyzing whether they have changed significantly from the first to the second subperiod.

One can translate the questions about tail behavior into questions about the probabilities of unusually large outcomes, the so-called 'exceedence probabilities'. What are these exceedence probabilities, have they changed over time, and can we discern differences in probabilities between banks. In the following we intend to provide answers to these questions. But, first, we will determine the optimal number of order statistics using Monte Carlo experiments.

\section{Monte Carlo Experiments: Choosing the Optimal $m$}

First of all, we have to determine the optimal number of order statistics, $m$, to take into account when estimating the tail index. In general this number is unknown. Minimal requirements are that $m(n)$ goes to infinity with $n$, and that $\mathrm{m} / \mathrm{n}$ remains finite. In order to determine $m$, we employ Monte Carlo experiments. We use the minimum mean-squared error (MSE) as a selection criterion, which is appropriate given the asymptotic normality of the estimator. Each Monte Carlo experiment consists of 1000 replications of $n$ draws from 6 student $t$ distributions with degrees of freedom $(\alpha)$ ranging from 2 to 7 . Separate experiments are conducted for using one or both tails and for 364, 731 and 1095 observations ( $n$ ). Optimal $m$ levels are reported in Table 3.2.

As expected, the optimal number of tail observations to be used for estimation, $m$, varies inversely with $\alpha$, the tail index. Since a lower tail index means fatter tails, and more observations in the tails, more observations should be used. Furthermore, both the theoretical and the empirical minimum MSE are smaller when using both tails instead of only one tail. This characterizes the greater precision in using both tails. 
Table 3.2: Optimal Choices of $m$ through Monte-Carlo Simulations by Minimizing MSE

\begin{tabular}{|c|c|c|c|c|c|c|}
\hline & $\alpha=2$ & $\alpha=3$ & $\alpha=4$ & $\alpha=5$ & $\alpha=6$ & $\alpha=7$ \\
\hline \multicolumn{7}{|l|}{$n=364$} \\
\hline$m$ (one tail) & 25 & 15 & 12 & 7 & 6 & 5 \\
\hline $\min$. MSE & 0.0156 & 0.0130 & 0.0134 & 0.0145 & 0.0140 & 0.0140 \\
\hline$r^{2} / m$ & 0.01 & 0.0074 & 0.0052 & 0.0057 & 0.0046 & 0.0041 \\
\hline$m$ (two tails) & 40 & 22 & 17 & 10 & 8 & 6 \\
\hline $\min . \mathrm{MSE}$ & 0.0083 & 0.0088 & 0.0089 & 0.0094 & 0.0094 & 0.0102 \\
\hline$r^{2} / m$ & 0.0063 & 0.0051 & 0.0037 & 0.0040 & 0.0035 & 0.0034 \\
\hline \multicolumn{7}{|l|}{$n=73 !$} \\
\hline$m$ (one tail) & 44 & 23 & 16 & 14 & 8 & 7 \\
\hline $\min$. MSE & 0.0092 & 0.0077 & 0.0083 & 0.0089 & 0.0094 & 0.0097 \\
\hline$r^{2} / m$ & 0.0057 & 0.0048 & 0.0039 & 0.0028 & 0.0035 & 0.0029 \\
\hline$m$ (two tails) & 77 & 38 & 22 & 19 & 15 & 12 \\
\hline $\min$. MSE & 0.0053 & 0.0055 & 0.0052 & 0.0062 & 0.0067 & 0.0065 \\
\hline$r^{2} / m$ & 0.0033 & 0.0029 & 0.0028 & 0.0021 & 0.0019 & 0.0017 \\
\hline \multicolumn{7}{|l|}{$n=1095$} \\
\hline$m$ (one tail) & 63 & 31 & 18 & 17 & 10 & 8 \\
\hline $\min . M S E$ & 0.0069 & 0.0066 & 0.0071 & 0.0067 & 0.0075 & 0.0088 \\
\hline$\gamma^{2 / m}$ & 0.0040 & 0.0036 & 0.0035 & 0.0024 & 0.0028 & 0.0026 \\
\hline$m$ (two tails) & 92 & 48 & 31 & 22 & 17 & 14 \\
\hline $\min$. MSE & 0.0039 & 0.0046 & 0.0046 & 0.0050 & 0.0052 & 0.0057 \\
\hline$\gamma^{2} / m$ & 0.0027 & 0.0023 & 0.0020 & 0.0018 & 0.0016 & 0.0015 \\
\hline
\end{tabular}

where $\gamma^{2} / m$ is the theoretical MSE value in the i.i.d. case 
For one of the experiments we have plotted in Figure 3.1 the MSE split up into a bias part and a variance part, as a function of $m$. One can observe that including too few tail observations causes the variance part of the MSE to dominate the bias part. However, including too many observations (those that actually belong to the center of the distribution) leads to the bias part dominating the variance part. The number of observations corresponding with the minimum MSE (at the crossing of the two lines) represents the optimal trade-off between the bias part and the variance part of the MSE.

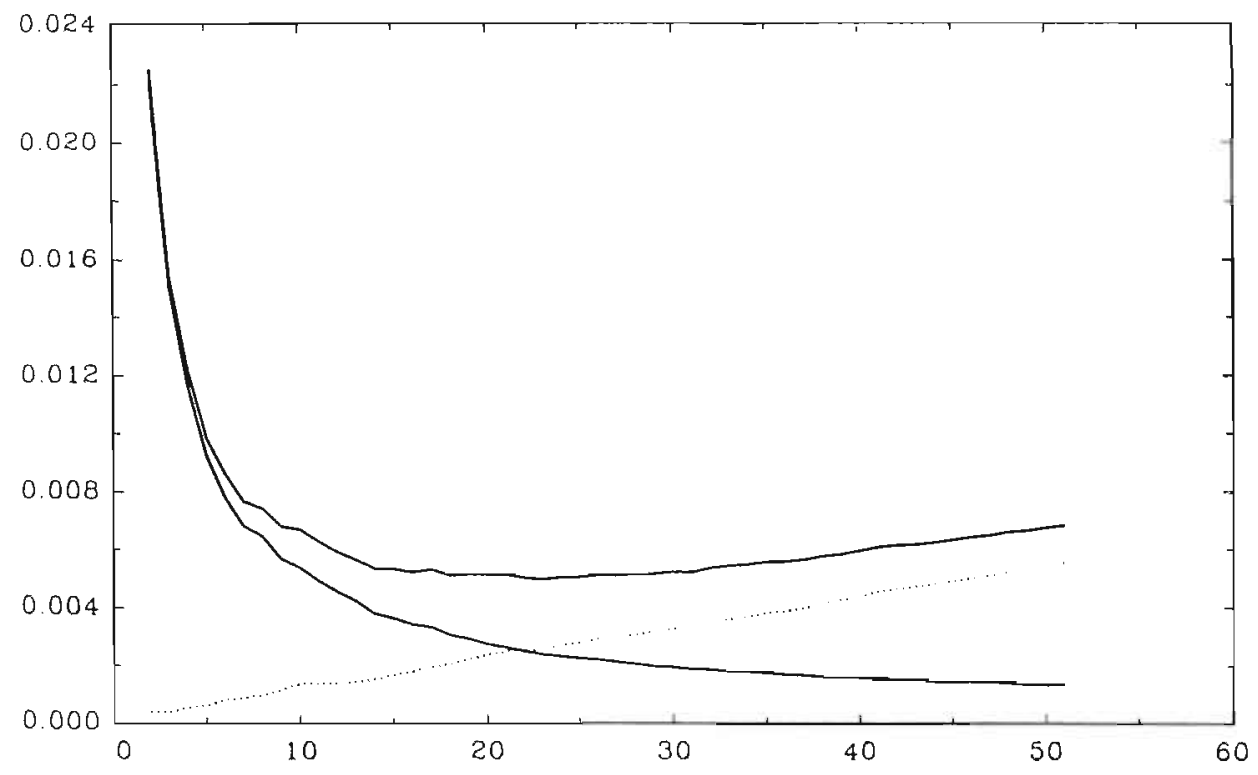

Figure 3.1: MSE, bias and variance part as functions of $m$ ( $\alpha=5, n=1095$, two tails, 1000 repetitions) 


\section{Empirical Results}

Now we are able to estimate tail indices, using the Hill estimator, for 6 different hypothesized $\alpha$ values, for three different time periods, using the left, right or both tails, and for 21 samples of returns (including the S\&P 500), yielding a total of $21^{*} 6 * 3 * 3=1134$ estimates. Given this huge amount of information some restriction and selection is in $\operatorname{order}^{3}$. We choose to present the results for $\mathrm{H}_{0}: \alpha=5$, using the information contained in both tails. We have several reasons for this. First of all, it is the lowest value of the tail index such that the first four moments exist. A second reason, related to the first one, is that a student $t$ distribution with 5 degrees of freedom, implies a kurtosis value of 9 which accords reasonably well with the sample evidence. The tail index estimates, in each period based upon the optimal number of order statistics as shown in Table 3.2, are presented in Table 3.3.

In the first column for each of the periods the $\alpha$ estimates (under $\mathrm{H}_{0}: \alpha=5$ ) are listed. For 14 of the 20 bank holding companies we find a decline of the estimated $\alpha$ values when we compare the second subperiod (1980-1993) with the first subperiod (1973-1979). The second column for each of the periods provides $t$ statistics for the hypothesis that the estimated lower tail index $\left(\alpha^{*}\right)$ equals the estimated upper tail index $\left(\alpha^{+}\right)$. These $t$ statistics are constructed as:

$$
\frac{\hat{y}^{+}-\hat{\gamma}^{-}}{\sqrt{2 \gamma^{2} / m}}
$$

using the fact that:

$$
(\hat{\gamma}-\gamma) \stackrel{a}{\sim} N\left(0, \gamma^{2} / m\right)
$$

In $15 \%$ of the 63 cases we have to reject the equality of the left and right tail at the $5 \%$ level. We tentatively conclude that it is allowed to use the information in both tails for the estimation of the tail indices, which procedure we followed while estimating the $\alpha$ values presented in the first column.

\footnotetext{
${ }^{3}$ All estimation results are available upon request.
} 
Table 3.3: Tail Index Estimates $\left(H_{0}: \alpha=5\right)$

\begin{tabular}{|c|c|c|c|c|c|c|c|c|c|}
\hline & \multicolumn{3}{|c|}{$1973-1979$} & \multicolumn{3}{|c|}{$1980-1993$} & \multicolumn{3}{|c|}{$1973-1993$} \\
\hline & $\hat{\alpha}$ & $\begin{array}{l}t \text { stat. } \\
\alpha^{*}=\alpha\end{array}$ & $\begin{array}{l}t \text { stat. } \\
a=5\end{array}$ & $\hat{\alpha}$ & $\begin{array}{l}l \text { stat. } \\
\alpha^{*}=\alpha\end{array}$ & $\begin{array}{l}t \text { stat. } \\
\alpha=5\end{array}$ & $\hat{a}$ & $\begin{array}{l}t \text { stat. } \\
\alpha^{+}=\alpha\end{array}$ & $\begin{array}{l}t \text { stat. } \\
\alpha=5\end{array}$ \\
\hline Banc One & 4.12 & -2.29 & -0.68 & 3.52 & 0.37 & -1.84 & 3.87 & 0.22 & -1.36 \\
\hline BankAmerica & 5.54 & 1.16 & 0.31 & 4.85 & 0.73 & 0.14 & 4.56 & 1.32 & -0.45 \\
\hline Bankers Trust & 4.20 & 0.24 & -0.61 & 4.46 & 1.39 & -0.53 & 4.24 & 1.39 & -0.84 \\
\hline Bank of Boston & 8.21 & -0.18 & 1.23 & 3.14 & -0.56 & -2.58 & 3.61 & -0.34 & -1.83 \\
\hline Bank of NY & 2.79 & -3.38 & -2.51 & 3.63 & 2.50 & -1.65 & 3.68 & 2.15 & -1.69 \\
\hline Barnett Bank & 3.79 & 1.60 & -1.00 & 3.55 & 0.14 & -1.79 & 4.04 & 0.82 & 1.12 \\
\hline Chase Manhartan & 4.80 & 0.72 & -0.13 & 3.60 & 2.40 & -1.71 & 4.00 & 2.67 & -1.17 \\
\hline Chemical Bank & 6.45 & -1.08 & 0.71 & 2.74 & 0.64 & -3.59 & 2.85 & 0.75 & -3.58 \\
\hline Citicorp & 4.83 & 1.08 & -0.11 & 2.75 & -1.90 & -3.57 & 3.19 & -0.65 & -2.66 \\
\hline First Chicago & 4.87 & 1.94 & -0.08 & 3.83 & 0.60 & -1.33 & 4.29 & 1.61 & -0.78 \\
\hline First Fidelity & 4.76 & -0.34 & -0.16 & 3.32 & 1.76 & -2.21 & 3.54 & 1.28 & -1.93 \\
\hline First Interstate & 4.40 & 0.28 & -0.43 & 3.33 & -1.85 & -2.20 & 3.52 & -2.11 & -1.97 \\
\hline First Union & 2.97 & -2.10 & -2.16 & 4.20 & 0.86 & -0.83 & 3.59 & -0.85 & -1.83 \\
\hline Fleet Financial & 3.93 & -1.03 & -0.86 & 3.79 & -1.03 & -1.39 & 3,48 & -1.59 & -2.03 \\
\hline JP Morgan & 8.22 & 0.80 & 1.24 & 4.94 & -0.71 & .0 .05 & 7.50 & 1.25 & 1.56 \\
\hline Mellon Bank & 4.18 & -0.57 & -0.62 & 4.53 & 1.05 & -0.46 & 4.78 & 0.70 & -1.20 \\
\hline Nationsbank & 3.23 & -1.62 & -1.74 & 4.84 & 0.68 & -0.14 & 3.58 & -0.32 & -1.87 \\
\hline PNC Financial & 3.47 & -1.68 & -1.39 & 4.16 & 0.22 & -0.88 & 4.24 & -1.10 & -0.84 \\
\hline Republic NY & 6.24 & -0.68 & 0.63 & 2.68 & -2.15 & -3.77 & 4.07 & -0.51 & -1.08 \\
\hline Wells Fargo & 5.06 & 0.27 & 0.04 & 3.39 & -1.29 & -2.06 & 3.90 & -0.95 & -1.33 \\
\hline S\&P 500 & 3.42 & 0.23 & -1.46 & 3.65 & 1.96 & -1.61 & 3.77 & 1.48 & -1.53 \\
\hline
\end{tabular}


The third column provides $t$ statistics for the hypothesis that $\alpha=5$ (again based on (3.5)). In the first subperiod this hypothesis is only rejected three times at the $10 \%$ level and twice at the $5 \%$ level. In the second subperiod, however, these rejection frequencies are 11 at the $10 \%$ level and 7 at the $5 \%$ level. For these seven bank holding companies (Bank of Boston, Chemical Bank, Citicorp, First Fidelity, First Interstate, Republic New York, and Wells Fargo) the hypothesis of $\alpha=5$ is not rejected in the first subperiod at the $5 \%$ level. This suggests a significant decline of $\alpha$ (given the $\alpha$ estimates) from the first to the second subperiod, implying a significant increased tail fatness and riskiness. So based on the criterion of the tail index, we find that the riskiness of seven of the twenty bank holding companies has increased significantly after 1979 .

JP Morgan also shows a large $\alpha$ drop but in neither period could we, even at the $10 \%$ level, reject the hypothesis that $\alpha$ is actually 5. The Bank of New York and First Union exhibit significant $\alpha$ surges at the $5 \%$ level, indicating decreased riskiness.

The larger risks of the seven banks listed above have been highlighted in the international press. For instance, on May 23, 1990 the Financial Times reported that the leading U.S. credit rating agencies (Moody's and Standard \& Poor's) had already downgraded more than two dozen U.S. banks since the start of 1990. Among these banks are Bank of Boston, Chemical Bank and Citicorp. The problem loans are concentrated in three areas: commercial real estate, highly leveraged takeovers and LDC loans. The Economist of October 10, 1992 discussed the real estate crisis in California where house prices more than doubled during the 1980s. California's big banks, such as First Interstate and Wells Fargo, were heavily involved in property lending and related losses.

We have also conducted stability ${ }^{4}$ tests, which are based on the so called $Q$ statistic which is defined as (see Jansen and De Vries 1991):

$$
Q=\left(\frac{\alpha}{\hat{\alpha}_{1}}-1\right)^{2} m_{1}+\left(\frac{\alpha}{\hat{\alpha}_{2}}-1\right)^{2} m_{2} \quad, \quad Q \stackrel{a}{\sim} \chi^{2}(2)
$$

The results from the stability tests and the range of $\alpha$ values that cannot be rejected in each period, are presented in Table 3.4 .

\footnotetext{
Whereas many other applications of extreme value theory to financial data use this test to confirm stability over subperiods, which is usually accomplished due to the large standard errors of the estimates, we try to reject stability in order to substantiate our claim of significantly increased (or decreased) riskiness.
} 
Table 3.4: Possible $\alpha$ values and stability tests under $H_{0}: \alpha=5$

\begin{tabular}{|c|c|c|c|c|c|}
\hline Bank & $\begin{array}{l}1973- \\
1993\end{array}$ & $\begin{array}{l}1973- \\
1979\end{array}$ & $\begin{array}{l}1980- \\
1993\end{array}$ & $Q$ & $p$ value \\
\hline Banc One & $3-5$ & $2-7$ & $3-5$ & 3.82 & 0.15 \\
\hline BankAmerica & $4-7$ & $3-7$ & $4-7$ & 0.11 & 0.94 \\
\hline Bankers Trust & $4-6$ & $3-7$ & 4,5 & 0.64 & 0.73 \\
\hline Bank of Boston & 3,4 & $3-7$ & 3 & 8.19 & 0.02 \\
\hline Bank of NY & $3-5$ & 3,4 & $3-5$ & 8.98 & 0.01 \\
\hline Bamett Bank & $3-6$ & $2-5$ & $3-5$ & 4.18 & 0.12 \\
\hline Chase Manhattan & 4,5 & $3-7$ & $3-5$ & 2.89 & 0.24 \\
\hline Chemical Bank & 3,4 & $4-7$ & 3 & 13.43 & $0.00^{*}$ \\
\hline Citicorp & 3,4 & $4-7$ & 3,4 & 12.73 & $0.00^{*}$ \\
\hline First Chicago & $3-5$ & $2-6$ & 4,5 & 1.78 & 0.41 \\
\hline First Fidelity & $3-5$ & $3-7$ & 3,4 & 4.89 & 0.09 \\
\hline First Interstate & 3,4 & $4-7$ & 3,4 & 4.96 & 0.08 \\
\hline First Union & $3-5$ & $2-4$ & $3-6$ & 5.36 & 0.07 \\
\hline Fleet Financial & 3,4 & $3-5$ & $3-5$ & 2.86 & 0.26 \\
\hline JP Morgan & $4-7$ & 4.7 & $4-7$ & 1.54 & 0.46 \\
\hline Mellon Bank & $3-7$ & $2-7$ & $3-6$ & 0.58 & 0.74 \\
\hline Nationsbank & $2-6$ & $2-6$ & $3-6$ & 3.02 & 0.22 \\
\hline PNC Financial & $3-6$ & $3-5$ & $3-6$ & 2.72 & 0.26 \\
\hline Republic NY & $3-5$ & $3-7$ & 3 & 14.63 & $0.00^{*}$ \\
\hline Wells Fargo & $3-5$ & $3-7$ & 3,4 & 4.29 & 0.11 \\
\hline S\&P 500 & 4,5 & $3-5$ & 4,5 & 4.73 & 0.09 \\
\hline
\end{tabular}

* a $p$ value of 0.00 means that the actual $p$ value is below 0.005 
The range of possible $\alpha$ values is calculated by using the same methodology as in Table 3.3, but this time $\alpha$ is estimated for a spectrum of null hypotheses with $\alpha$ ranging from 2 to 7 . The $t$ statistics for the hypotheses that $\alpha=2, \ldots, 7$ have been calculated at the $5 \%$ level again. One can observe that, in general, a shift to lower acceptable $\alpha$ values has occurred from the first to the second subperiod. Striking examples are Bank of Boston, Chemical Bank and Republic New York. This general shift to lower $\alpha$ values is indicative of increased riskiness in the second as opposed to the first subperiod. One could argue that these results are only caused by the larger number of tail observations in the second subperiod. The larger the number of tail observations, the lower the standard deviation of the tail index estimator will be (ceteris paribus). Consequently, estimates are more precise and more $\alpha$ values should be rejected in the second subperiod. This reasoning, however, is contradicted by the results for First Union, Nationsbank and PNC Financial, where more $\alpha$ values are acceptable in the second subperiod than in the first subperiod.

The $Q$ statistic tests whether the estimated values of $\alpha$ in the two subperiods are jointly plausible under the null hypothesis that $\alpha=5$ in both subperiods. In the case that an $\alpha$ value of 5 is not realistic in either one of the subperiods (see the listing of possible $\alpha$ values in Table 3.4), it is very likely that the $Q$ test will reject stability. We find that the $Q$ statistics, calculated under the null hypothesis of $\alpha=5$, are significant at the $5 \%$ level for 5 and at the $10 \%$ level for 8 out of 20 bank holding companies, which means that stability has to be rejected for the $\alpha$ values of these banks in the two subperiods. This group of eight banks consists of exactly the same group of banks for which we found a significant $\alpha$ change in Table 3.3 (based on the $t$ test for change of $\alpha$ ). The only difference is that in Table 3.3 we found a significant change for Wells Fargo as well, while in the case of the $Q$ test stability cannot be rejected, although it is not a very strong result given the $p$ value of 0.11 being just above the marginal significance level of $10 \%$. This difference between the $Q$ and $t$ test can be explained by the fact that the $Q$ statistic does not test whether the estimated individual values of $\alpha$ in the two subperiods are plausible in each subperiod given the null hypothesis that $\alpha=5$, but that it tests whether the estimated $\alpha$ values are jointly plausible under the null hypothesis that $\alpha=5$ in both subperiods.

For six of the eight banks (Bank of Boston, Chemical Bank, Citicorp, First Fidelity, First Interstate, and Republic New York) the rejection of stability implies a significant $\alpha$ drop (given the $\alpha$ estimates in Table 3.3) and hence an increase in riskiness. The two remaining banks (Bank of New York and First 
Union) witness a significant $\alpha$ surge and decreased riskiness.

The results reported in Tables 3.3 and 3.4 reveal that in a substantial number of cases there is a significant increase in the degree of fat-tailedness and hence riskiness of U.S. banks. One could argue that our findings are related to the 1987 stock market crash. The crash of 1987 generated a large one week return, one that is obviously present in the left tail of the distribution. This could have caused increased tail fatness and, consequently, lower $\alpha$ estimates. This claim is contradicted by the facts: several banks that did not experience an $\alpha$ shift were hit as severely by the crash than the banks that did experience an $\alpha$ shift. Furthermore, there is no evidence of an $\alpha$ shift for the S\&P 500: in Table 3.3 we obtain $\alpha$ estimates of 3.42 and 3.65 in the two subperiods and, moreover, conducting the $Q$ test under the null hypothesis that $\alpha=4$ results in a very high $p$ value of 0.98 with a $Q$ statistic of 0.05 . Furthermore, one could argue that the multitude of stock splits caused extreme negative returns, to be found in the left tail. Since our data have been corrected for all stock splits, this is not a valid critique. Thirdly, high dividends could cause subsequent stock prices to drop considerably, thereby generating negative returns. As it happens, however, bank dividend yields have dropped from the first to the second subperiod, so this explanation too has to be dismissed.

An important application of extreme value theory is that it allows for the calculation of probabilities of extremely high or low returns, even returns which have not been observed historically. In the next subsection we calculate these so-called 'exceedence probabilities'.

\section{Exceedence Probabilities}

Given the evidence presented in the previous part, we can observe that stock returns from the twenty largest U.S. bank holding companies are characterized by distributions with much thicker tails than the normal. As a consequence, the frequency of extreme returns (observations in the tails) is much higher than one would expect under the normal distribution. The obvious question to ask is: how large are these frequencies? We can employ the $\alpha$ estimates to answer this question, and calculate the frequencies. Moreover, since we know how the limit law extends in the tails, we have sufficient information to determine the probability of the occurrence of extreme returns that are rarely exceeded, and we can even determine probabilities for extreme returns that did not emerge in 
sample.

The exceedence probabilities, $p$, are related to the exceedence levels, $x_{p}$, which are return levels that are rarely exceeded, or exceeded with probability $p$. We can determine the extreme return levels by extrapolating the empirical distribution beyond the sample domain. The procedure only requires regular variation at infinity, which means that the distribution should have fat tails (see Jansen and De Vries 1991). More specifically, we are looking for exceedence levels $x_{p}$ such that :

$$
P\left(X_{1} \leq x_{p}, \ldots, X_{k} \leq x_{p}\right)=F^{k}\left(x_{p}\right)=1-p
$$

where $k$, the time period, and $p$, the exceedence probability are given.

A consistent estimator for the exceedence levels (see Jansen and De Vries 1991 and Dekkers and De Haan 1989) is given by:

$$
\hat{x}_{p}=\frac{(k r / p n)^{\hat{\gamma}}-1}{1-2^{-\hat{\gamma}}}\left(X_{(n-r)}-X_{(n-2 r)}\right)+X_{(n-r)}
$$

In this formula $n$ is the number of observations, $k$ is the time period considered, $r=m / 2$ and $p$ is the exceedence probability.

One could give the following interpretation to this estimator. The pattern of the empirical distribution as given by the order statistic $X_{(n-r)}$ and the step-size $\left(X_{(n-r)}\right.$ - $\left.X_{(n-2 r)}\right)$ is extrapolated beyond its domain, using the multiplication factor attached to the step-size. This factor represents the fashion by which the limit law extends. From given exceedence levels one can also determine exceedence probabilities. We have chosen exceedence levels (weekly returns) of $20 \%$ and $30 \%$. In Table 3.5a, using information contained in both tails, we present probabilities that the stock price of a bank experiences a one-week return of $20 \%$ or $30 \%$ (both positive and negative) within a given year $(k=52)$. Stated differently, on average every $1 / p$ years the stock price of a given bank will increase/decrease by $20 \%$ or $30 \%$ in one week. 
Table 3.5a: Exceedence Probabilities $\left(\mathrm{H}_{0}: \alpha=5\right.$, both tails)

\begin{tabular}{|c|c|c|c|c|c|c|}
\hline \multirow[b]{2}{*}{ Bank } & \multicolumn{3}{|c|}{ Weekly retum $+20 \%$ and $-20 \%$} & \multicolumn{3}{|c|}{ Weekly return $+30 \%$ and $-30 \%$} \\
\hline & $73-93$ & $73-79$ & $80-93$ & $73-93$ & $73-79$ & $80-93$ \\
\hline Banc One & 0.144 & 0.039 & 0.267 & 0.037 & 0.008 & 0.083 \\
\hline BankAmerica & 0.064 & 0.019 & 0.062 & 0.009 & 0.002 & 0.007 \\
\hline Bankers Trust & 0.060 & 0.070 & 0.031 & 0.011 & 0.015 & 0.004 \\
\hline Bank of Boston & 0.228 & 0.022 & 0.332 & 0.057 & 0.001 & 0.092 \\
\hline Bank of NY & 0.106 & 0.032 & 0.133 & 0.023 & 0.009 & 0.028 \\
\hline Bamett Bank & 0.326 & 0.336 & 0.211 & 0.081 & 0.068 & 0.049 \\
\hline Chase Manhattan & 0.160 & 0.053 & 0.182 & 0.038 & 0.008 & 0.042 \\
\hline Chemical Bank & 0.203 & 0.012 & 0.285 & 0.070 & 0.001 & 0.097 \\
\hline Citicorp & 0.260 & 0.030 & 0.138 & 0.087 & 0.003 & 0.039 \\
\hline First Chicago & 0.178 & 0.042 & 0.145 & 0.031 & 0.002 & 0.029 \\
\hline First Fidelity & 0.165 & 0.015 & 0.223 & 0.047 & 0.002 & 0.064 \\
\hline First Interstate & 0.164 & 0.072 & 0.251 & 0.038 & 0.015 & 0.062 \\
\hline First Union & 0.137 & 0.285 & 0.026 & 0.033 & 0.083 & 0.004 \\
\hline Fleet Financial & 0.107 & 0.049 & 0.059 & 0.025 & 0.008 & 0.010 \\
\hline JP Morgan & 0.011 & 0.003 & 0.042 & 0.001 & $0.000^{*}$ & 0.007 \\
\hline Mellon Bank & 0.024 & 0.062 & 0.034 & 0.003 & 0.014 & 0.004 \\
\hline Nationsbank & 0.351 & 0.768 & 0.129 & 0.096 & 0.253 & 0.021 \\
\hline PNC Financial & 0.063 & 0.101 & 0.050 & 0.010 & 0.027 & 0.007 \\
\hline Republic NY & 0.119 & 0.026 & 0.141 & 0.028 & 0.002 & 0.047 \\
\hline Wells Fargo & 0.200 & 0.047 & 0.231 & 0.050 & 0.006 & 0.062 \\
\hline S\&P 500 & 0.008 & 0.030 & 0.003 & 0.002 & 0.008 & 0.001 \\
\hline
\end{tabular}

* a probability of 0.000 means that the measured probability is below 0.0005 
The results are quite revealing. For fourteen out of twenty bank holding companies we find large increases in probabilities from the first to the second subperiod. For example, in the case of Bank of Boston the exceedence frequency for a $20 \%$ weekly return increases from $1 / 0.022$, or once every 45 years, to $1 / 0.332$, or once every 3 years. On the other hand, for the S\&P 500 the excess frequency for a $20 \%$ weekly return has decreased from once every 33 years to once every 333 years. in spite of the 1987 crash. Striking is the large difference in probability levels across banks. JP Morgan, for instance, is very rarely hit by extreme returns, whereas Barnett Bank frequently exhibits extreme returns, although substantially less in the second subperiod.

It is also interesting to focus on either only extreme negative returns (left tails) or only extreme positive returns (right tails). In this way we can decompose the exceedence probabilities for individual banks. Barnett Bank will prove to be an interesting example.

In Table $3.5 \mathrm{~b}$ we present exceedence probabilities associated with weekly returns of $-20 \%$ and $-30 \%$ (the so-called 'crash probabilities'), based upon information in the left tails. For thirteen out of twenty banks we find large to extremely large increases in crash probabilities from the first to the second subperiod. For example, for Chase Manhattan the excess frequency of a $-20 \%$ weekly return is once every 104 years in the first subperiod and once every 9.5 years in the second subperiod, which is a considerable increase. However, there are also banks that show a large drop in crash probabilities (e.g. Nationsbank and to a lesser extent Barnett Bank). Apparently, there is considerable difference in the level of crash probability across banks.

In Table $3.5 \mathrm{c}$ we present the exceedence probabilities for extreme positive returns. For eighteen out of twenty banks we observe an increase in the probability of extreme positive returns. Barnett Bank exhibits a substantial increase of the probability of a weekly retum of $+20 \%$ (from 0.026 to 0.187 ), whereas the probability of a weekly return of $-20 \%$, as we saw in Table $3.5 \mathrm{~b}$, has decreased from 0.408 to 0.092 . 
Table 3.5b: Exceedence Probabilities $\left(H_{0}: \alpha=5\right.$, left tails)

\begin{tabular}{|c|c|c|c|c|c|c|}
\hline \multirow[b]{2}{*}{ Bank } & \multicolumn{3}{|c|}{ Weekly retum $-20 \%$} & \multicolumn{3}{|c|}{ Weekly retum $-30 \%$} \\
\hline & $73-93$ & $73-79$ & $80-93$ & $73-93$ & $73-79$ & $80-93$ \\
\hline Banc One & 0.038 & 0.012 & 0.063 & 0.010 & 0.002 & 0.018 \\
\hline BankAmerica & 0.056 & 0.024 & 0.104 & 0.014 & 0.006 & 0.032 \\
\hline Bankers Trust & 0.031 & 0.027 & 0.059 & 0.007 & 0.005 & 0.018 \\
\hline Bank of Boston & 0.090 & 0.121 & 0.145 & 0.022 & 0.033 & 0.042 \\
\hline Bank of NY & 0.092 & $0.000^{*}$ & 0.125 & 0.034 & $0.000^{*}$ & 0.049 \\
\hline Bamett Bank & 0.126 & 0.408 & 0.092 & 0.032 & 0.126 & 0.025 \\
\hline Chase Manhattan & 0.073 & 0.010 & 0.105 & 0.021 & 0.002 & 0.034 \\
\hline Chemical Bank & 0.026 & $0.000^{*}$ & 0.006 & 0.006 & $0.000^{*}$ & 0.019 \\
\hline Citicorp & 0.010 & 0.010 & 0.006 & 0.001 & 0.001 & 0.001 \\
\hline First Chicago & 0.157 & 0.196 & 0.011 & 0.049 & 0.060 & 0.001 \\
\hline First Fidelity & 0.053 & 0.001 & 0.180 & 0.015 & $0.000^{*}$ & 0.069 \\
\hline First Interstate & 0.057 & 0.009 & 0.075 & 0.009 & 0.001 & 0.012 \\
\hline First Union & 0.039 & 0.013 & 0.004 & 0.008 & 0.001 & 0.001 \\
\hline Fleet Financial & 0.035 & 0.010 & 0.067 & 0.005 & 0.001 & 0.014 \\
\hline JP Morgan & 0.012 & 0.041 & 0.001 & 0.002 & 0.007 & $0.000^{*}$ \\
\hline Mellon Bank & 0.052 & 0.005 & 0.079 & 0.012 & 0.001 & 0.022 \\
\hline Nationsbank & 0.204 & 0.389 & 0.059 & 0.064 & 0.116 & 0.013 \\
\hline PNC Financial & 0.090 & $0.000^{*}$ & 0.133 & 0.026 & $0.000^{*}$ & 0.047 \\
\hline Republic NY & 0.025 & 0.006 & 0.002 & 0.005 & $0.000^{*}$ & $0.000^{*}$ \\
\hline Wells Fargo & 0.006 & 0.008 & 0.075 & 0.001 & 0.001 & 0.020 \\
\hline S\&P 500 & 0.007 & 0.007 & 0.010 & 0.002 & 0.002 & 0.003 \\
\hline
\end{tabular}

* a probability of 0.000 means that the measured probability is below 0.0005 
Table 3.5c: Exceedence Probabilities $\left(\mathrm{H}_{0}: \alpha=5\right.$, right tails)

\begin{tabular}{|c|c|c|c|c|c|c|}
\hline \multirow[b]{2}{*}{ Bank } & \multicolumn{3}{|c|}{ Weekly retum $+20 \%$} & \multicolumn{3}{|c|}{ Weekly retum $+30 \%$} \\
\hline & $73-93$ & $73-80$ & $80-93$ & $73-93$ & $73-80$ & $80-93$ \\
\hline Banc One & 0.104 & 0.111 & 0.163 & 0.027 & 0.049 & 0.050 \\
\hline BankAmerica & 0.046 & 0.056 & 0.097 & 0.057 & 0.010 & 0.021 \\
\hline Bankers Trust & 0.026 & 0.003 & 0.047 & 0.004 & $0.000^{*}$ & 0.009 \\
\hline Bank of Boston & 0.068 & 0.075 & 0.286 & 0.014 & 0.018 & 0.108 \\
\hline Bank of NY & 0.053 & 0.002 & 0.076 & 0.010 & 0.009 & 0.016 \\
\hline Bamett Bank & 0.136 & 0.026 & 0.187 & 0.033 & 0.019 & 0.055 \\
\hline Chase Manhattan & 0.019 & 0.008 & 0.036 & 0.002 & 0.001 & 0.005 \\
\hline Chemical Bank & 0.026 & $0.000^{*}$ & 0.066 & 0.006 & $0.000^{*}$ & 0.019 \\
\hline Citicorp & 0.052 & $0.000^{*}$ & 0.115 & 0.010 & $0.000^{*}$ & 0.035 \\
\hline First Chicago & 0.057 & 0.053 & 0.052 & 0.008 & 0.003 & 0.008 \\
\hline First Fidelity & 0.028 & 0.025 & 0.046 & 0.005 & 0.005 & 0.008 \\
\hline First Interstate & 0.147 & $0.000^{*}$ & 0.205 & 0.052 & $0.000^{*}$ & 0.077 \\
\hline First Union & 0.083 & 0.097 & 0.008 & 0.021 & 0.027 & 0.001 \\
\hline Fleet Financial & 0.026 & 0.010 & 0.053 & 0.006 & 0.002 & 0.013 \\
\hline JP Morgan & 0.002 & 0.004 & 0.033 & $0.000^{*}$ & $0.000^{*}$ & 0.006 \\
\hline Mellon Bank & 0.053 & 0.001 & 0.062 & 0.011 & $0.000^{*}$ & 0.013 \\
\hline Nationsbank & 0.180 & 0.576 & 0.105 & 0.053 & 0.345 & 0.019 \\
\hline PNC Financial & 0.102 & 0.017 & 0.108 & 0.034 & 0.004 & 0.033 \\
\hline Republic NY & 0.099 & 0.049 & 0.127 & 0.127 & 0.008 & 0.046 \\
\hline Wells Fargo & 0.129 & 0.035 & 0.232 & 0.035 & 0.004 & 0.096 \\
\hline S\&P 500 & 0.001 & $0.000^{*}$ & $0.000^{*}$ & $0.000^{*}$ & $0.000^{*}$ & $0.000^{*}$ \\
\hline
\end{tabular}

* a probability of 0.000 means that the measured probability is below 0.0005 


\subsection{Conclusion}

In the literature a consensus exists that distributions of asset returns are fattailed. We use a non-parametric tail index estimator based on extreme value theory to shed light on the empirical distributions of stock returns for the twenty largest U.S. bank holding companies between January 1973 and December 1993. Since the tail index is a good indicator of thickness of the tails, it provides an accurate measure of the degree of riskiness of the underlying bank stocks. Based on this criterion, we find that the riskiness of seven of the twenty bank holding companies has increased significantly after 1979. Moreover, for fourteen out of twenty bank holding companies we find large increases in the probabilities that the stock prices of these banks experience a one-week return of $20 \%$ or $30 \%$ (both positive and negative).

The 1980s witnessed the greatest crisis in U.S. commercial banking since the Great Depression. Boyd and Gertler (1994) show that banks with the largest total assets contributed in a significantly disproportionate way to aggregate loan losses. The intuition is that, while deregulation and financial innovation led to increased overall competition for the banking industry, the existing regulatory environment tended to subsidize risk taking by large banks more than that by small banks (too-big-to-fail policy). The study by Boyd and Gertler corresponds with our empirical findings of increased riskiness of several of the twenty largest U.S. bank holding companies. 



\section{Chapter 4 \\ The U.S. Banking Crisis}

During the period 1946-1992 the U.S. financial system has experienced major changes in terms of new financial products, deregulation, increasing competition, lower margins and changing risk attitudes. To a large extent the prevailing banking regulations at the beginning of the 1970s mirrored the legislation adopted after the banking crisis of 1929-1933. The banking failures of 19291933 induced the Banking (Glass-Steagall) Act of 1933 which changed fundamentally the parameters of the functioning of the U.S. financial system. Federal deposit insurance was introduced in order to avoid new bank runs. The activities of banks were restricted with a view to the perceived excessive competition of the previous period. Commercial and investment banking were separated, each type of bank was restricted to a specific type of lending and interstate banking was discouraged. Furthermore, payment of interest on demand deposits was prohibited and interest rates on time deposits were restricted to a maximum. In this way a new regulatory framework was created which can be characterized as a regulated, non-competitive equilibrium.

These conditions of a protected financial system resulted in a period of financial tranquility during the first twenty years after World War II (19461965). No serious threat of a financial crisis or a debt-deflation process took place (Minsky 1982 and 1986). However, the price to be paid for this period of financial tranquility was an inefficient financial system creating incentives to circumvent the restricting regulations.

The gradual movement since the 1970 s towards a more deregulated and competitive equilibrium has increased the efficiency of the U.S. financial system. At the same time, however, one could argue that the lower bank margins, higher corporate debt ratios and the relative decline in low risk investments by banks have increased financial fragility in the sense of vulnerability of the financial system to future outbreaks of financial disorder. In this view increasing efficiency and increasing fragility are two sides of the same coin. However, increasing fragility is not necessarily a bad thing: as long as risks are known and correctly priced by market participants, then these periods of financial disorder are unlucky, but calculated events. As we discussed in chapter 2 , increased financial fragility may lead to more frequent periods of 
financial disorder without causing serious damage to the functioning of financial markets and the economy.

Wolfson (1990) presented an empirical analysis of indicators of financial fragility in the U.S. banking sector (commercial banks and savings \& loan associations) in order to explain U.S. bank failures and insolvencies (so-called 'financial instability') during the period 1946-1987. The aim of this chapter is twofold. First, since Wolfson provides an aggregate analysis for the commercial banks and savings \& loan associations together, we disaggregate the analysis in order to look for differences among the two sectors. Second, we present an update of Wolfson's analysis including the turbulent period 1988-1992 during which the U.S. experienced a lot of banking problems.

This chapter is organized as follows. In section 4.1 we summarize Wolfson's empirical analysis (including a data correction to one variable). Wolfson kindly provided me with the data. Section 4.2 contains our sectoral analysis of Wolfson's data for the same period 1946-1987 and includes a split up of the data into two subperiods, namely 1946-1965 and 1966-1987. In section 4.3 the data set is updated so that it includes the period 1988-1992, which will enable us to implement a sectoral analysis for the period 1966-1992. The conclusion of the chapter is in section 4.4 .

\subsection{Wolfson's Empirical Analysis}

Wolfson (1990) presents an empirical analyis aimed at explaining so-called 'financial instability' in the U.S. banking sector during the period 1946-1987. Wolfson's approach is an aggregate analysis of all U.S. commercial banks and savings \& loan associations (S\&Ls).

Using the standard OLS regression technique Wolfson estimates a regression equation in which 'financial instability' is regressed as a dependent variable upon four independent variables. These four independent variables are indicators of financial fragility in the commercial banking or S\&L sector. 'Financial instability' is taken to be the actual outbreak of problems in the financial system whereas the term 'financial fragility' is designed to measure the vulnerability of the system to the future outbreak of these problems. 
As dependent variable in his analysis Wolfson uses a 'financial instability' variable indicating periods of financial disorder or turmoil. This variable is formed as the principal component of four different variables expressing in some way the overall concept of 'financial instability'. If we create a set of mutually orthogonal (uncorrelated) linear combinations of these four variables that account for the total variance of the four variables, the principal component is the one that accounts for the maximum percentage of the total variance. Thus it is best able to represent the variation of the original four variables ${ }^{1}$.

The four variables are:

1. Assets of failed commercial banks as a percentage of total commercial bank assets.

2. Assets of failed savings \& loan associations (S\&Ls) as a percentage of total S\&L assets.

3. Assets of insolvent S\&Ls as a percentage of total S\&L assets.

Many insolvent S\&Ls have been allowed to remain open and have not failed due to the bankrupt condition of the thrift insurer, the Federal Savings and Loan Insurance Corporation (FSLIC). These institutions had negative net worth and would probably have failed if the FSLIC had not been bankrupt.

4. Dummy variable for financial crises.

It has the value of one in those years in which financial crises took place, and zero otherwise. For the postwar period Wolfson identifies the following events as financial crises: the credit crunch of 1966 which centered around a run on bank-negotiable certificates of deposit, the Penn Central bankruptcy in 1970, the failure of Franklin National Bank in 1974, the Hunt Brothers episode in 1980, the failures of Drysdale and Penn Square and the threatened default of Mexico in 1982, the troubles of Continental Illinois and the Financial Corporation of America (the holding company for American Savings

\footnotetext{
' In matrix notation, if $\mathbf{X}$ is an $n$ by $k$ matrix of the $n$ observations on $k$ variables, and $z_{1}$ $=\mathbf{X} \mathbf{a}_{1}$ is a linear combination of the original variables, the principal component is formed by maximizing $\mathbf{z}^{\prime} \mathbf{z}_{\mathbf{1}}=\mathbf{a}^{\prime}{ }_{1} \mathbf{X}^{\prime} \mathbf{X} \mathbf{a}_{1}$ subject to the normalization constraint $\mathbf{a}^{\prime}{ }_{1} \mathbf{a}_{1}=1$. The solution to the Lagrangian $\phi=\mathbf{a}^{\prime}{ }_{1} \mathbf{X}^{\prime} \mathbf{X} \mathbf{a}_{1}-\lambda_{1}\left(\mathbf{a}^{{ }^{\prime}}{ }_{1} \mathbf{a}_{1}-1\right)$ is $\left(\mathbf{X}^{\prime} \mathbf{X}\right) \mathbf{a}_{1}=\lambda_{1} \mathbf{a}_{1}$, so that the principal component $\mathbf{a}_{1}$ is the eigenvector of $\mathbf{X}^{\prime} \mathbf{X}$ corresponding to $\lambda_{1}$, which is chosen to be the largest eigenvalue of $\mathbf{X}^{\prime} \mathbf{X}$ (see Johnston 1984).
} 
and Loan Association, at the time the largest thrift in the nation) in 1984, the runs on state-insured thrifts in Ohio and Maryland in 1985, and the stock market crash of 1987.

Wolfson uses four independent variables. These variables are:

1. Financial fragility variable for the commercial banking sector.

It is the principal component of two variables, namely the ratio of corporate interest payments to gross capital income and net bank loan losses as a percentage of average bank loans. An increase in the first variable will mean that corporations have more difficulty in meeting debt payment commitments. This fragility will then be transmitted to the banking sector by means of increased defaults on bank loans. Both variables are expected to have a positive relationship with the dependent variable because they increase the likelihood of bank failures. The consequence is that the principal component also has a positive relationship with the dependent variable.

2. Purchased funds as a percentage of total commercial bank liabilities.

Purchased funds are the sum of large time deposits, Eurodollar borrowing, net Fed funds purchased, and commercial paper borrowing. Better access to the market for purchased funds enables banks to meet in a more flexible way the borrowing needs of corporations. In this way banks can, especially in periods of tight money, still accomodate loan demand and stave off large business failures and potential financial crises (purchasing liabilities in the market to fund new loans rather than liquidating existing assets). The foregoing implies from a theoretical point of view a negative relationship between the purchased funds variable and the dependent variable 'financial instability'.

3. Dummy variable for purchased funds of commercial banks.

Wolfson introduces this variable in order to capture the effects of the introduction of money market deposit accounts (MMDAs) in 1982 and 1983. The dummy variable for purchased funds consists of a dummy variable (with a value of one in 1982 and 1983 and with a value of zero in other years) multiplied by the purchased funds variable. The growth of MMDAs came to a significant degree at the expense of the growth of large time deposits held at commercial banks ('banks' hereafter). Thus for 1982 and 1983 a decline in purchased funds was due not to investor runs (associated with 'financial 
instability') but to an increase in insured bank deposits (assumed to be associated with a decrease in 'financial instability'). Implication of the preceding argument is that one would expect a positive relationship between the dummy variable and the dependent variable 'financial instability'.

4. Financial fragility variable for S\&Ls.

This variable aims at measuring changes in the regulatory structure and financial fragility of the S\&Ls. It is the principal component of the following three variables: the percentage increase of $S \& L$ deposits, the $S \& L$ interest margin, and the ratio of home mortgages to total financial S\&L assets. All three variables are expected to have a negative relationship with 'financial instability'.

A smaller percentage increase of S\&L deposits is a measure of disintermediation of the S\&Ls and is a sign of potential S\&L insolvencies and failures. The $S \& L$ interest margin is defined as the mortgage interest income on both mortgage loans and mortgage-backed securities as a percentage of average mortgage-related loans and securities minus deposit interest expense as a percentage of average deposits. A smaller interest margin enhances the danger of problems in the S\&L sector. A lower ratio of home mortgages to total financial $\mathrm{S} \& \mathrm{~L}$ assets is a sign of riskier $\mathrm{S} \& \mathrm{~L}$ investments and increased risk of credit quality problems.

Since all three variables have a negative relationship with 'financial instability', the principal component of these three variables also shows in theory such a negative relationship.

Except for the crisis and purchased funds dummy variables Wolfson uses annual data provided by official U.S. institutions: Federal Deposit Insurance Corporation, Board of Governors of the Federal Reserve System, Federal Home Loan Bank Board, and Department of Commerce. Wolfson's OLS estimation results for the period 1946-1987 are presented in Table 4.1.

The statistical results are highly satisfactory. All independent variables have high $t$ statistics. The signs of the estimated regression coefficients correspond to our expectations formulated above. The explanatory power of the regression is relatively high with an adjusted $\mathrm{R}^{2}$ of 0.84 . The Durbin-Watson statistic is close enough to the value of 2 so that residual first-order autocorrelation does not seem to pose a problem. 


\section{Table 4.1 \\ Wolfson's OLS estimation 1946-1987}

The dependent variable 'financial instability' is regressed upon a constant and four independent variables ( $l$ statistics are in parentheses).

Independent variable

Constant

Financial fragility banks

Purchased funds banks

Dummy purchased funds banks

Financial fragility S\&Ls 


\subsection{Sectoral Analysis for 1946-1987}

Test for structural change

Wolfson's OLS estimation is based upon the entire dataset covering the period 1946-1987. At the same time, however, he suggests that there are two distinct subperiods in the postwar period. There was the period of financial tranquility (1946-1965) followed by the period of more or less frequent financial disorder or 'instability'. The preceding justifies the question whether it is a sound procedure to base the OLS estimation upon the entire period 1946-1987. Wolfson's remark suggests a structural change in the data.

One way of testing for structural change in the model is making use of recursive residuals. In recursive least squares the equation is estimated repeatedly, using ever larger subsets of the sample data. The one-step forecast error is defined to be a recursive residual. Figure 4.1 pictures the recursive residuals for the entire period 1946-1987.

In Figure 4.1 we present a plot of the recursive residuals about the zero line. Plus and minus two standard errors (SE) are also shown at each point. The plot was generated using Wolfson's dataset for the period 1946-1987. All variables included in Wolfson's regression presented in section 4.1 were used except for the dummy variable for the purchased funds of banks. The dummy variable is almost always zero, only in the years 1982 and 1983 it has a non-zero value. Including the dummy in the recursive residuals procedure would just generate a plot starting in 1983 .

From the plot we can easily observe that 1966 (the first year of financial turmoil) is the first year that the recursive residual lies outside the standard error bands. But also in later years this happens frequently suggesting instability in the parameters of the equation due to a structural change in the model. We also see the increased variance of the residuals since the recursive residuals lie further outside the standard error bands as time elapses. 


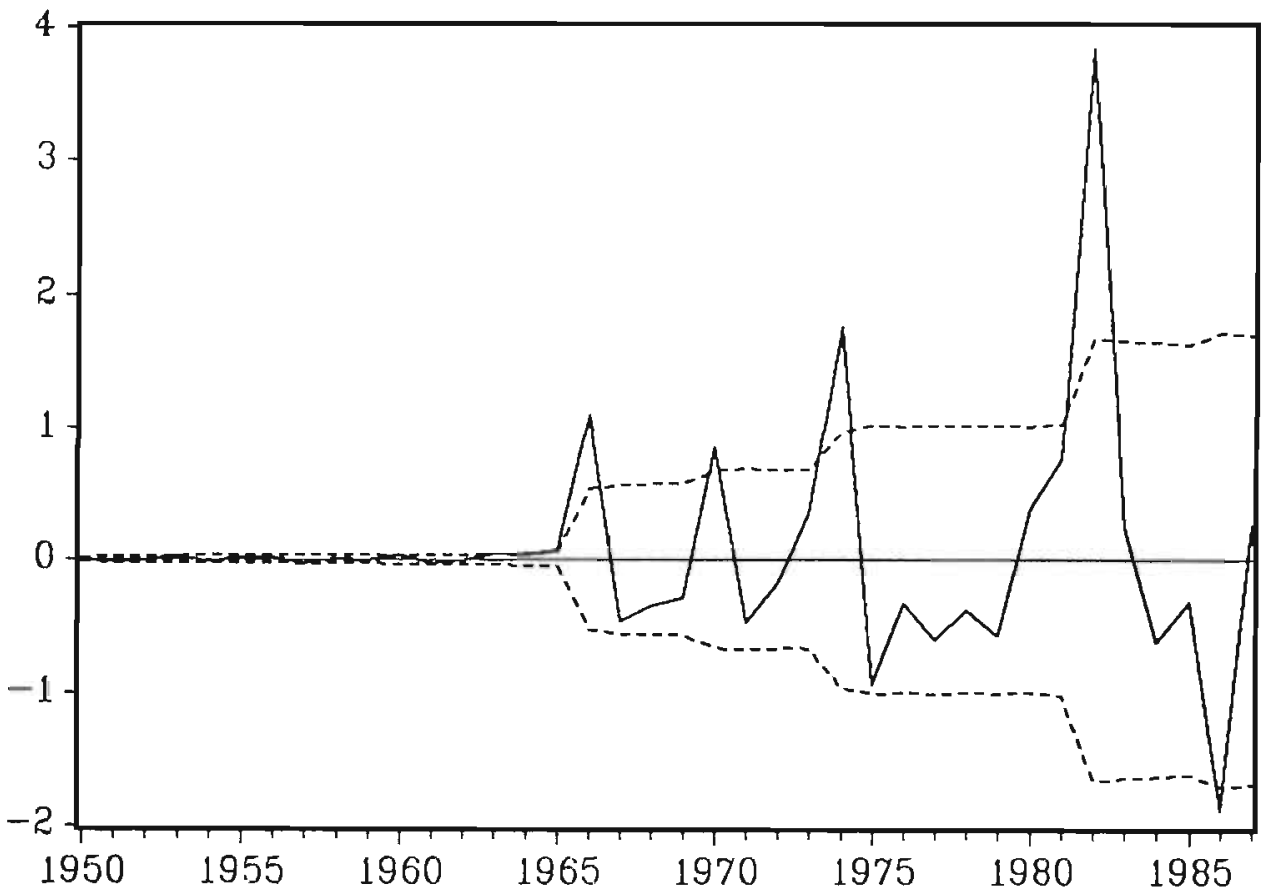

Recursive Residuals _.... 2 S.E.

Figure 4.1: Recursive residuals 
An alternative way of testing for structural change in the model is using a $F$ test (see Johnston 1984). The null hypothesis of no structural change is the restricted form of the model. In the unrestricted form of the model intercepts and slopes can be different in the two subperiods 1946-1965 and 1966-1987. The F statistic for testing the restricted versus the unrestricted form was computed on the basis of $q=4$ (number of restrictions embodied in the null hypothesis), $n=42$ (sample size), and $k=9$ (number of regression coefficients estimated in the unrestricted regression). The resulting $\mathrm{F}(\mathrm{q}, \mathrm{n}-\mathrm{k})$ statistic equals 4.84 , which is significant at the $1 \%$ level.

The conclusion of the statistical analysis is that even at the $1 \%$ level of significance the null hypothesis of no structural change has to be rejected. We can improve the quality of the regression for the period 1966-1987 by omitting the period of financial tranquility 1946-1965 and by just using the data for the period 1966-1987.

\section{Dependent variable as a principal component}

In section 4.1 it was stated that Wolfson uses as dependent variable a 'financial instability' variable which is the principal component of four different variables expressing in some way the overall concept of 'financial instability'. The following four variables are the components of the principal component:

* Assets of failed banks as a percentage of total bank assets;

* Assets of failed S\&Ls as a percentage of total S\&L assets;

* Assets of insolvent S\&Ls as a percentage of total S\&L assets;

* Dummy variable for financial crises.

The question arises whether it is useful to put all 'instability' in one principal component variable. One could imagine that bank failures are strongly related to the financial fragility variable for the banking sector and the purchased funds as a percentage of total bank liabilities variable and to a lesser extent related to the independent variable measuring changes in the regulatory structure and financial fragility of the S\&Ls. In the same way one could argue that S\&L failures and insolvencies are particularly related to the $S \& L$ independent variable and not so much to banking independent variables. Because of this the four dependent variables could behave quite differently: problems in the banking sector do not need to be accompanied by problems in the S\&L sector. 
In order to test the usefulness of the principal component approach we run the same type of regression as Wolfon (for the period 1946-1987 and including the dummy variable), the only difference being that we run four separate regressions with the four variables listed above as dependent variables instead of Wolfson's single regression with the principal component of the four variables as dependent variable.

The principal component approach is only useful if the estimated regression coefficients for a particular independent variable do not differ significantly from a statistical point of view in the four different regressions. Only then we can conclude that the four dependent variables forming the principal component dependent variable show the same pattern in time and embody the same informational content so that the reduction of the four dependent variables to one principal component dependent variable is a valid approach.

In Table 4.2 we test for each independent variable the null hypothesis that the estimated regression coefficients do not differ significantly in the four different regressions.

Except for the financial fragility S\&Ls variable (whose test statistic has a marginal significance level of 0.19) we find that the test statistics of all other independent variables have marginal significance levels of almost zero (because of these strong results we do not correct for the slight residual autocorrelation in two of the four regressions). From this observation we can conclude that in general the estimated regression coefficients do differ significantly in the four different regressions so that the principal component approach for the dependent variable ignores too much sectoral differences.

\section{Independent variables as principal components}

In the previous subsection we concluded that there are sectoral differences between the four dependent variables that might be worth exploring. In the present subsection we want to analyze whether the use of principal components for the independent variables is significant from a statistical point of view.

As we observed in section 4.1, Wolfson uses four independent variables of which two are the principal components of other independent variables: 
Table 4.2

\section{Testing for the dependent variable as a principal component}

For each independent variable the $\chi^{2}$ test statistic and corresponding probability value indicate whether the estimated regression coefficients differ significantly in the four different regressions making use of four different dependent variables instead of one dependent variable which is the principal component of these four variables.

\begin{tabular}{|c|c|}
\hline $\begin{array}{l}\text { Independent variable } \\
\text { Value test statistic } \\
\text { Probability value }\end{array}$ & $\begin{array}{l}\text { Constant } \\
y^{2}=173.66 \\
0.00\end{array}$ \\
\hline $\begin{array}{l}\text { Independent variable } \\
\text { Value test statistic } \\
\text { Probability value }\end{array}$ & $\begin{array}{l}\text { Financial fragility banks } \\
\chi^{2}=303.50 \\
0.00\end{array}$ \\
\hline $\begin{array}{l}\text { Independent variable } \\
\text { Value test statistic } \\
\text { Probability value }\end{array}$ & $\begin{array}{l}\text { Purchased funds banks } \\
\chi^{2}=129.01 \\
0.00\end{array}$ \\
\hline $\begin{array}{l}\text { Independent variable } \\
\text { Value test statistic } \\
\text { Probability value }\end{array}$ & $\begin{array}{l}\text { Dummy purchased funds banks } \\
\chi^{2}=17.83 \\
0.00\end{array}$ \\
\hline $\begin{array}{l}\text { Independent variable } \\
\text { Value test statistic } \\
\text { Probability value }\end{array}$ & $\begin{array}{l}\text { Financial fragility S\&Ls } \\
\chi^{2}=4.80 \\
0.19\end{array}$ \\
\hline
\end{tabular}


* Financial fragility variable for the banking sector being the principal component of two explanatory variables, namely the ratio of corporate interest payments to gross capital income and net bank loan losses as a percentage of average bank loans;

* Financial fragility variable for the S\&L sector being the principal component of three explanatory variables, namely the percentage increase of S\&L deposits, the S\&L interest margin, and the ratio of home mortgages to total financial S\&L assets.

The two other independent variables are the purchased funds as a percentage of total bank liabilities variable and the dummy variable for purchased funds. However, these are not principal components.

In the following we will test for the appropriateness of using principal components as independent variables. This means that we test whether it is more appropriate to use principal components as independent variables or to use the individual explanatory variables as independent variables.

The null hypothesis that the use of principal components is a valid approach will be the restricted form of the model. In the unrestricted form of the model the individual explanatory variables will be allowed to replace the principal component independent variables. Since we concluded in the previous subsection not to use a dependent variable principal component for the four dependent variables, we run here the pair of restricted/unrestricted regressions for each dependent variable. The results are presented in Table 4.3.

The $F$ statistics for testing the restricted versus the unrestricted form were computed on the basis of residual sum of squares in the restricted model (first column), in the unrestricted model (second column), $\mathrm{q}=3, \mathrm{n}=42$, and $\mathrm{k}=8$. In the cases of 'assets of insolvent S\&Ls' and 'financial crises' as dependent variables the regressions include a first-order autoregressive AR(1) independent variable since the original regressions are distorted by residual first-order serial correlation.

Only in the case of the 'assets of failed S\&Ls' as dependent variable we find a $F$ statistic which is significant at the $5 \%$ level. This implies that the variability in the failed S\&Ls dependent variable is better explained by using the individual explanatory variables rather than the principal component independent variables. However, in the case of the other three dependent variables the $F$ statistics are not significant at the $5 \%$ level. For these variables the null hypothesis of the use of principal components cannot be rejected. 
Table 4.3

Testing for the independent variables as principal components

The dependent variable is 'assets of failed banks' in column I, 'assets of failed S\&Ls' in column II, 'assets of insolvent S\&Ls' in column III and 'financial crises' in column IV ( $t$ statistics are in parentheses).

\begin{tabular}{|c|c|c|c|c|c|c|c|c|}
\hline Independent variable & \multicolumn{2}{|c|}{1} & \multicolumn{2}{|c|}{ II } & \multicolumn{2}{|c|}{ III } & \multicolumn{2}{|c|}{ IV } \\
\hline Constant & $\begin{array}{c}0.10 \\
(2.37)\end{array}$ & $\begin{array}{c}-0.17 \\
(-0.47)\end{array}$ & $\begin{array}{c}0.68 \\
(2.32)\end{array}$ & $\begin{array}{c}0.80 \\
(0.33)\end{array}$ & $\mid \begin{array}{l}-0.64 \\
(-0.38)\end{array}$ & $\begin{array}{l}11.30 \\
(1.44)\end{array}$ & $\begin{array}{l}0.36 \\
(2.65)\end{array}$ & $\begin{array}{c}0.78 \\
(0.52)\end{array}$ \\
\hline $\begin{array}{l}\text { Financial fragility } \\
\text { banks }\end{array}$ & $\begin{array}{c}0.05 \\
(2.84)\end{array}$ & & $\begin{array}{l}-0.03 \\
(-0.24)\end{array}$ & & $\begin{array}{c}-0.29 \\
(-0.55)\end{array}$ & & $\begin{array}{c}0.12 \\
(1.96)\end{array}$ & \\
\hline $\begin{array}{l}\text { Corporate interest } \\
\text { payments }\end{array}$ & & $\begin{array}{c}1.09 \\
(1.89)\end{array}$ & & $\begin{array}{c}5.85 \\
(1.53)\end{array}$ & & $\begin{array}{l}-5.96 \\
(-0.53)\end{array}$ & & $\begin{array}{c}2.72 \\
(1.33)\end{array}$ \\
\hline Net bank loan losses & & $\begin{array}{c}0.10 \\
(0.90)\end{array}$ & & $\begin{array}{c}0.59 \\
(0.77)\end{array}$ & & $\begin{array}{l}-1.52 \\
(-0.82)\end{array}$ & & $\begin{array}{c}0.16 \\
(0.32)\end{array}$ \\
\hline $\begin{array}{l}\text { Financial fragility } \\
\text { S\&Ls }\end{array}$ & $\begin{array}{l}-0.03 \\
(-1.74)\end{array}$ & & $\begin{array}{l}-0.53 \\
(-4.82)\end{array}$ & & $\begin{array}{l}-0.02 \\
(-0.06)\end{array}$ & & $\begin{array}{l}-0.14 \\
(-2.68)\end{array}$ & \\
\hline S\&L deposits & & $\begin{array}{l}-0.00 \\
(-2.09)\end{array}$ & & $\begin{array}{l}-0.05 \\
(-3.37)\end{array}$ & & $\begin{array}{c}0.00 \\
(0.10)\end{array}$ & & $\begin{array}{c}-0.02 \\
(-1.68)\end{array}$ \\
\hline S\&L interest margin & & $\begin{array}{c}0.02 \\
(0.66)\end{array}$ & & $\begin{array}{c}-0.57 \\
(-3.12)\end{array}$ & & $\begin{array}{c}-0.26 \\
(-0.52)\end{array}$ & & $\begin{array}{l}-0.08 \\
(-0.68)\end{array}$ \\
\hline S\&L home mortgages & & $\begin{array}{c}0.00 \\
(0.42)\end{array}$ & & $\begin{array}{c}0.01 \\
(0.49)\end{array}$ & & $\begin{array}{l}-0.15 \\
(-1.56)\end{array}$ & & $\begin{array}{l}-0.01 \\
(-0.34)\end{array}$ \\
\hline $\begin{array}{l}\text { Purchased funds } \\
\text { banks }\end{array}$ & $\begin{array}{l}-0.00 \\
(-1.00)\end{array}$ & $\begin{array}{l}-0.01 \\
(-1.33)\end{array}$ & $\begin{array}{l}-0.03 \\
(-1.57)\end{array}$ & $\begin{array}{l}-0.08 \\
(-2.82)\end{array}$ & $\begin{array}{c}-0.11 \\
(-1.22)\end{array}$ & $\begin{array}{c}-0.06 \\
(-0.47)\end{array}$ & $\begin{array}{l}-0.01 \\
(-1.28)\end{array}$ & $\begin{array}{l}-0.02 \\
(-1.50)\end{array}$ \\
\hline $\begin{array}{l}\text { Dummy purchased } \\
\text { funds banks }\end{array}$ & $\begin{array}{c}0.01 \\
(4.51)\end{array}$ & $\begin{array}{c}0.01 \\
(4.22)\end{array}$ & $\begin{array}{c}0.13 \\
(9.46)\end{array}$ & $\begin{array}{c}0.12 \\
(7.16)\end{array}$ & $\begin{array}{c}0.06 \\
(2.40)\end{array}$ & $\begin{array}{c}0.06 \\
(2.16)\end{array}$ & $\begin{array}{l}-0.00 \\
(-0.61)\end{array}$ & $\begin{array}{l}-0.01 \\
(-0.48)\end{array}$ \\
\hline $\operatorname{AR}(1)$ & & & & & $\left(\begin{array}{c}1.13 \\
(26.54)\end{array}\right.$ & $\begin{array}{c}1.14 \\
(18.51)\end{array}$ & $\begin{array}{l}-0.48 \\
(-3.15)\end{array}$ & $\begin{array}{c}-0.47 \\
(-2.80)\end{array}$ \\
\hline Adjusted $\mathrm{R}^{2}$ & 0.72 & 0.72 & 0.82 & 0.85 & 0.95 & 0.95 & 0.44 & 0.40 \\
\hline $\begin{array}{l}\text { Residual sum of } \\
\text { squares (RSS) }\end{array}$ & 0.16 & 0.14 & 8.11 & 6.36 & 29.06 & 26.54 & 3.17 & 3.07 \\
\hline F statistic & & 1.11 & & 3.11 & & 1.01 & & 0.32 \\
\hline
\end{tabular}


The preceding is mirrored in the adjusted $\mathrm{R}^{2}$. In the case of the financial crises dependent variable the adjusted $\mathrm{R}^{2}$ is even lower in the unrestricted model. In the two other cases it is slightly higher, but apparently not in a statistically significant way.

\section{Dynamics of the model}

In the first subsection we found a structural change in the dataset: the subperiod 1946-1965 is substantially different from the subperiod 1966-1987. From the second subsection we concluded that the principal component approach for the dependent variable eliminates too much the informational content of sectoral differences. The third subsection showed mixed evidence concerning the use of principal components for the independent variables. Therefore, from now on we will base our analysis on the following principles: annual data for the period 1966-1987 and no application of principal component analysis for the dependent variables nor for the independent variables. Moreover, we do not employ the dummy variable for financial crises as a dependent variable since this variable might be arbitrary to some extent and would also require a different econometric technique (probit). Hence, we limit ourselves to three dependent variables: assets of failed banks as a percentage of total bank assets, assets of failed S\&Ls as a percentage of total S\&L assets, and assets of insolvent S\&Ls as a percentage of total S\&L, assets.

In this subsection we will analyze the potential dynamics of the model by reestimating Wolfson's OLS regression equation which now includes a one-period lag. Table 4.4 contains the statistical results.

From Table 4.4 we can conclude that in the case of 'assets of failed banks' (column I) and 'assets of insolvent S\&Ls' (column III) the inclusion of a oneperiod lag is not statistically significant. The estimated coefficients of the lagged dependent variables have low $t$ statistics $(0.71$ and -1.64 respectively). Moreover, the null hypothesis of deleting all lagged explanatory variables can in both cases not be rejected as is mirrored in the marginal significance levels (probability values) of 0.45 and 0.10 respectively. 
Table 4.4

Testing for dynamics of the model

The dependent variable is 'assets of failed banks' in column I, 'assets of failed S\&Ls' in column II and 'assets of insolvent S\&Ls' in column III ( $t$ statistics are in parentheses).

A one-period lag is indicated by $(-1)$. The F statistic and probability value at the bottom of the table test the null hypothesis of deleting all lagged explanatory variables.

\begin{tabular}{|c|c|c|c|c|c|c|}
\hline Independent variable & & I & & II & & III \\
\hline Constant & -0.25 & $(-0.13)$ & 4.03 & $(0.76)$ & 132.76 & $(2.90)$ \\
\hline Dependent variable $(-1)$ & 0.37 & $(0.71)$ & -0.93 & $(-3.37)$ & -0.97 & $(-1.64)$ \\
\hline Net bank loan losses & 0.92 & $(1.35)$ & -0.64 & $(-0.35)$ & -11.30 & $(-2.2 l)$ \\
\hline Net bank loan losses $(-1)$ & -0.43 & $(-0.85)$ & 2.24 & $(1.88)$ & 7.98 & (2.40) \\
\hline Corporate interest payments & -0.56 & $(-0.26)$ & -8.47 & $(-1.60)$ & 1.70 & $(0.12)$ \\
\hline Corporate interest payments $(-1)$ & 0.42 & $(0.16)$ & 14.54 & $(2.04)$ & -25.84 & $(-0.99)$ \\
\hline S\&L deposits & -0.00 & $(-0.10)$ & -0.07 & $(-1.74)$ & -0.29 & $(-2.63)$ \\
\hline S\&L deposits $(-1)$ & -0.00 & $(-0.04)$ & -0.01 & $(-0.29)$ & -0.06 & $(-0.74)$ \\
\hline S\&L interest margin & -0.02 & $(-0.17)$ & -1.23 & $(-3.94)$ & 0.07 & $(0.08)$ \\
\hline S\&L interest margin $(-1)$ & -0.23 & $(-1.22)$ & 0.74 & $(1.22)$ & 0.00 & $(0.00)$ \\
\hline S\&L home mortgages & 0.02 & $(0.58)$ & -0.09 & $(-0.76)$ & -1.64 & $(-3.44)$ \\
\hline S\&L home mortgages $(-1)$ & -0.02 & $(-0.33)$ & 0.07 & $(0.46)$ & -0.16 & $(-0.37)$ \\
\hline Purchased funds banks & 0.05 & $(1.83)$ & 0.03 & $(0.32)$ & -0.20 & $(-0.89)$ \\
\hline Purchased funds banks $(-1)$ & -0.06 & $(-2.13)$ & -0.12 & $(-1.57)$ & 0.40 & $(1.59)$ \\
\hline Dummy purchased funds banks & -0.00 & $(-0.01)$ & 0.25 & $(8.39)$ & 0.03 & $(0.39)$ \\
\hline $\begin{array}{l}\text { Dummy purchased funds banks } \\
(-1)\end{array}$ & -0.01 & $(-1.84)$ & 0.05 & $(1.73)$ & 0.21 & (3.19) \\
\hline Adjusted $\mathbf{R}^{2}$ & & 0.67 & & 0.97 & & 0.98 \\
\hline F statistic & & 1.13 & & 8.88 & & 3.01 \\
\hline Probability value & & 0.45 & & 0.01 & & 0.10 \\
\hline
\end{tabular}


The case of 'assets of failed S\&Ls' is more complicated. The estimated coefficient of the lagged dependent variable has a high $t$ statistic (-3.37) and the null hypothesis of deleting all lagged explanatory variables is rejected (probability value of 0.01 ). The question arises why one would find dynamic properties of the model for the assets of failed S\&Ls but not for the assets of insolvent S\&Ls and the assets of failed banks. We believe that this phenomenon is caused coincidentally by the fact that the dummy variable for the purchased funds of banks (which is always zero except during 1982 and 1983) is the only variable moving together with the peak values of the assets of failed S\&Ls during 19811983. In Figure 4.2 the two variables are plotted in one diagram. However, since the dummy variable for purchased funds is related to banks and not to S\&L.s, one could argue that this correlation is just coincidental. Apparently there are no other, theoretically more convincing. explanatory variables in the data set which are able to explain the sudden peaking of the S\&L failed assets variable during 1981-1983. A reason might be that the S\&L failed assets variable is a rather strange variable since, as was noted in section 4.1, many insolvent thrifts have been allowed to remain open and have not failed due to the bankrupt condition of the thrift insurer, the Federal Savings and Loan Insurance Corporation (FSLIC).

Re-estimating the regression equation of column II in Table 4.4 while excluding the dummy variable for purchased funds of banks (both the lagged and non-lagged variables) fundamentally changes the statistical results. The estimated coefficient of the lagged $S \& L$ failed assets variable now has a low $t$ statistic of -1.58 (coming down from -3.37). Moreover, the null hypothesis of deleting all lagged explanatory variables can not be rejected any more (probability value of 0.26 ). A dynamic specification of the model is no longer necessary.

\section{Reduction of explanatory variables}

In this subsection we analyze the extent to which we can come to a reduction in the number of explanatory variables. Following our analysis in section 4.1 of the expected relationships between the various independent (explanatory) and dependent variables, the assumption is that the variability in the banking dependent variable (failed assets of banks) can better be explained by the independent variables linked to the banking sector rather than those linked to the S\&L sector. Applying the same intuition to the S\&L sector one would expect the varia- 


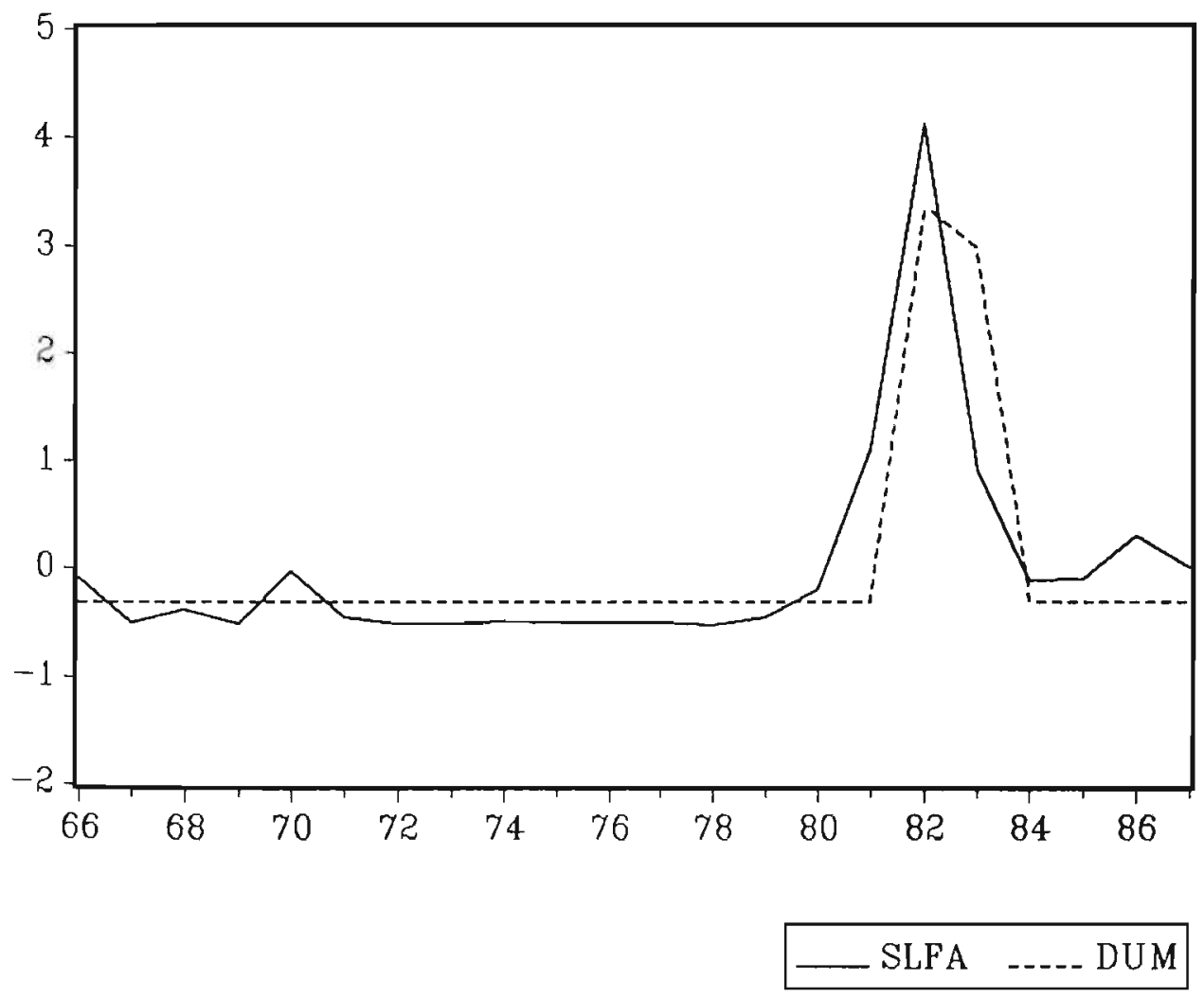

Figure 4.2: S\&L failed assets ratio and dummy variable for purchased funds of banks 
bility in the S\&L dependent variables (failed and insolvent assets of S\&Ls) to be strongly related to independent variables linked to the S\&L sector. Therefore, we test in this subsection for each of the three dependent variables the null hypothesis of deleting the explanatory variables linked to the other sector.

The procedure is first to run a regression on all eight explanatory variables (seven explanatory variables in the case of the failed assets of S\&Ls since we have already excluded in the previous subsection the dummy for purchased funds in this particular case) after which we will test for deleting the independent variables linked to the other sector. The eight independent variables are: a constant, three banking variables (net bank loan losses as a percentage of average bank loans, ratio of corporate interest payments to gross capital income, purchased funds as a percentage of total bank liabilities), a dummy for the purchased funds of banks, and three S\&L variables (percentage increase of S\&L deposits, S\&L interest margin, and ratio of home mortages to total financial S\&L assets).

In the case of the failed assets of banks as a percentage of total bank assets we test the null hypothesis of deleting the three $S \& L$ variables plus the dummy variable for the purchased funds of banks as explanatory variables. The $\mathrm{F}$ statistic has a value of 2.97 and is insignificant at the $5 \%$ level. A test for deleting the three banking variables as explanatory variables in the case of the failed assets of S\&LS as a percentage of total $S \& L$ assets results in a $F$ statistic of 0.35 , which is insignificant at the $5 \%$ level. In the case of the insolvent assets of S\&Ls as percentage of total S\&L assets we test for deleting the three banking variables plus the dummy for the purchased funds of banks as explanatory variables. The $F$ statistic has a value of 1.84 which is, again, insignificant at the $5 \%$ level.

Our conclusion is that we can run the regressions in all three cases making use of a reduced number of explanatory variables. 


\subsection{Update for the Period 1988-1992}

The analysis of section 4.2 made it clear that the use of lags in general does not contribute in a statistically significant way to the explanatory power of the regressions. This is unfortunate since it means that the outbreak of banking and S\&L crises can not be foreseen. Furthermore, it was shown that the variability in the banking dependent variable (failed assets of banks) can better be explained by the independent variables linked to the banking sector rather than those linked to the S\&L sector. Applying the same intuition to the S\&L sector it was demonstrated that the variability in the S\&L dependent variables (failed and insolvent assets of S\&Ls) can adequately be described by independent variables related to the $S \& L$ sector.

Therefore, in this section we present some regressions using no lags and explaining variability in the banking dependent variable by banking independent variables just as explaining variability in the S\&L dependent variables by S\&L independent variables. Moreover, the sample period is now 1966-1992 so that it includes the turbulent period 1988-1992 in which the U.S. experienced a lot of problems both in the banking and S\&L sector.

For the variability in the assets of failed banks as a percentage of total bank assets (BKFA) regressed upon a constant, the net bank loan losses as a percentage of average bank loans (BKLOSS), the ratio of corporate interest payments to gross capital income (CORPINT), and the purchased funds as a percentage of total bank liabilities (PUR) we obtain the following result ( $t$ statistics are in parentheses):

$$
\begin{aligned}
& \text { BKFA }=-0.17+0.71 \times \text { BKLOSS }+1.64 \times \text { CORPINT }-0.02 \times \text { PUR } \\
& (-0.68) \quad(2.39)
\end{aligned}
$$

Adjusted $\mathrm{R}^{2}=0.62$

Durbin-Watson $=1.95$

The signs of the estimated regression coefficients for BKLOSS, CORPINT and PUR are as expected (see section 4.1). A Durbin-Watson statistic of 1.95 indicates absence of residual first-order autocorrelation.

The only significant independent variable is BKLOSS with a $t$ statistic of 2.39. A test for deleting CORPINT and PUR confirms this result ( $F$ statistic value of 0.32 and probability value of 0.73 ). The new regression equation is: 


$$
\begin{aligned}
\mathrm{BKFA}= & -0.23+0.89 \times \text { BKLOSS } \\
& (-2.42) \quad(6.95)
\end{aligned}
$$

Adjusted $\mathrm{R}^{2}=0.65$

Durbin-Watson $=1.88$

The increase in the net bank loan losses as a percentage of average bank loans has played a major role in causing bank failures. In Figure 4.3 we illustrate this relationship between the bank failed assets ratio and the bank loan losses ratio. It is this deterioration in the loan performance of the commercial banking sector (third world loans, junk bonds, real estate loans) that led to the largest U.S. bank failures since the banking crisis of 1929-1933. This could suggest that banks' risk awareness and risk pricing were not taking account of the increased riskiness of U.S. commercial banking. Evidence of this increased riskiness was presented in chapter 3.

The variability in the assets of failed S\&Ls as a percentage of total S\&L assets (SLFA) is regressed upon a constant, the percentage increase of S\&L deposits (SLDEP), the S\&L interest margin (SLMARG), and the ratio of home mortgages to total financial S\&L assets (SLMORTG) delivering as result ( $t$ statistics are in parentheses):

$$
\begin{aligned}
& \text { SLFA }=14.17-0.19 \times \text { SLDEP }-0.66 \times \text { SLMARG }-0.15 \times \text { SLMORTG } \\
& \text { (2.50) (-3.32) } \\
& (-1.06)
\end{aligned}
$$

Adjusted $\mathrm{R}^{2}=0.37$

Durbin-Watson $=2.22$

All signs of the estimated regression coefficients are negative, as was expected (see section 4.1). Residual first-order autocorrelation does not seem to pose a problem. However, the adjusted $\mathrm{R}^{2}$ is relatively low. The reason might be, as was previously noted, that the S\&L failed assets variable is a rather strange variable since many insolvent thrifts have been allowed to remain open and have not failed due to the bankrupt condition of the thrift insurer, the Federal Savings and Loan Insurance Corporation (FSLIC). Therefore, it might be better to look at the assets of insolvent S\&Ls as a measure of 'instability' in the S\&L sector. This is what is done in the next regression. 


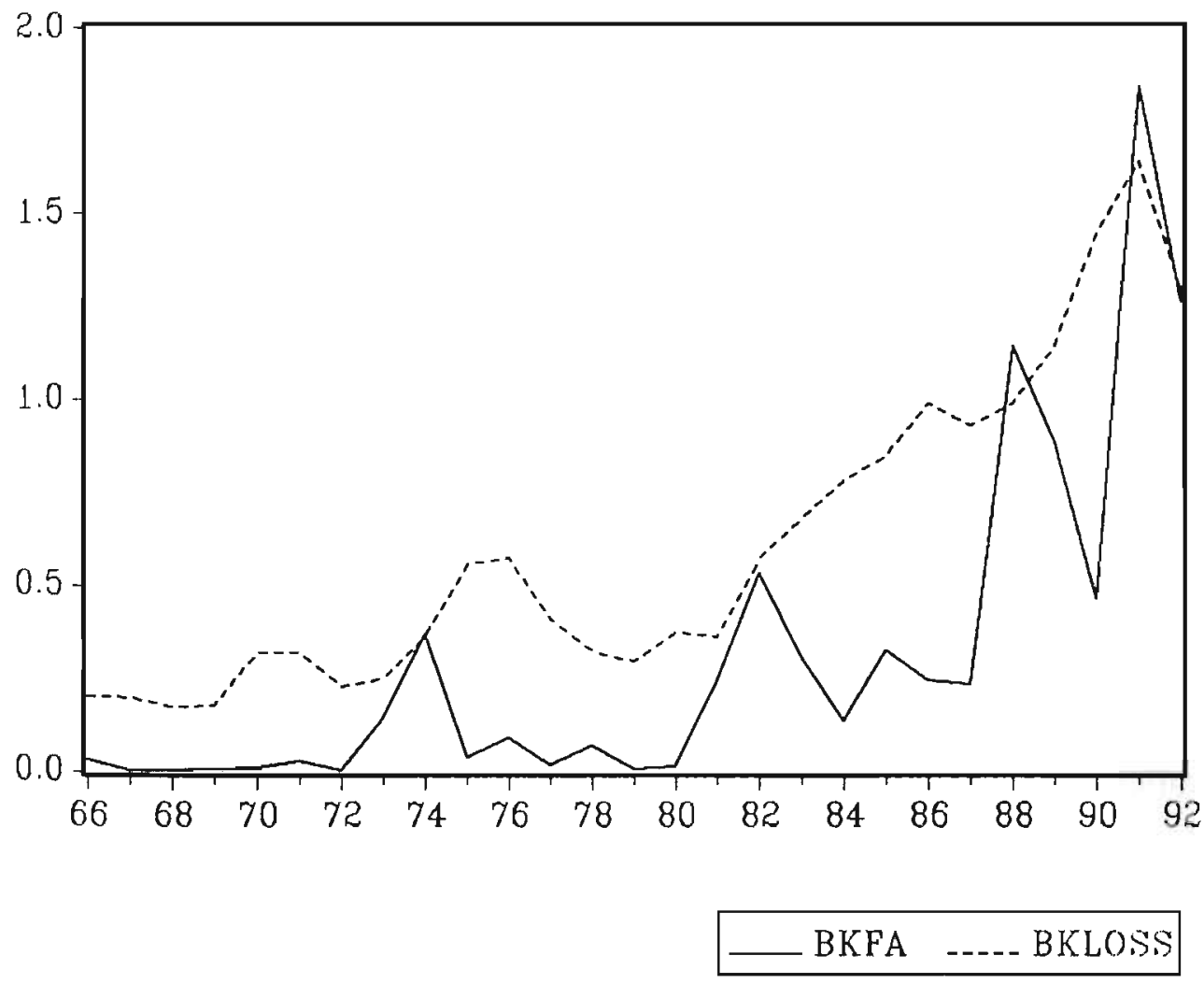

Figure 4.3: Bank failed assets ratio and loan losses ratio 
The variability in the assets of insolvent S\&Ls as a percentage of total S\&L assets is indicated by the SLIA variable. Since 1980 is the first year that the SLIA variable has a non-zero value, we compute the regression for the period 1980-1992. The independent variables are the same as in the previous regression and $t$ statistics are again in parentheses:

$$
\begin{aligned}
& \text { SLIA }=79.28-0.15 \times \text { SLDEP }-2.03 \times \text { SLMARG }-1.11 \times \text { SLMORTG } \\
& (5.81) \quad(-1.50) \quad(-1.95)
\end{aligned}
$$

Adjusted $\mathrm{R}^{2}=0.72$

Durbin-Watson $=2.45$

Just as in the case of the SLFA regression all signs of the estimated regression coefficients are negative, as was expected. The Durbin-Watson statistic of 2.45 does not imply residual first-order autocorrelation. Only the S\&L independent variable indicating the ratio of home mortgages to total financial S\&L assets is significant. A test for deleting SLDEP and SLMARG confirms this observation ( $F$ statistic value of 1.54 and probability value of 0.27 ). The new regression estimation now becomes ( $t$ statistics are in parentheses):

$$
\text { SLIA }=\begin{gathered}
59.78-0.84 \times \text { SLMORTG } \\
(5.93)(-5.10)
\end{gathered}
$$

Adjusted $\mathrm{R}^{2}=0.68$

Durbin-Watson $=1.79$

During the 1980s the gradual decline of home mortgages in the total financial assets of S\&Ls has caused a substantial increase in S\&L insolvencies. This relationship is summarized in Figure 4.4. The decrease of the home mortgages share in total financial S\&L assets indicates riskier investment policies of S\&Ls. Starting at the beginning of the 1980s when a lot of S\&Ls found themselves locked into negative interest margins (low fixed rates at the assets side and high floating rates at the liabilities side because of a restrictive monetary policy), they decided to take a bet on the deposit insurance system in order to try to save their heads. This was done by investing in riskier products like options, futures and junk bonds (White 1991). Deregulation enabled S\&Ls to do this. Especially in the second half of the 1980s the effects of the risk taking became visible in the form of S\&L insolvencies and failures. 


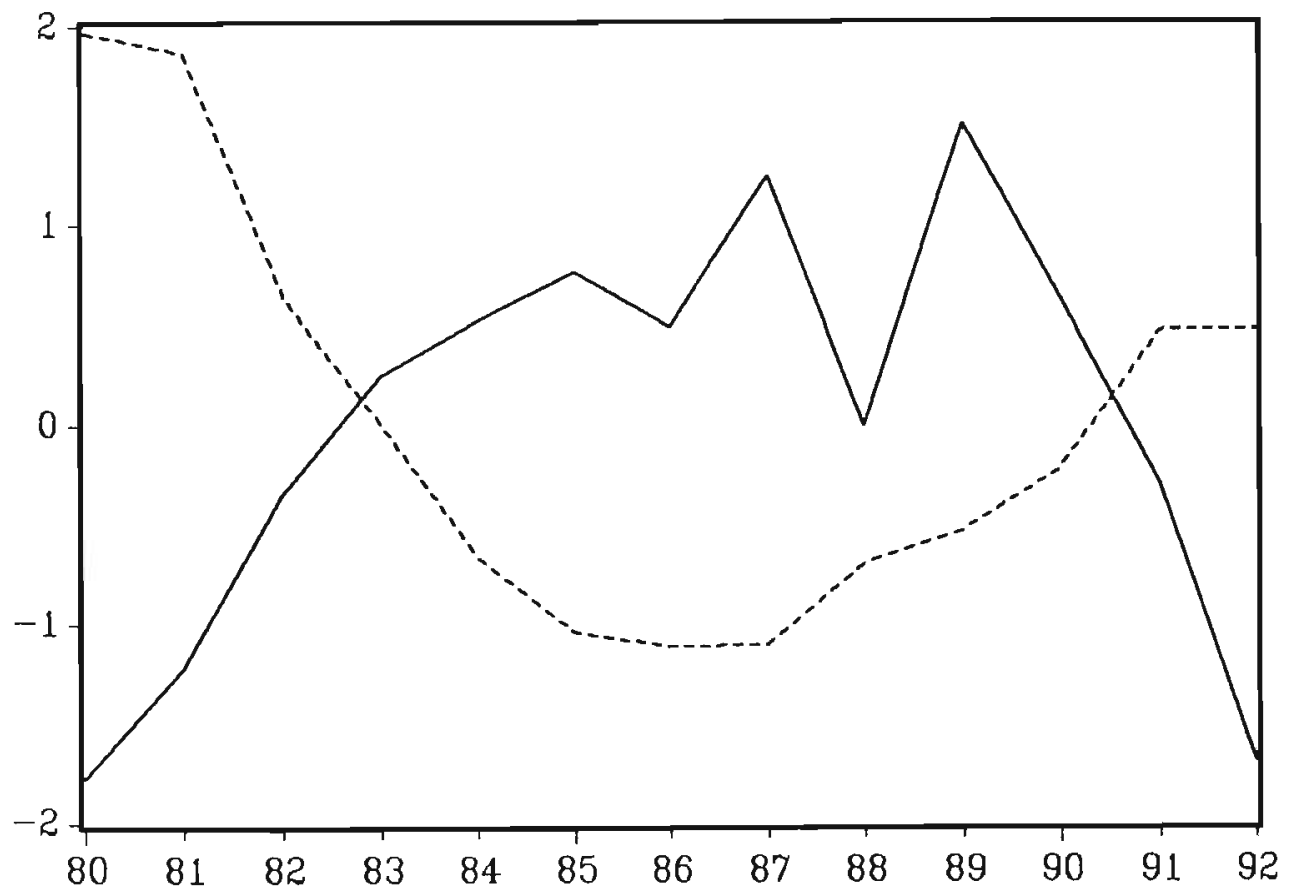

SLIA -.... SLMORTG

Figure 4.4: S\&L insolvent assets ratio and home mortgages share 


\subsection{Conclusion}

In this chapter, extending the analysis of Wolfson (1990), we have presented an empirical analysis of indicators of financial fragility in the U.S. banking sector (commercial banks and S\&Ls).

For the commercial banking sector our main conclusion is that the increased variability in the assets of failed banks as a percentage of total bank assets can be explained for a substantial part by the increase of the net bank losses as a percentage of average bank loans. It is this deterioration in the loan performance of the commercial banking sector (third world loans, junk bonds, real estate loans) that led to the largest U.S. bank failures since the banking crisis of 19291933. This could suggest that banks' risk awareness and risk pricing were not taking account of the increased riskiness of U.S. commercial banking. Evidence of this increased riskiness was presented in chapter 3.

For the $S \& L$ sector we can conclude that the main factors accounting for the 'instability' in the S\&L sector are the decrease in the S\&L interest margin and, in particular, the decrease of the home mortgages share in total financial S\&L assets. The last variable indicates riskier investment policies of S\&Ls. Starting at the beginning of the 1980s when a lot of S\&Ls found themselves locked into negative interest margins (low fixed rates on the assets side and high floating rates on the liabilities side because of a restrictive monetary policy), they decided to take a bet on the deposit insurance system in order to try to save their heads. This was done by investing in riskier products like options, futures and junk bonds. Deregulation enabled S\&Ls to do this. Especially in the second half of the 1980s the effects of the risk taking became visible in the form of S\&L insolvencies and failures. 


\section{Chapter 5 \\ The Scandinavian Banking Crisis}

Up to the early 1980s the banking system in the Nordic countries (Norway, Sweden and Finland) can be characterized as a highly regulated regime consisting of controls on interest rates, credit controls and capital controls. The rapid process of financial liberalization and deregulation intensified dramatically competition between financial institutions (IMF 1993a). This led to an unprecedented growth in bank lending. Although in the early phase of the expansion banking appeared to be very profitable, developments towards the end of the decade indicated that profitability had been over-estimated and risks under-rated. Massive rescue and support operations (state ownership, capital injections, guarantees etc.) were mounted in Norway, Sweden and Finland. Atle-Berg (1993) calculates that the volume of official support operations by 1992 amounted to 2.8 per cent, 3.1 per cent and 7.2 per cent of GNP in Norway, Sweden and Finland respectively.

Until the early 1980s the banking system in the Nordic countries was highly regulated and protected by explicit and implicit government guarantees. In chapter 2 we discussed a paper by Keeley (1990) in which he analyzes under a fixed-rate deposit insurance system the influence of increased competition on bank charter values, risk taking and captital ratios. Following Keeley's analysis the rapid pace of deregulation and competition in the Nordic countries led to an increased willingness for risk taking. In itself such a process of increased competition, lower margins and greater risk taking should not necessarily be seen as an undesirable phenomenon. For one thing it enhances the efficiency of the financial system with all the welfare benefits for demanders of financial services. At the same time lower margins and increased risk taking make the banking system more fragile in the sense of vulnerability of the system to future outbreaks of financial disorder. If, however, the risks involved are known and correctly priced, then these periods of financial disorder are unlucky, but calculated events (see chapter 2). Increased financial fragility may lead to a significant increase in the net loan losses as a percentage of total bank loans without causing bank failures and insolvencies. 
As long as banks are compensated for increased risk taking by higher, correctly priced risk premia, they will be able to build up sufficient reserves in order to bear larger credit losses without reaching the brink of failure or insolvency.

The interesting point about Norway, Sweden and Finland is that the transition from a regulated and uncompetitive banking sector to a less regulated and more competitive regime went together with a banking crisis of unprecendented scale. This could suggest, that at least during the transitional phase, risk awareness and risk pricing were not adequate.

In this chapter we present maximum likelihood estimates for pooled banking data of Norway, Sweden and Finland during the period 1980-1992. Our empirical analysis shows strong evidence that mounting credit losses played a significant role in the banking crises of Norway, Sweden and Finland. At the same time we observe that the bank failures and insolvencies were not caused by a significant deterioration of net interest margins. A logical interpretation could be that banks have not been able to charge adequate risk premia in order to be compensated for the higher lending risks after deregulation had taken effect. This resulted in built-up capital reserves being too small in order to be able to bear the credit losses and, consequently, in massive bank failures and insolvencies.

This chapter is organized as follows. In section 5.1 we give a descriptive overview of the financial deregulation process in the Nordic countries during the 1980s. Moreover, we analyze common features in the deregulation process and the later banking crisis. While special factors apply in each country, there is a remarkable parallel between the three countries in the origin and nature of the decline in financial performance of banks. In section 5.2 we give an overview of the data and methodology of our empirical analysis. Section 5.3 presents the empirical results. In section 5.4 we give our interpretation of the Nordic banking crisis. Section 5.5 contains the conclusion of the chapter. 


\subsection{Financial Deregulation}

While special factors apply in each of the three Nordic countries, such as a sharp fall in oil prices in Norway in 1986 and the initial low profitability and capitalisation of Norwegian banks (Skanland 1992) and the collapse of trade with the former Soviet Union for Finland, there is a remarkable parallel between the three countries in the origin and nature of the decline in financial performance of banks. The parallel arises in five areas (Benink and Llewellyn 1994a): the regulatory regime; the banks' responses to changes in regulation and the competitive environment; debt trends of the corporate and perscnal sectors; the business cycle, and in macroeconomic policy responses.

\section{Regulation}

In each of the case-study countries there were major changes in the regulatory regime. Substantial measures of deregulation were made. In Norway, monetary policy was conducted via direct regulations and the administered setting of interest rates below equilibrium levels until the middle of the 1980s; direct lending restrictions were abolished in 1984 (Solheim 1994). In Sweden, all credit ceilings were removed in 1985 (Englund 1990, Barr and Gustavsson 1991). Deregulation started in Finland in the early 1980s with the deregulation of interest rates and the abolition of direct lending guidelines (Nyberg and Virhriala 1993). At the same time regulations were eased to allow some subordinated debt to be included in the banks' capital base which raised the banks' lending capacity. The Norwegian official report on the banking crisis (1992) argues that the rise in subordinated debt capital was inappropriate.

The common features were that banks' regulatory balance sheet constraints were removed, interest rates became more market-determined and less administered, and banks' lending capacity was increased. Such deregulation induced a more competitive market environment in banking which was one of the policy objectives (OECD 1989). A new priority was given to enhancing the efficiency of financial systems through creating a more competitive market environment. 


\section{Responses of banks}

Banks responded in a remarkably similar way by substantially increasing the volume of lending in a short period (see Figure 5.1). Bank lending as a proportion of GDP rose from 64 per cent to 85 per cent (1983-1986) in Norway, from 43 per cent to 68 per cent (1986-1990) in Sweden, and from 55 per cent to 76 per cent (1986-1990) in Finland.

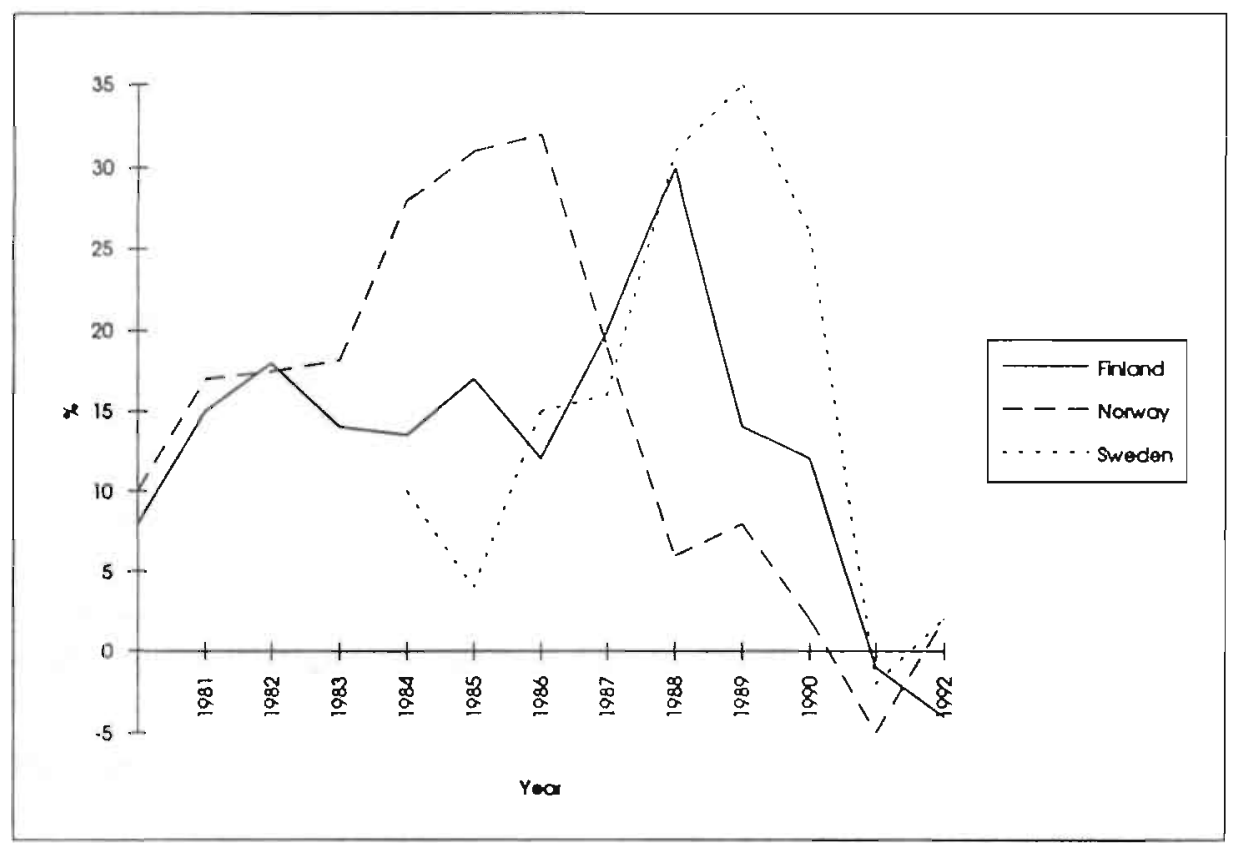

Figure 5.1: Nordic banks' nominal growth of lending 1980-1992 (Source: IMF International Financial Statistics) 
As a result of increased competitive pressures banks lowered credit rationing and risk thresholds (Llewellyn and Holmes 1992). Bank profitability at first rose due to this expansion but later deteriorated sharply due to massive provisions for bad debt. Banks developed more concentrated portfolios as lending to property and property companies expanded particularly rapidly and increased their share in loan portfolios. Property was also used as collateral for a high proportion of loans. In Sweden, loans against real estate made in 1989 and 1990 accounted for around 80 per cent of subsequent loan losses (Dalheim et al 1992). It is also evident that in each of the countries there was an aura of optimism most especially given the sharp rise in asset prices which eroded both risk aversion and perception of risk by banks. At the same time, balance sheet growth and market share considerations dominated bank business strategies.

\section{Responses of borrowers}

Borrowers also substantially increased their debt in each of the countries with debt-income and gearing ratios rising substantially. For instance, the debtdisposable income ratio of the household sector in Sweden rose from 100 per cent in 1985 to a peak of 130 per cent in 1988 (Barr and Gustavsson 1991). Corporate sector gearing ratios also rose sharply.

\section{Business cycle}

A common feature of the case-study countries was a sharp cyclical upswing at the time of the acceleration in bank lending, but most especially a very sharp rise in asset and property prices. Figures $5.2 \mathrm{a}$ and $5.2 \mathrm{~b}$ show the trend of stock market and real estate prices during the 1980s. The rise in asset vales induced both borrowers to incur more debt (on the assumption that their debt-servicing capacity had increased) and banks to increase their lending and acquiesce in higher gearing ratios. The rise in asset prices made banks less risk-averse, generally more optimistic, more confident of borrowers' ability to service debt, and more confident about the value of collateral. In addition, much of the borrowing was speculative in nature, most especially with respect to borrowing to finance the acquisition of property and real estate.

However, in each of the countries the economy moved into recession in the late 1980s and early 1990s, and asset prices (most especially real estate) fell 
precipitously. Combined with the sharp rise in gearing ratios, a tightening of monetary policy, and resultant rise in interest rates on floating-rate debt, this created debt-servicing problems for personal and corporate sector borrowers, and default rates rose sharply in each country precipitating the deterioration in the financial performance of banks. The fall in property prices in particular undermined the assumptions upon which many loans had been made and eroded the value of loan collateral held by banks. Vikkula (1992) notes that in Finland lending on the bases of real asset values rather than cash flows made banks especially vulnerable when asset prices fell.

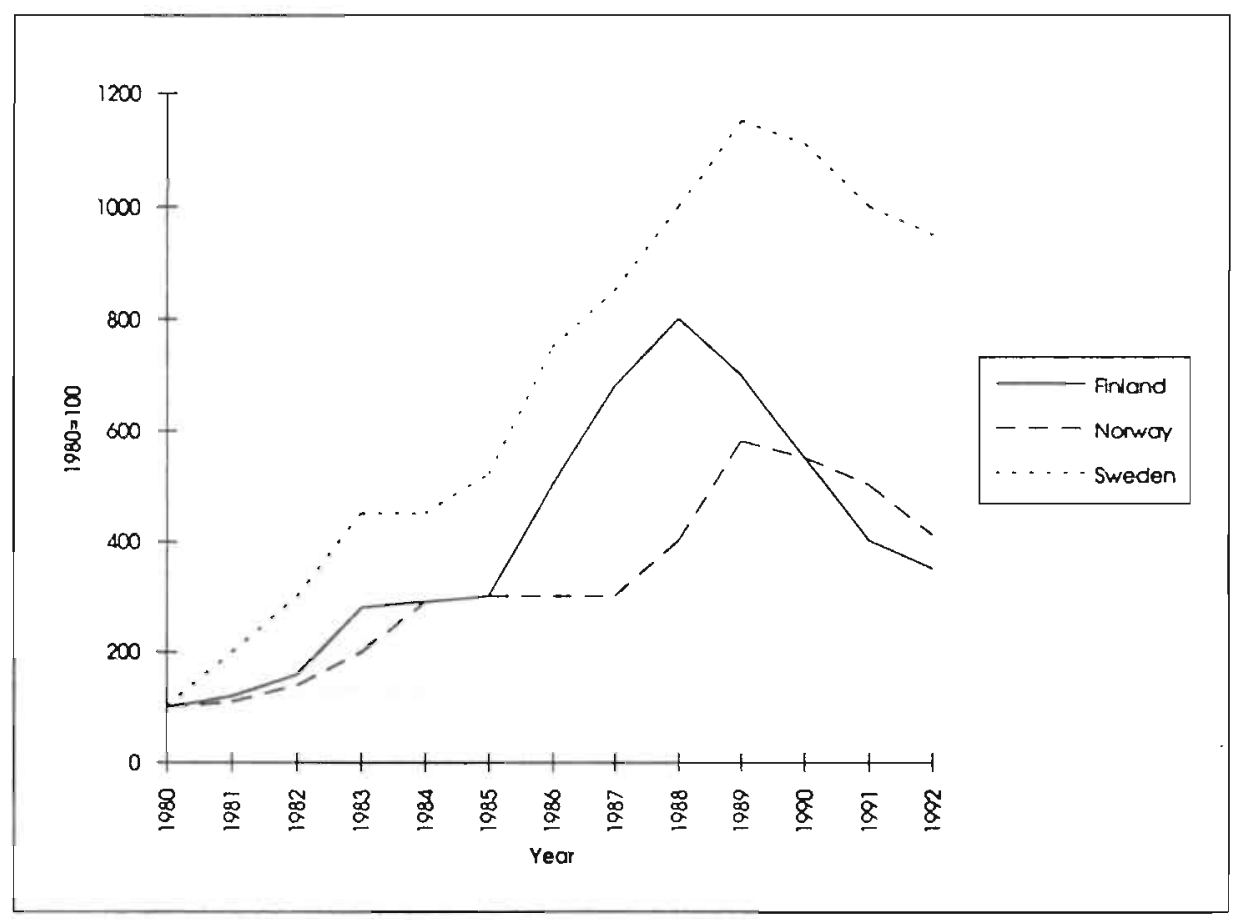

Figure 5.2a: Nordic countries stock market prices 1980-1992

(Sources: Central Bureaus of Statistics of Norway, Sweden and Finland) 


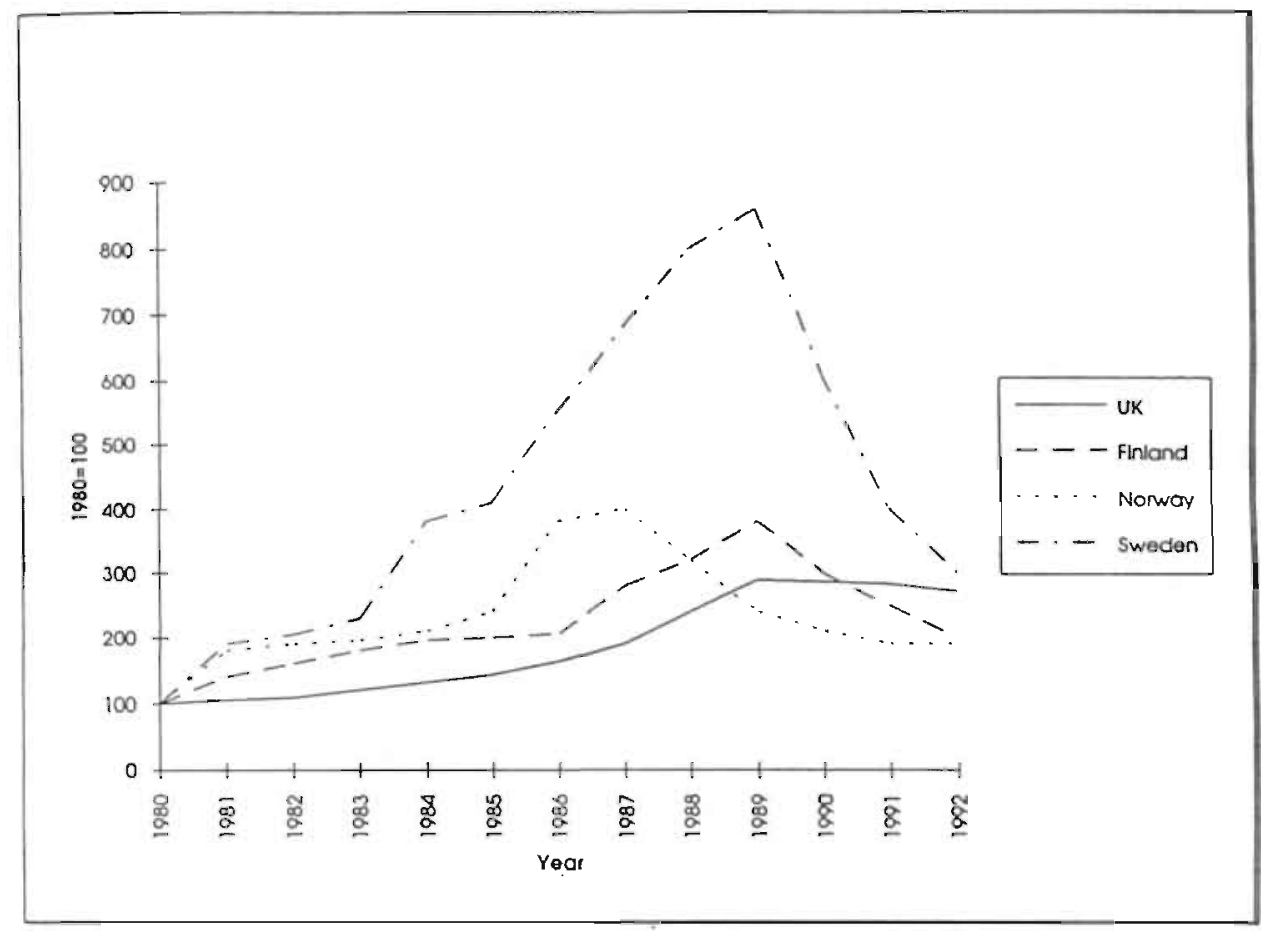

Figure 5.2b: Nordic countries real estate prices 1980-1992

(Sources: Central Bureaus of Statistics of Norway, Sweden and Finland; Bank of Norway; Enskilda Research, Sweden)

Macroeconomic policy response

In several countries, the post-deregulation period was accompanied by an excessively expansionary monetary policy. Monetary policy was particularly expansionary in the late 1980s: the impact of deregulation on bank lending was accentuated by a simultaneous expansionary monetary policy. In Norway and Sweden the impact was also enhanced by the effect of tax relief on loan interest payments. 


\subsection{Data and Methodology}

Using OECD data and using data which were kindly provided to us by the central banks of Norway, Sweden and Finland, we have constructed a data set for commercial and savings banks in the three countries during the period 19801992 (annual data). The following variables are distinguished:

CBFIA: Assets of failed/insolvent commercial banks as a percentage of assets of all commercial banks

SBFIA: Assets of failed/insolvent savings banks as a percentage of assets of all savings banks

CBLOSS: Commercial banks' net loan losses as a percentage of total loans made by commercial banks

SBLOSS: Savings banks' net loan losses as a percentage of total loans made by savings banks

CBDEP: Commercial banks' deposits growth

SBDEP: Savings banks' deposits growth

CBINT: Commercial banks' net interest margin as a percentage of average balance sheet total

SBINT: Savings banks' net interest margin as a percentage of average balance sheet total

In the case of Norway we use loan provisions as a proxy for net loan losses.

In our model the CBFIA and SBFIA variables are considered as dependent variables. We want to determine to what extent the failures and insolvencies of banks can be explained by changes in the net loan loss ratio, deposits growth and the net interest margin.

The net loan loss ratio variable is expected to have a positive relationship with the dependent variable because credit losses increase the likelihood of bank failures and insolvencies. We would expect for the deposits growth variable that it shows a negative relationship with failures and insolvencies: a smaller percentage increase of deposits is a measure of disintermediation and is a sign of potential failures and insolvencies. For the net interest margin we would also expect a negative correlation since a smaller interest margin enhances the danger of problems in the banking sector. 
In order to separate developments in the commercial banking sector from those in the savings banking sector we run separate regressions for commercial banks and savings banks.

Because of the fact that the CBFIA and SBFIA dependent variables have a positive, non-zero value in a relatively limited number of years (in most years they have a value of zero), we are not dealing with the standard regression model but with the so-called 'Tobit model' or 'censored regression model'. The consequence is that we can not use the standard least squares estimation technique, since this procedure will not lead to a consistent estimator of the population regression function. However, a maximum likelihood estimation of the Tobit model does generate consisent results (see Judge, Hill, Griffiths, Lütkepohl and Lee 1988).

The general form of the model is:

$$
y_{i}=x_{i} \beta+e_{i}
$$

To estimate the parameter $\beta$ consistently, we can apply maximum likelihood procedures. The likelihood of the sample has a component for the observations that are positive and one for those that are zero. Define $f_{i}$ and $F_{i}$ to be the probability density function and cumulative probability density function, respectively, of a standard normal random variable evaluated at $z_{i}=x_{i} \beta / \sigma$. Denoting the product over the zero observations by $\Pi_{0}$ and the product over positive observations by $\Pi_{1}$, the likelihood function is given by:

$$
l=\Pi_{0}\left(1-F_{i}\right) \Pi_{1}\left(2 \pi \sigma^{2}\right)^{-1 / 2} \exp \left\{-\left(y_{i}-x_{i} \beta\right)^{2} / 2 \sigma^{2}\right\}
$$

The log-likelihood function is:

$$
L=\ln l=\Sigma_{0} \ln \left(1-F_{i}\right)-\left(T_{1} / 2\right) \ln 2 \pi-\left(T_{1} / 2\right) \ln \sigma^{2}-\Sigma_{1}\left(y_{i}-x_{i} \beta\right)^{2} / 2 \sigma^{2}
$$

Maximization of this log-likelihood function generates the estimates of the Tobit model. 
In our regressions we will be using a pooled data set of the three countries together which consists of 39 observations and three independent variables. The estimation requires that the number of independent variables is smaller than the number of non-zero observations of the dependent variable; in the case of running regressions for each individual country this prerequisite is not always met. We believe that pooling the data of the three countries can be justified by referring to our discussion in section 5.1 on the common features of the banking crises in the Nordic countries.

\subsection{Empirical Results}

For the commercial banking sector we estimate the following regression equation ( $t$ statistics are in parentheses):

$$
\begin{aligned}
\text { CBFIA }= & -11.95+8.80 \times \text { CBLOSS }-\frac{3.67 \times \text { CBDEP }}{(-1.09)(3.12)}=(-2.92)
\end{aligned}
$$

The CBLOSS and CBDEP variables are both significant and the signs of the estimated coefficients are as expected. In an earlier regression we also included the CBINT variable, but this variable is not statistically significant.

The estimation for the savings banking sector generates the following result:

$$
\text { SBFIA }=\underset{(-3.42)}{-33.53+1}+\frac{(4.58)}{(43)} \times \text { SBLOSS }
$$

Only the SBLOSS variable turns out to be significant and has the expected positive sign. In the earlier regression including the SBDEP and SBINT variables, these two variables appeared to be statistically insignificant.

The results are plotted in Figure 5.3a for the commercial banking sector and in Figure 5.3b for the savings banking sector. 


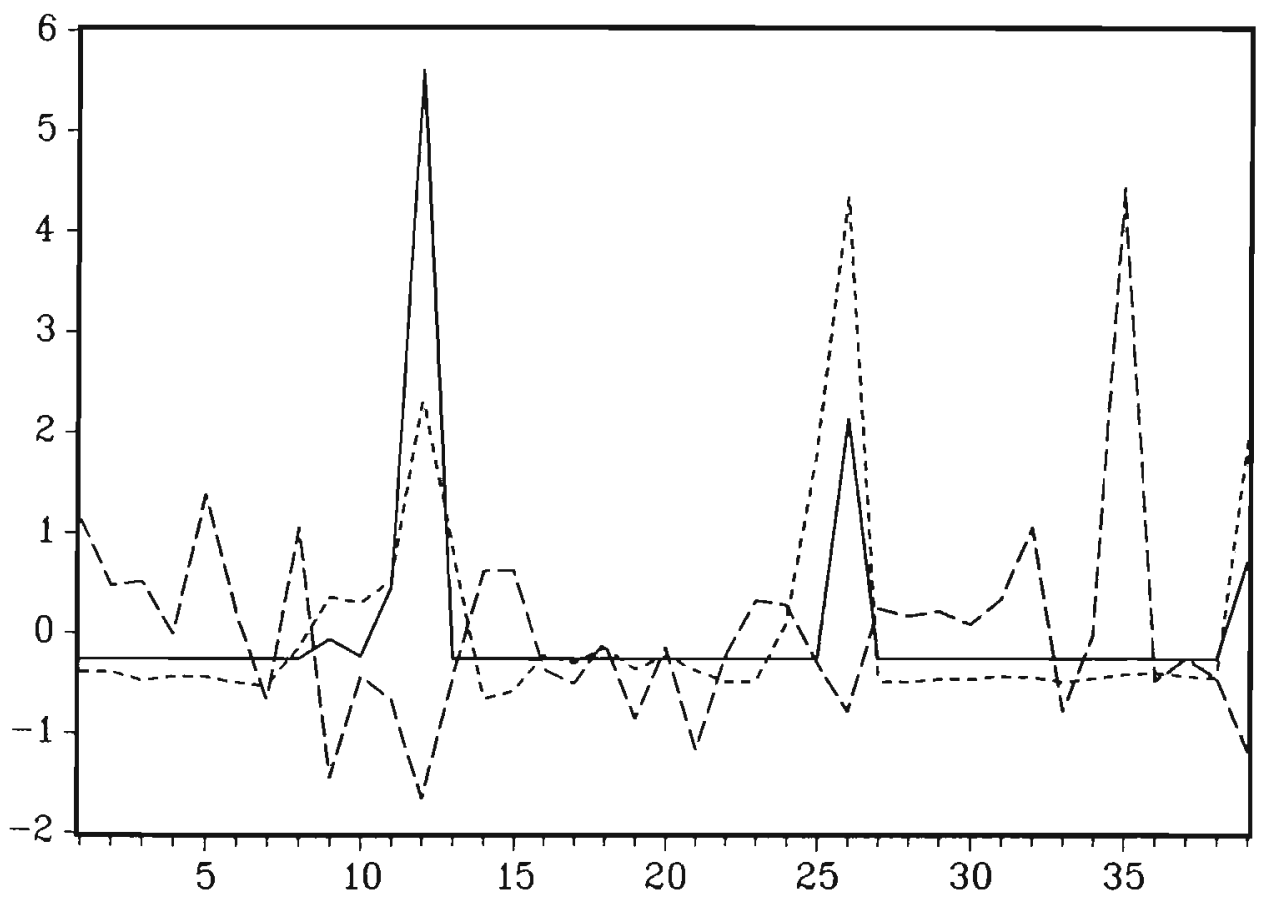

CBFIA -... CBLOSS --- CBDEP

Figure 5.3a: Nordic countries pooled data set commercial banks 1980-1992 


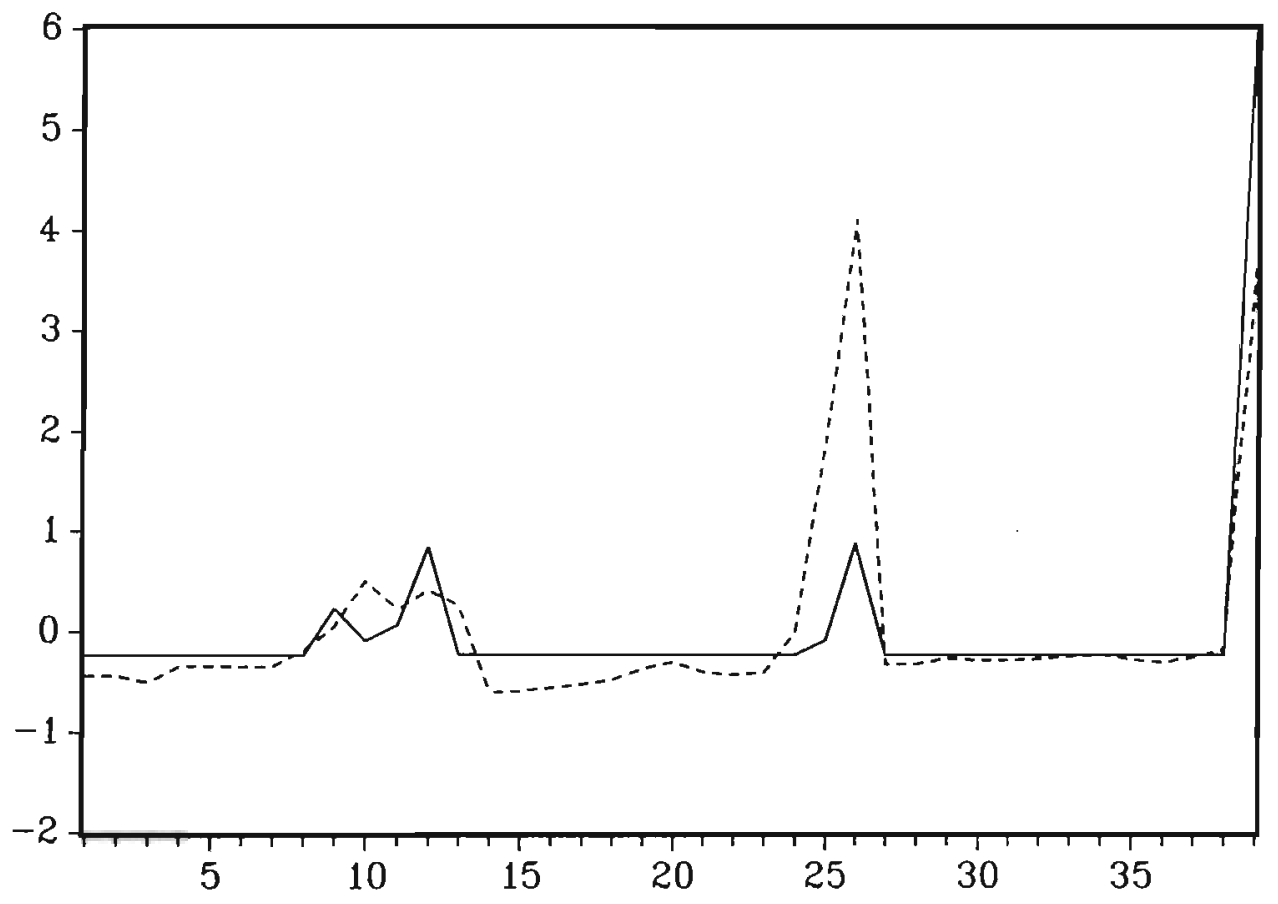

SBFIA SBLOSS

Figure 5.3b: Nordic countries pooled data set savings banks 1980-1992 


\subsection{Interpretation}

Our empirical analysis shows strong evidence that mounting credit losses played a significant role in the banking crises of Norway, Sweden and Finland. At the same time we observe that the bank failures and insolvencies were not caused by a significant deterioration of net interest margins. A logical interpretation could be that banks have not been able to charge adequate risk premia in order to be compensated for the higher lending risks after deregulation had taken effect. This resulted in built-up capital reserves being too small in order to be able to bear the credit losses and, consequently, in massive bank failures and insolvencies.

In interpreting the conditions behind the emergence of financial fragility and the banking crisis in the Nordic countries, two separate pressures should be distinguished (Benink and Llewellyn 1994): cyclical and structural.

The proximate and cyclical cause of the banking crisis was the move into recession in the domestic economy. Given that debt is a non-contingent liability, recessions are always hazardous for banks as they lead to increased insolvencies among borrowers, asset prices tend to fall, the value of banks' collateral on loans declines, and risks in bank lending tend to rise. The recession of the early 1990s was particularly serious for banks partly because of the substantial rise in bank lending that preceded it, the fact that credit rationing had been eroded during the period of expansion which raised the probability of defaults, asset prices fell particularly sharply, and the rise in bank lending led to a significant increase in the gearing of bank borrowers. In effect, banks entered the recession in a potentially more vulnerable position than in previous recessions. The high income- and capital-gearing positions made borrowers (and hence banks) especially vulnerable at a time of high interest rates, a sharp fall in property prices, and an unprecedentedly high level of real interest rates at the time of recession. Overall, the asset-price cycle contributed to financial fragility both because the sharp rise in asset prices during the 1980s contributed to increased borrowing and lending and high gearing ratios, and the subsequent fall in asset prices aggravated the normal effect of a recession.

The structural component of the banking crisis relates to the fact that deregulation and increased competition structurally change the market environment in which banks operate. Before deregulation had come into effect, regulation acted as a protection to banks. The key elements to the underlying banking structure were: low degrees of competition, the existence of restrictive practices, cartels and anti-competitive mechanisms, high entry barriers into banking, and 
limited growth of bank assets and size of balance sheets. Restrictive regulation almost invariably creates economic rents which have the effect of enhancing the value of the banking franchise. It is also the case that non-price competition created a degree of excess capacity that would not be sustainable in a more competitive market environment. Overall, therefore, the impact of the regulatory environment was to create excess capacity, monopolistic profits and economic rents in the banking industry.

The immediate impact of deregulation is likely to be an initial stock adjustment response by banks towards new steady state sustainable balance sheet positions. Financial institutions have a desired portfolio structure for a given set of market and regulatory conditions, and if any of these conditions change, the desired portfolio changes and stock adjustments are made to achieve them. While the new portfolio equilibrium is being achieved through a finite once-forall stock adjustment, the volume of credit is substantially increased. The IMF (1993a) argues: "The increase in borrowing was broadly based, suggesting that the debt accumulation reflected a backlog of unsatisfied demand for credit unleashed after financial liberalization". During such a transitional period of adjustment from a credit-constrained to a credit-liberalized market regime economic agents have to learn the new structural equilibrium relations. As long as learning is still taking place expectations errors need not satisfy any of the optimality properties usually assumed in the rational expectations literature (Pesaran 1987). This implies that in such a transitional phase of learning systematic estimations errors by bankers can be made resulting in inadequate risk premia, huge credit losses and substantial bank failures and insolvencies.

\subsection{Conclusion}

In this chapter we observe that the transition from a regulated and uncompetitive banking sector to a less regulated and more competitive regime went together with a banking crisis of unprecendented scale in Norway, Sweden and Finland. This could suggest, that at least during the transitional phase, risk awareness and risk pricing were not adequate. We present maximum likelihood estimates for pooled banking data of Norway, Sweden and Finland during the period 1980-1992. We find strong evidence that mounting credit losses played a significant role in the banking crises of Norway, Sweden and Finland. At the same time we observe that the bank failures and insolvencies were not caused by a significant deterioration of net interest margins. A logical interpretation 
could be that banks have not been able to charge adequate risk premia in order to be compensated for the higher lending risks after deregulation had taken effect. This resulted in built-up capital reserves being too small in order to be able to bear the credit losses and, consequently, in massive bank failures and insolvencies.

The movement from the regulated to the deregulated regime does not necessarily imply that, once the deregulated and new competitive steady-state equilibrium has been reached, the errors will be repeated. What remains to be determined in each of the case study countries is whether the precarious position of banks is transitory in nature (associated with the once-for-all shock of deregulation and increased competition) and whether, once the impact of stock adjustment effects has been unwound, banks will learn from past mistakes. What can safely be concluded from the experience in the Nordic countries is that big shocks to banking systems (such as sharp changes in regulation) can easily produce severe reactions. However, it cannot be concluded that the aftermath of such shocks indicates the characteristics of the new deregulated environment itself once the adjustment has been made and the lessons leamed.

Nevertheless, the deregulated banking environment may have made banking potentially more fragile. The erosion of the economic rents induced by previous regulation is likely to have made banking a more vulnerable industry than in the past. 



\section{Chapter 6}

\section{Systemic Stability and Competitive Neutrality Issues in the International Regulation of Banks}

The increasing globalization of banking and finance means that autarky (selfsufficiency at the national level) is no longer a feasible strategy in financial regulation: there is the potential for regulation determined at the national level to be undermined by developments in other regulatory jurisdictions, and regulatory requirements in one country have impacts in others. This creates a standard case for international regulatory co-operation as, given the externalities involved, co-operative strategies have the potential to increase the effectiveness of regulation, and limit the scope for regulatory arbitrage.

The focus of this chapter is upon the international dimension to regulation in two areas (banking and securities business) which, while they have common considerations, also raise different issues. The focus is upon two issues in internationally co-operative regulatory strategies: systemic stability and competitive neutrality. Two central themes emerge. Firstly, while in some areas there is a potential case for international co-ordination to increase the effectiveness of regulation for systemic stability reasons, issues of competitive neutrality might be dominant and, at times, in conflict with the requirements of prudential regulation for systemic stability. Secondly, specific examples of international co-ordination (the examples chosen are the 1988 Basle Capital Convergence Arrangements with respect to banking and the 1993 European Union's Capital Adequacy Directive with respect to securities business) demonstrate that the approaches adopted may be inefficient in two respects: they do not achieve their systemic stability or competitive neutrality objectives, and the two objectives may be in conflict with the resultant compromise, being sub-optimum for both.

The structure of the chapter is as follows. Section 6.1 considers the regulatory implications of the increasing globalization of banking and financial markets. Section 6.2 considers the potential conflicts between systemic stability and competitive neutrality. Section 6.3 discusses the systemic stability and competitive neutrality dimensions of the 1988 Basle Capital Convergence Arrangements with respect to banking and the 1993 European Union's Capital Adequacy Directive with respect to securities business. Section 6.4 concludes. 


\subsection{International Dimension to Regulation}

The internationalization of finance has accelerated as both suppliers and users of financial services increasingly have global options and are less restricted to purely domestic facilities. The international dimension of finance means that competitive pressures in banking, securities trading and other financial services have become increasingly international. For these reasons national financial systems have become sub-sets of a global system. In the process, something of a two-tier structure of banking and financial services has emerged in which the corporate sector increasingly has global options while financial services at the retail level is still more limited to within national financial systems. Nevertheless, as noted by Grundfest (1990): “In today's internationalized securities market, even the smallest investor can treat national regulatory regimes as partially discretionary constraints on investment activity".

These trends imply that effective and efficient regulation in one country can no longer be applied independently of regulatory levels in other major systems. The international dimension to regulation has both competitive neutrality and systemic stability implications. Firstly, given that financial institutions and markets compete globally, regulation in national systems has the capacity to confer competitive subsidies or disadvantages. Secondly, this can have the effect of inducing regulatory arbitrage. This in turn creates a third potential hazard: international competition in laxity. The potential danger is that the stability of the financial system (systemic stability) can be threatened because of a failure in a poorly regulated jurisdiction. Thus, partly through the international inter-bank market, risks can be spread and the failure of an institution can have repercussions in other countries. The risk of widespread contagion or spillover effects is often referred to as systemic risk.

The word 'potential' should be emphazised. Although international supervisors and regulators, such as the Basle Committee and the European Union, acknowledge explicitly the stability of the international financial system as one of the main reasons for international regulatory co-operation, this issue is not unresolved. Corrigan (1992) argues: "The speed, volume, value and complexity of international banking transactions have introduced new linkages and interdependencies between markets and institutions that have the potential to transmit problems and disruptions from place to place and institution to institution at almost breakneck speed" (italics added). Similarly, Steil (1992) asserts: "Since any systemic effects of inadequate or misguided regulation in one jurisdiction cannot be contained within that single jurisdiction, the imposition of universal 
standards or modes of operation is likely to be the only effective response".

Against these positions, Benston (1994) sees no link between individual bank failures and the stability of a financial system in either a national or international context as long as central banks offset the reduction in total bank reserves associated with individual bank failures. The failure of an individual bank does not threaten the stability of the financial system if a liquidity crisis in the whole system is prevented by timely liquidity assistance from central banks. Moreover, according to Kaufman (1994) and Benston and Kaufman (1995) there is no historical evidence to support the widely held belief that, even in the absence of deposit insurance, bank contagion is a holocaust that can jeopardize solvent banks, the financial system, and even the macroeconomy in domino fashion. It is also evident that two recent major bank failures (BCCI and Barings) did not produce either domestic or international systemic problems even though both were involved in international business.

In this chapter we will not deal with this unresolved issue. Starting from the premise that international regulators perceive the preservation of systemic stability as a rationale for international regulatory co-operation, we analyze to what extent regulation with systemic stability objectives can be effective and consistent with competitive neutrality objectives of regulation in an international context.

The general problem in banking and securities regulation is that the jurisdiction of national regulators is smaller than the geographical area of regulated financial institutions and markets. There is no overriding international regulatory authority as supervision and prudential regulation is conducted at the national level, while the issues have an international dimension. Different legal systems are involved, the powers and authority of individual central banks and bank supervisors vary considerably as do institutional structures in different countries. Steil (1992) puts it as follows: "The global integration process in capital markets means that the system with which policymakers are concerned extends over a multitude of regulatory jurisdictions".

The central issues are the extent to which international factors undermine the power of exclusively national regulation, and whether, in an increasingly integrated global financial system, some or all of the objectives of regulation can only be achieved by abandoning the autarky of exclusively national legislation, implying that the design of effective regulatory structures can be met more effectively through various forms of international co-operation. 
The collapse of BCCI in the summer of 1991 revealed several problems and weaknesses in the international dimension to banking regulation: uncertainty over the division of responsibility between different national regulators; doubt about the quality of supervision in some jurisdictions; inadequate means of verifying the supervisory practices, effectiveness and standards of regulatory authorities: the fact that complex company structures may make effective supervision more complicated; the importance, but absence of, consolidated supervision under a clear lead regulator; fraudulent exploitation of offshore banking centres with strict secrecy laws, and inadequate co-operation on the exchange of information among national supervisors. For a full description of the BCCI collapse, see Dale (1993). Hall (1991a, b, c, 1992 and 1993) and Herring (1993).

The Basle Committee (with the endorsement of the central bank governors of the Group of Ten countries) subsequently responded with a series of proposals to reinforce the 1983 Concordat which governs the division of supervisory responsibility between parent and host supervisors of international banks. The objective is designed to "provide greater assurances that in the future no international bank can operate without being subject to effective consolidated supervision" (Basle Committee 1992). In particular, the Basle Committee recommended that: (1) all international banking groups and international banks should have a home country authority that capably performs consolidated supervision, (2) the creation of cross-border banking establishments should receive the prior consent of both the host country supervisor and their home country supervisor, (3) supervisory authorities should possess the right to gather information from the cross-border establishments of banks for which they are the home country supervisor, and (4) if a host country authority determines that any of the above minimum standards is not met to its own satisfaction, that authority could impose restrictive measures necessary to satisfy its prudential concerns consistent with the minimum standards. This last-mentioned would include the prohibition of the creation of banking establishments. The key is that all international banks should be supervised by a home country supervisor "that capably performs consolidated supervision". This presupposes that national supervisory authorities are able in practice to monitor the quality of each other s supervision. Measures were also incorporated into the European Union's Second Consolidated Supervision Directive, including an extension to the information exchange requirement between supervisory agencies (see Benink 1993a and Hall 1993). 


\subsection{Systemic Stability and Competitive Neutrality}

\section{Systemic stability vs. competitive neutrality}

The specific rationale of international collaboration in regulation may focus upon one or more of three broad objectives: (1) to increase the efficiency of regulation in achieving its objectives of systemic stability and consumer protection to the extent that the international dimension to finance has the potential to undermine the effectiveness of nationally determined regulation, (2) to equalize competitive conditions between suppliers of financial services in different countries, or (3) to contribute towards the creation of a single market in financial services. The last mentioned is particularly relevant for the European Union and this may require a greater degree of harmonization than would otherwise be the case. The type of collaboration will depend largely upon which of the three objectives is dominant. A central issue is the extent to which collaboration, including harmonization, is to extend beyond the requirements of systemic stability.

We focus on the two key issues of systemic stability and competitive neutrality which are considered in two areas: banking and securities business. The systemic stability objective relates to internationally co-operative mechanisms to ensure the effectiveness of regulation to reduce the probability of default, and the potential for default of an institution in one country to threaten the stability of the financial system in others. This requirement arises to the extent that systemic stability considerations cannot be confined to individual countries and hence countries have a mutual interest in each others' regulatory arrangements. However, international co-operation need not cover areas wider than those necessary to ensure the solvency of institutions. In particular, it does not in itself require harmonization of conduct of business rules. Thus, systemic stability need not be compromised if other countries have different conduct of business rules providing that those regulations which relate specifically to systemic stability are effective. Conversely, systemic stability is potentially compromised if, for instance, a country has capital adequacy rules for banks which are less than those necessary for prudential reasons as the lax regime may impose costs on other countries (e.g. because of the failure of banks in these countries). Thus competition in regulation (while it has merits in some areas) should not apply to those regulatory requirements which specifically impinge on 
systemic stability. While the ultimate objective of international co-operation is to make such regulation effective, it does not have to extend to all aspects of regulation as different countries may choose regulatory arrangements for a wider set of objectives than systemic stability. The question is how far, and in what areas, international corroboration is to extend.

The focus of the competitive neutrality objective is different. It implies international collaboration in those aspects of regulation (e.g. conduct of business rules) that have the potential to affect the competitive position of suppliers of financial services in different countries. The premise is that all forms of regulation have a potential impact on the cost of providing services.

The issue arises as to whether competitive neutrality should relate to institutions (similar institutions in different countries operate under a similar regulatory regime) or functions, irrespective of which institutions provide those functions. The distinction between institutional and functional regulation arises because institutions may not be specialised, and institutional structures vary between countries. The obvious example is with respect to securities business, which is conducted both by banks and specialist securities firms. This aspect is discussed below.

A central issue relates to which areas of regulation are to be undertaken at the national level and which need overt international collaboration. In general, because of potential links between financial systems, regulation for systemic stability requires a higher degree of international collaboration in order to make it effective than does regulation with respect to conduct of business. While it is potentially hazardous to leave systemic stability issues strictly within the jurisdiction of national authorities there may be considerable merit in allowing national differences in other areas where systemic stability considerations do not arise. Following the general principle of subsidiarity, regulation which does not have a systemic stability dimension is best left to the choices of individual countries.

Even so, there may be a case for extending international collaboration to wider aspects of regulation than purely systemic stability considerations. Two areas in particular arise: (1) where the objective is to create a single market in financial services across several countries, and (2) where cross-border transactions are undertaken and a judgement is made that consumers may be unaware of differences in regulation and may assume that the same regulation applies as in their home country. The latter consideration is easier to handle when financial firms supply services to consumers by locating in the latter's home country. 
The generally accepted principle is that host country regulation applies with respect to conduct of business rules even though it is home countries that are responsible for prudential regulation.

Regulation for systemic stability relates to the probability of default and the social costs associated with it (disruption of the financial and economic system). Such regulation is not appropriate when, because of the nature of a firm's business, there is a low probability of failure or where, if failure does occur, the social costs are zero or are less than the costs of preventing the failure (costs associated with lower bank efficiency because of regulation). This raises the issue of the uniqueness of banks compared to securities firms. If the social costs of bank failure are positive or significantly higher than those associated with the failure of a securities firm, then it is appropriate, for instance, for capital adequacy requirements to be greater for banks than securities firms. In other words, if the probability of failure and the social costs of failure are different, capital requirements also should be different. However, this may conflict with objectives related to competitive neutrality. In this case, while applying the same capital adequacy requirements for different firms (functional regulation) may satisfy the competitive neutrality objective, it would be sub-optimum with respect to the systemic stability objective. In this case competitive neutrality and systemic stability objectives are in conflict. Also, Mayer (1993) finds that systemic risks associated with securities activities are different in different countries, which implies that harmonized capital requirements are not appropriate. If, in general, capital requirements should be greater for banks, then meeting the competitive neutrality argument by applying the same capital ratio implies either that they are set too low for banks or too high for securities firms. In the first case, there is a potentially greater danger of incurring social costs through bank failure, whereas in the latter case consumer welfare is impaired because the costs of securities firms (in terms of the costs of required capital) are higher than are necessary to avoid the social costs of failure.

If, because of the unique position of banks and the higher social cost of failure, capital adequacy requirements are set higher for banks' securities business than are set for specialist securities firms, banks may be placed at a competitive disadvantage in this type of business. This is not necessarily an issue for regulatory authorities to the extent that they are concemed about systemic stability rather than industrial structure. If, by setting optimum capital requirements, business migrates to particular types of firms, then this may be regarded as an acceptable consequence of optimum capital adequacy re- 
quirements. Indeed, if higher capital requirements for banks were justified because bank failures were more likely to impose systemic negative externalities, it would be socially desirable that they lose securities business unless they can offset capital costs with savings from economies of scope.

\section{Alternative forms of international collaboration}

As international financial integration erodes the viability of autarky there is a prima facie case for at least a limited form of international collaboration. In highly interdependent systems, co-operative strategies can yield welfare benefits in terms of enhancing the effectiveness of regulation. In those cases where autarky is either not viable or less efficient than international collaboration, there is a spectrum of alternative forms of international collaboration, in which harmonisation and competition represent two polar cases. The full spectrum of international regulatory collaboration encompasses what might be termed: systemic harmonization; economic harmonization; international co-ordination; co-operation; extra-territorial enforcement; and international competition.

Systemic harmonization implies a high degree of harmonization of regulation for systemic stability reasons in order to make common regulatory objectives effective. It reflects the weakness of autarky in achieving regulatory objectives because of externalities at the international level.

The case for economic harmonization arises when there are differences in regulation which, while serving no regulatory or other objective and may simply be a product of history, impose unnecessary costs and inconvenience. The regulation of securities markets, for instance, is based on arrangements which vary considerably between countries (OECD 1993). Harmonization in these cases, while not impairing any country's regulatory objectives or detracting from consumer welfare, could reduce costs and inconvenience involved when suppliers and consumers operate under different regulatory regimes. Examples include arrangements with respect to information disclosure, registration procedures, accounting conventions etc. While the case for reducing unnecessary or unchosen differences in regulation is strong, if the benefits of standardization are significant, the market should be able to devise its own mechanisms for securing regulatory convergence without the intervention of official regulatory authorities. Self-regulatory agencies are in a position to respond to market pressures if there are mutual advantages in standardisation and no regulatory objectives are involved. This is one of the roles of IOSCO in the securities 
market.

Co-ordination aims not at harmonization but at establishing a common set of minimum regulatory standards above which individual countries can make choices, and the removal of evident inconsistencies and conflicts in regulation between jurisdictions.

Co-operative strategies relate to enforcement procedures and informationsharing. With institutions conducting business in several regulatory jurisdictions, there can be advantages in sharing information between host and home countries. However, problems can be encountered, such as confidentiality and legal power to divulge information to foreign agencies. Such co-operative arrangements are well established in the banking sector through the Basle Committee but fairy rudimentary in the securities industry, though IOSCO has made some contributions (e.g. establishment of a common code of conduct record). Co-operative strategies are also beneficial in enforcement where the co-operation of foreign regulatory authorities may be essential for the enforcement of home regulation and the prosecution of infringements. Regulatory authorities have a mutual interest in co-operation to secure enforcement and, where necessary, prosecution. This has been well-developed by the Securities and Exchange Commission in the United States which has successfully negotiated a network of treaties, communiqués and accords with regulatory authorities outside the US.

A further option to address problems encountered with the international dimension to regulation is the application of extra-territorial jurisdiction. In some cases, though this may require the consent of host country authorities, a home regulator may require certain regulatory standards to be met by institutions under its jurisdiction even when the operations are being conducted by a foreign subsidiary of that institution which is formally under the jurisdiction of a host regulator. A host country would not normally allow a more lenient regulatory arrangement to apply, but in practice has no choice other than to acquiesce in more demanding standards being set.

In the absence of harmonized arrangements, international competition in regulation enables transactors to choose markets and institutions regulated under different regulatory regimes. This in particular applies to conduct of business rules where the case for harmonization is limited. Providing systemic stability is not put in jeopardy through non-harmonized regulation, diversity can enhance welfare and yield potentially valuable information. The counter-argument, even when systemic dangers do not arise, is that consumers may not have access to the necessary information about different regulatory regimes, may assume that regulatory standards are universal, may be ill-equipped to make informed judge- 
ments, and may become confused. Furthermore, the institutions may be unwilling or unable to inform consumers of the differences.

In selecting the form of international collaboration, the ultimate focus needs to be on the objectives of regulation (systemic stability and consumer protection) and the extent to which they can be secured more efficiently through international collaborative strategies. There is a danger that, once the principle of collaboration is accepted, harmonization in particular is pursued for its own sake and questions related to competitive neutrality come to dominate prudential requirements and systemic stability. Such 'international escalation' may take harmonization beyond the point where benefits (in terms of increased effectiveness in regulation) exceed costs. The original motive for the Basle Capital Convergence Arrangements for banks was related both to questions of safety and soundness of banks and systemic stability. Over time, however, the emphasis has shifted decisively towards requirements of competitive neutrality with more emphasis on harmonization. In section 4 we will elaborate on this issue.

There are many reasons why, in some areas at least, differences in regulation between countries are both viable and desirable. They allow for different social choices to be made with respect to objectives. for different institutional structures and potential for systemic hazard, and for differences in externalities and the social cost of institutional failure. Competition in regulation can be beneficial providing systemic stability is not impaired; the externalities of one regime do not impose costs on others; that consumers have sufficient information about differences in regulatory regimes, or when the costs do not exceed the benefits of competition.

The principle of subsidiarity, which surfaced in the Delors Report on European Monetary Union (1989) and is related to the level at which general policy decisions are to be made in a monetary union, can equally be applied to regulation. For the reasons just outlined, the benefits that can be derived from competition, and questions of accountability of regulatory authorities, there is a strong case for regulation being framed at a local level except when its effectiveness is significantly impaired for systemic stability reasons, and where clear economic gains can be made by intemational collaboration which exceed the benefits to be derived from local regulation. The position has been highlighted by Grundfest (1990): "The major challenge for regulators will, however, be to distinguish situations in which co-ordination is desirable from those in which diversity yields greater benefits". We add that decisions also relate to the particular form of collaboration of which the fashion for harmonization is at one 
end of a spectrum.

\subsection{Banking and Securities Business}

\section{Rules vs. systems}

The principal objective of regulation in banking and securities business relates to safety and soundness of institutions and systemic stability. Capital is the main focus of bank regulation for this objective and is the dominant aspect of international collaboration in regulation. The key issue is whether regulation for capital requirements for safety and soundness reasons is more efficiently based upon prescribed and internationally agreed rules, or banks' risk management systems coupled with use of market indicators.

Both nationally and internationally the rules approach dominates. Although such rules have the advantage of being quantifiable and internationally agreed, in a later section we argue that precision may be a substitute for accuracy, and the capital requirements for banks based upon the 1988 Basle Capital Convergence $(\mathrm{BCC})$ rules bear little resemblance to what would be derived from risk and portfolio analysis models. The BCC regime, and the 1993 European Union's Capital Adequacy Directive (CAD) with respect to securities business, hardly offer any advantage to banks with superior systems (Taylor 1994).

An alternative approach is to abandon fixed rules and focus on banks' systems and efficiency with respect to: identification and measurement of risks, banks' management of risks, the extent to which risks are hedged or externalized, and the way risks are combined and managed within the overall portfolio. The focus would be on whether banks have satisfactory risk management systems with imposed capital requirements being set in relation to the efficiency of systems. Thus, banks which demonstrate superior risk management systems would be subject to lower capital requirements. This could act as an incentive for banks to develop superior risk management systems which is likely to contribute more to systemic stability than formal capital adequacy rules. It is pertinent to note that the collapse of Barings Bank in 1995 was a product of inadequate risk management systems rather than a failure to adhere to capital adequacy requirements.

An advantage of a rules system (even though the rules may, to some extent, be arbitrary and not based upon actuarial assessment or risk) is that rules can be 
precisely quantified and intemationally agreed. In this respect they may serve the competitive neutrality objective of international collaboration. However, providing that systems effectively and efficiently contribute to systemic stability, competitive neutrality is of second-order importance. A focus on systems could alleviate a potential dual moral hazard of rules to the extent that rules reduce the incentive both for banks to create effective risk management systems, and for private monitoring of banks' behaviour and balance sheet positions.

At the international level, the focus of a systems approach would be international agreement on the assessment and monitoring of systems rather than specific rules. This could create a new role for the Basle Committee: monitoring the approach of national regulatory authorities with respect to risk management systems of banks under their jurisdiction. International agreement would centre on the methodology and systems of risk analysis and management rather than precise rules, as at present.

\section{Capital for credit risks}

The 1988 Basle Capital Convergence (BCC) arrangements, which established a common framework for capital regulation of banks, were designed to satisfy both systemic stability and competitive neutrality objectives. The primary objective was, as stated in the original document, "to strengthen the soundness and stability of the international banking system" (Basle Committee 1988). Competitive neutrality was addressed as follows: "The framework should be fair and have a high degree of consistency in its application to banks in different countries". The approach is highly prescriptive and capital adequacy is measured in terms of capital ratios against risk-adjusted assets. The approach generally can be criticised on the grounds that the 'safety and soundness' of banks is determined not by fine capital calculations but by the quality of the asset book, the structure of the loan and asset portfolio, the banks' risk analysis and management systems, and internal control arrangements. The experience of Scandinavian banks in the early 1990s demonstrates that these were the reasons for bank failures rather than failure to meet prescribed capital ratios (Benink and Llewellyn 1994).

More specific weaknesses relate to the risk weight methodology applied. Firstly, it cannot realistically be claimed that the risk weights applied to each category of assets are based upon actuarial assessments of true, absolute or relative risk. Secondly, the largest category of most banks assets is the portfolio 
of loans to the private sector and yet all these loans are assigned a risk weight of unity. In practice, the differences in risk characteristics within the loan portfolio far exceed the differences between loans on average and other components of the asset portfolio. The largest single component of a bank's assets is not a homogeneous category. Thirdly, no allowance is made for the degree of diversification in the asset structure or for the way assets are combined in the total loan portfolio. Risks in a balance sheet are not additive, though this is the procedure adopted in the $\mathrm{BCC}$ methodology. Even accepting the validity of the basic methodology, if risk weights do not accurately reflect 'true' risk, suboptimum business structures and pricing strategies may emerge. There is a danger that, through the objective of seeking competitive neutrality, banks' pricing and other business decisions will come to be based upon a set of dubious and spuriously precise risk weights and conversion factors for offbalance sheet business. This can have the effect of creating arbitrary and unwarranted distortions in business structures between different nationalities of banks, between banks and other institutions supplying 'banking' services, within the asset portfolio, and between on- and off-balance sheet business.

Because of the weaknesses embodied in the $\mathrm{BCC}$ risk weight methodology. it is questionable whether BCC makes a significant contribution to systemic stability. At the same time competitive neutrality seems to be important, since the Basle capital arrangements allegedly create competitively neutral capital positions through common capital adequacy requirements, definitions of allowable capital, risk weights attached to different assets, and conversion factors for off-balance-sheet items. Although competitive neutrality has been a dominant principle in the arrangements, they do not in practice create competitively neutral conditions. In a detailed comparison of U.S. and Japanese banks, Scott and Iwahara (1994) enumerate several examples of where different regulatory requirements are imposed on US and Japanese banks and which undermine the competitive neutrality of BCC: the different role of the safety net and other non-BCC policies; imposed regulatory ratios in addition to those contained in BCC; differences in the scope of BCC requirements; differences in the definition of qualifying capital; differences in the risk weighting of some assets, and the manner in which BCC is enforced in the two countries. Differences in accounting procedures, the cost of capital and in taxation also impinge on competitiveness in the two countries. In general, applying the principle of the second-best, harmonizing one aspect of regulation when other aspects are not equalized does not produce overall competitive neutrality. 


\section{Capital for market risks}

The 1993 Capital Adequacy Directive (CAD) of the European Union seeks to apply common capital standards on banks (which conduct securities business) and specialist securities firms. The CAD seeks to harmonize regulation in four dimensions: by placing banks and securities firms under the same capital adequacy regime; by prescribing specific capital requirements with respect to market risk; defining the form of regulatory capital for both, and by applying broadly similar consolidated supervision rules to both banking and investment groups.

Three alternative approaches are applied by different regulators with respect to capital requirements against position risks: (1) the comprehensive approach applied by the Securities and Exchange Commission (SEC) in the United States; (2) the building block approach which is incorporated within the CAD, and (3) the portfolio approach which, in a simplified form, is used in the United Kingdom by the Securities and Futures Authority (SFA). With the comprehensive approach, the capital requirement of a securities firm is set on the basis of a specified proportion of the value of its long positions plus a proportion of the value of its short positions. This has been the traditional method of setting capital requirements on securities firms both in the United States and elsewhere (though not in the United Kingdom). The building block approach sets capital requirements partly on the net value (i.e., the extent of any net long or short position) of the trading book (representing market risk) and partly on the gross value of the book (representing specific risks). By distinguishing net and gross positions, this method at least recognizes that balanced books (i.e., where there is no net long or short position) provide partial hedging and therefore justify lower capital requirements. Under the theoretically superior portfolio approach the setting of capital requirements is based upon a specific portfolio model which reflects the risk (volatility) of a firm's trading book which in turn is influenced by the extent to which the portfolio is diversified. In other words, it sets capital requirements by reference to an explicit estimate of overall portfolio variability. The SFA in the United Kingdom applies a simplified version in that the model is based on a set of strong simplifying assumptions (Dimson and Marsh 1995).

The Capital Adequacy Directive's approach to capital adequacy requirements for securities business and interest rate risk favours the building block approach, although there is little theoretical justification for it. With the building block approach, only a partial offset is allowed for balanced trading books. For 
instance, the overall capital requirement is set equal to $X$ per cent of the gross position plus $\mathrm{Y}$ per cent of the net position. These percentages are largely arbitrary and ad hoc, although some allowance is given for a balanced book. With respect to the $\mathrm{CAD}$, the original idea was that $\mathrm{X}$ would be equal to 4 per cent and $\mathrm{Y}$ equal to 8 per cent. Eventually it was agreed to impose arbitrary values of 2 per cent and 8 per cent respectively for large diversified portfolios.

Dimson and Marsh (1995) have tested the three alternative approaches based on the books of 58 U.K.-based securities firms. The overall conclusion is that the simplified portfolio approach applied in the United Kingdom is superior to the comprehensive approach and the building block approach in terms of economic efficiency and consumer protection. The others were rated poorly on these criteria. The authors conclude: "The portfolio approach should be the preferred methodology for setting capital requirements. Yet international regulators have shown a marked preference for the building block approach, while the SEC has

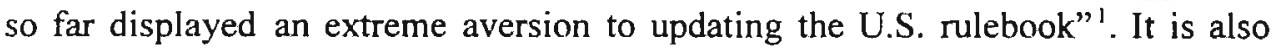
the case that the portfolio approach tends to give the lowest measure of capital requirements. This seems to suggest that international regulators are risk-averse and cautious in the setting of capital requirements and in the process impair economic welfare to the extent that capital requirements are set in excess of what are needed for systemic stability. It also suggests that capital adequacy requirements are dominated by issues of competitive neutrality rather than the safety and soundness of institutions. Here seems to be an example where the motive of competitive neutrality has in practice taken precedence over efficiency of regulation, even though, as argued above, a set of regulatory requirements designed for competitive neutrality may not in practice be neutral.

Apart from the question of methodology of capital requirements, which was discussed above, there is the question whether the securities activities of banks

\footnotetext{
${ }^{1}$ In April 1995 the Basle Committee announced a new proposal to calculate the capital that banks must set aside for market risks. The proposal gives banks a choice between applying the building block approach or using their own financial models to calculate the 'value-at-risk'. These models should meet certain regulatory quality standards (The Economist, April 15-21, 1995). The new approach is likely to be adopted by the European Union as well, which would require a modification of the $C A D$. After finalizing the consultative phase with the international banking community, the Basle proposal is due to be implemented at the end of December 1997.
} 
and securities firms should have the same capital requirements. In the European Union, contrary to the United States, securities business is conducted both by banks and specialist securities firms and the CAD seeks to apply a common capital adequacy regime for competitive neutrality reasons. However, there are substantial differences between banks and securities firms which have a bearing on the way they should be regulated, most especially with respect to capital adequacy requirements.

Most, if not all, of the special characteristics of banks which give rise to the alleged case for regulation do not apply to securities firms: in the absence of deposit insurance and a lender-of-last-resort, there is no moral hazard to be protected against; the systemic risk is less evident, and may not exist at all (Mayer 1993); contagion is less likely, and the potential disruption of the payments system does not arise with securities firms. The main consideration, however, relates to the nature of securities firms' assets. Being readily marketable they can be liquidated, albeit at the risk of a fall in prices, in the event of difficulty. Ultimately, securities firms can contract the balance sheet more easily than can banks, since they are not subject to the asymmetric asset and liabilities contracts that are a feature of banking. This in itself justifies higher capital requirements for banks than securities firms ${ }^{2}$.

While systemic risks are less than with banks, they might not be totally absent. A default of a securities firm could have a potentially de-stabilizing impact on a financial system. A recent official study (OECD 1993) has opined as follows:

"...the rising importance of securities markets in the financial systems of OECD countries, the growing concentration in the securities industry, the effects of new technologies, the nature of the risks now being borne by securities market intermediaries and the links between the securities market and the banking and payments system all suggest that the occurrence of serious misfunctions in the securities markets would have the potential to destabilize the entire financial system".

\footnotetext{
${ }^{2}$ Benston (1989), analyzing the potential effects of a repeal of the Glass-Steagall Act's separation of commercial and investment banking in the United States (U.S.), sees both from a theoretical and empirical point of view no fundamental difference in terms of risk exposure and potential strain of the safety net (including deposit insurance) between commercial banks (U.S. model) and 'universal' banks combining commercial and investment banking (European model).
} 
In the European Union's 1993 Capital Adequacy Directive (CAD) the choice was made for competitive neutrality rather than systemic stability. Both banks and securities firms have to comply with the same capital requirements to their trading book position. In the case of banks the mechanism devised is to isolate banks' trading books in securities from their portfolio holding of securities (i.e., that part of their securities business which is similar to that of specialist securities firms) and to apply the same capital requirements to the trading book position as are applied to non-bank securities firms. The trading book of a bank covers positions where market risk is a more accurate measure of exposure than credit risks where the normal banking capital adequacy requirements apply. The capital requirements in the $\mathrm{CAD}$ are less onerous than those applying to credit risks of banks in two respects: less capital is required and greater use can be made of subordinated debt capital to meet the capital requirements.

Overall, the potential danger implicit in the CAD, as far as the securities business of banks is concerned, is that the drive for a measure of competitive neutrality based on functional regulation makes banks potentially more vulnerable (too low capital requirements from a systemic stability point of view), and more so than specialist banks that have no securities business. This seems to imply that, in order to achieve a common regulatory framework for banks and securities firms, bank supervisors have acquiesced in lower standards for banks than they would have ideally chosen. Overall, and given the unique position of banks, the drive for alleged competitive neutrality in the $C A D$ results in treating as equal institutions that, at both the micro and systemic level, are not equal.

\subsection{Conclusion}

Our focus has been upon the international dimension to regulation and the interaction between systemic stability and competitive neutrality issues. Particular reference has been made to the 1988 Basle Capital Conergence (BCC) arrangements for banks and the 1993 European Union's Capital Adequacy Directive (CAD) with respect to the securities business of banks and specialist securities firms. The main themes may be summarized as follows: 
* Intemational co-operation in regulation focuses upon systemic stability and competitive neutrality issues. Although the two elements are interactive, the dominant objective in co-operative strategies should be systemic stability, while in practice the motivating force is predominantly competitive neutrality. There is a danger of harmonization being pursued for its own sake without reference to the ultimate objectives of regulation. The escalation of harmonization may take it beyond the point when benefits exceed costs.

* Several specific problems arise when following competitive neutrality objectives in regulation: they may be in conflict with systemic stability objectives (e.g. securities activities of banks vs. specialist securities firms); institutions which are not equal may be treated as if they are; different social choices may be denied through 'escalating harmonization'; the potential benefits of competition between regulators may be lost; and harmonization within some areas may be insufficient to create overall competitive neutrality.

* The business of banks and securities firms is different and, because the social cost of failure is different, this raises different systemic risks. The objectives and nature of regulation are different in the two sectors. Applying competitive neutrality principles to banks (with respect to their securities business) and securities firms may compromise systemic stability objectives of regulation.

* Notwithstanding the powerful international dimension in the design of optimum regulatory structures, harmonization in regulation is only one of several ways of incorporating international considerations. Financial integration does not in itself create sufficient conditions for total regulatory integration. Harmonization is a polar case along a spectrum with competition in regulation being the other polar case.

* Different approaches should be applied to different aspects of regulation and there is no presumption in favour of harmonization. The general principle of subsidiarity is relevant in the design of regulatory structures: regulation is most effectively constructed at the national level, unless it is evidently more efficiently devised at a broader level. 
* Specific examples of international co-ordination demonstrate that the approaches adopted may be inefficient in two respects: they do not achieve their systemic stability and competitive neutrality objectives, and the two objectives may be in conflict with the resultant compromise being suboptimum for both. The BCC rules (the most detailed form of international regulatory co-operation) are seriously flawed with respect to both systemic stability and competitive neutrality objectives.

* Regulation, and international collaboration, has normally been conducted on the basis of rules. An alternative, superior approach is to focus upon financial firms' systems of risk analysis and management, and for the regulatory authorities to set capital requirements which reflect the efficiency of banks' risk analysis and management systems.

The ultimate objective of harmonization is to ensure the effectiveness of regulation. Questions of competitive neutrality raise fundamentally different issues to those of systemic stability and the case for harmonization for competitive neutrality is considerably less and, under some circumstances, can be hazardous and welfare-reducing. The central issue is about what areas of regulation require international collaboration and what form such collaboration should take. 



\section{Chapter 7}

\section{Survey Data and the Interest Rate Sensitivity of U.S. Bank Stock Returns}

The interest rate sensitivity of U.S. bank stock returns has been the research topic of many academic papers. Most papers start from the two-index model developed by Stone (1974). This asset pricing model expands the standard market model of asset returns by adding an interest-rate index. The function of this interest rate factor is to account for the influence of unexpected interest rate changes on the stock returns of banks. Empirical research by, among others, Fama and Schwert (1977) and Folger, Kose and Tipton (1981) has shown that the inclusion of an interest-rate factor adds substantial explanatory power to the single-factor market model.

A group of papers combining years from the 1970s and 1980s into one data set find that U.S. bank stocks exhibit a statistically significant inverse relationship between unanticipated interest rate changes and the returns on these stocks (Flannery and James 1984, Brewer and Lee 1985, Scott and Peterson 1986, Kane and Unal 1988, Saunders and Yourougou 1990, Yourougou 1990, Kwan 1991, Akella and Greenbaum 1992, and Choi, Elyasiani and Kopecky 1992). This result is not qualitatively influenced by the choice of a short-term or longterm interest rate variable. Neither is it qualitatively influenced by the size of the banks: large money-center banks, middle-sized superregional banks, or smaller regional banks. There is also a group of papers containing (sub)sets of data only covering the 1970s (Chance and Lane 1980, Sweeney and Warga 1986, Kane and Unal 1988, and Choi, Elyasiani and Kopecky 1992). These papers find an insignificant interest rate sensitivity during the 1970s. This result is not counter-intuitive given the fact that on October 6, 1979 the Federal Reserve Board announced a switch from interest rates to unborrowed reserves as its short-term operating target, which led to an increase in the level and variability of interest rates. However, Saunders and Yourougou (1990) and Yourougou (1990) still find significant interest rate sensitivity for the October 1977 - September 1979 period.

The contribution of this chapter to the literature is twofold. First, using weekly data for the period 1974-1993 and using the forecast errors of autoregressive integrated moving average (ARIMA) processes in order to model 
the unexpected interest rate, we provide empirical evidence on the interest rate sensitivity of the stock returns of the twenty largest U.S. bank holding companies. As in most previous studies, we do not find statistically significant interest rate sensitivity during the 1970 s and strong evidence of negative interest rate sensitivity during the 1980 s. However, the statistically significant relation disappears completely during the second half of the 1980s. This result is qualitatively independent of using the three-month Treasury bill rate or the rate on ten-year Treasury bonds as input for the ARIMA modelling of the unexpected interest rate variable. Interestingly, our result indicates that, contrary to the existing literature which only covers the period until the mid-1980s, the interest rate sensitivity of bank stock returns varies with the subperiod considered. The only other paper incorporating recent data is Robinson (1995). Robinson employed quarterly data in contrast to the weekly data in our analysis. His results are quite mixed in the sense that the sign of the interest rate sensitivity appears to depend on the choice of the interest rate variable in his time series models.

The second contribution of this chapter is to use survey data in order to model the unexpected interest rate variable'. This is an alternative approach compared to the existing literature. Flannery and James (1984) and Robinson (1995) use the forecast errors of an autoregressive (AR) model as a proxy for unexpected interest rate movements. Scott and Peterson (1986), Sweeney and Warga (1986) and Kane and Unal (1988) use changes in the yield on a given maturity of long-term government bonds to capture unanticipated changes in interest rates. Finally, Mishkin (1982) and Brewer and Lee (1985) proxy unanticipated changes in interest rates by the difference between the spot threemonth Treasury bill rate at time $t$ and the forward three-month Treasury bill rate imbedded in the yield curve at time $t$-1. In this chapter we use weekly survey data on the U.S. federal funds rate for the period April 29, 1980 until December 22, 1993. The survey was conducted by Money Market Services (MMS) International (part of Standard \& Poor's) in Belmont, California. The weekly surveys generate a market expectation for the federal funds rate for a certain survey period which is then confronted with the realized value of the federal funds rate during the same survey period. This enables us to calculate an unexpected change in the federal funds rate for the relevant survey period which is then used for estimating the interest rate sensitivity in the two-index model. We find a statistically significant negative interest rate sensitity for the period April 1980

'We would like to thank Kees Koedijk for bringing this possibility to our attention. 
through May 1985. Since then, the statistically significant relation between unexpected federal fund rate changes and bank stock returns has broken down. This result is consistent with our previous findings where we used the forecast errors of ARIMA processes related to the three-month Treasury bill rate and the ten-year Treasury bond rate as a proxy for unanticipated interest rate movements. Also in the latter case we found a breakdown of the interest rate sensitivities during the second half of the 1980s.

The chapter is organized as follows. In section 7.1 we present our model and data selection. Section 7.2 contains our empirical analysis for the period 1974 1993 using the forecast errors of ARIMA processes for the U.S. three-month Treasury bill rate and ten-year Treasury bond rate as proxies for the unexpected interest rate variable. Section 7.3 contains our empirical findings while using survey data for the U.S. federal funds rate. In section 7.4, concluding this chapter, we interpret the breakdown of the statistical significance of the interest rate sensitivity during the second half of the 1980s.

\subsection{Model and Data Selection}

We start the analysis from the two-index model developed by Stone (1974). This asset pricing model expands the standard market model of asset returns by adding an interest rate index. In this model $R_{p}$, being the return on asset $p$, is expressed as:

$$
R_{p t}=\beta_{0}+\beta_{m} R_{m t}+\beta_{i} R_{i t}+e_{p t}
$$

$\beta_{\mathrm{m}}$ and $\beta_{1}$ are measures of the asset's systematic market and interest rate risk, while $R_{m}$ and $R_{i}$ represent a stock market return and a return on debt'.

In our sample we have chosen for the return on the S\&P 500 composite index as a proxy for the stock market return $R_{m}$. The variable $R_{p}$ is the return on an equally weighted portfolio of the common stocks of the twenty largest U.S. bank holding companies. The data have been corrected for stock-splits. $R_{i}$ serves as the variable indicating the unexpected interest rate movement on government

2 Following Kane and Unal (1988) we employ the unorthogonalized two-index model. This means that no orthogonalization is used between $R_{m}$ and $R_{r}$. 
debt.

In the following we will elaborate on the choices of data and methodology in our empirical analysis for both the ARIMA and the survey data modelling of the unexpected interest rate variable.

Un'xpected interest rate generated as forecast error of an ARIMA process

For a period of twenty years (1974-1993) we calculate weekly returns for the S\&P 500 composite index. the individual bank stocks, and the equally weighted bank index consisting of the twenty individual bank stocks. The weekly data, retrieved from Datastream, cover the periods from the closing value at a Wednesday until the closing value on the next Wednesday.

For both the three-month Treasury bill rate and the ten-year Treasury bond rate, on which we obtained data from the H15 release of the Board of Governors of the Federal Reserve System, we estimate ARIMA processes. The calculations cover the same weekly periods as those used for the calculations of stock returns.

For each interest rate variable we selected two processes, one based upon the Akaike lag-length selection criterion and the other based upon the Schwarz laglength criterion (see Priestley 1981). The residuals generated by the estimation of the optimal ARIMA processes are considered as the best approximation of the unexpected interest rate movement. These residuals are then used as $R_{i}$ in our model.

Unexpected interest rate generated as forecast error of survey data

For a period of about 13.5 years (April 29, 1980 until December 22, 1993) we use weekly survey data on the U.S. federal funds rate. The weekly survey were conducted by MMS International (part of Standard \& Poor's) in Belmont, California. The methodology of the survey was changed in November 1987 which required us to split the 1980-1993 data set into two subperiods.

From April 29, 1980 until October 30, 1987 the weekly surveys were conducted on a week/next week basis. This implies that individual market participants were asked to formulate their expectation for the federal funds rate for the next week, i.e. for the coming five trading days. Moreover, the survey did not ask 
for the expected value of the federal funds rate at the end of the coming five trading days, but required individual market participants to give their average expected value of the federal funds rate for the next five trading days. The average federal funds rate expectations of the individual market participants were then combined into one market expectation for the average value of the federal funds rate during the next five trading days by taking the median of the individual expected values.

In our sample we confront the average value expected by the market for the next five trading days with the realized average value of the federal funds rate for the same five trading days. By subtracting the realized average value from the expected average value we construct a variable indicating the unexpected average federal funds rate during the next five trading days. This variable then becomes the $R_{i}$ in our model. For reasons of consistency we also compute average returns on the equally weighted bank index $\left(R_{p}\right)$ and the S\&P 500 composite index $\left(R_{m}\right)$. Moreover, these average returns are calculated in such a way that they exactly match the periods of five trading days on which the survey expectations are based.

Starting from April 29, 1980 the surveys were conducted on Tuesdays and were related to the next five trading days (Wednesday through Tuesday). However, on February 17, 1984 the survey day was changed to Friday causing the surveys to be related to Monday through Friday as the next five trading days. In our sample we took this change into account when we calculated $R_{p}, R_{m}$ and $R_{i}$.

Sometimes the survey was conducted one day later than usual, e.g. during 1980-1984 not on the regular Tuesday but on the Wednesday just after this Tuesday. In these cases the survey expectation is related to the next four (and not five) trading days. For these particular cases we computed $R_{p}, R_{m}$ and $R_{i}$ as four-day averages for the relevant four-day periods. In some rare cases the survey was conducted one, two or three days earlier than the regular survey day. In these cases the survey expectations still cover a period of five days. However, the survey periods are not the next five trading days immediately following the earlier survey days, but still the next five trading days as if the surveys had been conducted on the regular days and not on the earlier days.

Starting November 6,1987 the weekly surveys were no longer on a week/next week basis but were related to the two-week Federal Reserve Board's reserve maintenance period beginning on a Thursday and ending on a Wednesday two weeks later. The weekly surveys (still on Fridays) started now to ask market 
participants for their expectation of the federal funds rate on the Wednesday ending the two-week maintenance period. Market participants were no longer asked for the average expected value of the federal funds rate during the remaining trading days of the maintenance period, but they were asked to give the expected value of the federal funds rate at the end of the two-week maintenance period.

Because the weekly surveys are now related to a Wednesday occurring once every two weeks, we are confronted with survey expectations covering different numbers of days. The surveys conducted at the first Friday of the two-week maintenance period require market participants to give their expectations for a period of twelve days (eight trading days) ahead, while the surveys at the second Friday of the same maintenance period cover an expectation period of five (three trading days) ahead. In order to deal with this phenomenon in an adequate way we split the November 1987/December 1993 sample into two subsamples. The first subsample uses the expectations for the federal funds rate eight trading days ahead. By subtracting the realized value of the federal funds rate at the end of the eight trading days (corresponding to the Wednesday ending the maintenance period) from the expected value based on the survey, we are able to compute the unexpected federal funds rate at the end of the next eight trading days. This variable then becomes the $R_{i}$ in our model. For reasons of consistency we also compute the end-of-period returns on the equally weighted bank index $\left(R_{p}\right)$ and the S\&P 500 composite index $\left(R_{m}\right)$. Moreover, these end-of-period returns are calculated in such a way that they exactly match the periods of eight trading days on which the survey expectations are based. For the second subsample using the expectations for the federal funds rate three trading days ahead, we follow exactly the same methodology. Naturally, all variables are constructed for the relevant three days.

Just as for the 1980-1987 period we corrected our data set for surveys not conducted on the regular Fridays, but on an earlier or later day. 


\subsection{The Period 1974-1993 Using ARIMA Processes}

In this section, we present our results on the interest rate sensitivity of U.S. bank stock returns using time series processes to generate unexpected interest rates. ARIMA models are estimated for both three-month Treasury bills and tenyear Treasury bonds. Model selection is performed on the basis of the Akaike and Schwarz lag-length selection criteria. As the interest rate sensitivity results are quite similar for the two selection criteria, we only report results obtained using the Schwarz criterion. The estimation results for equation (7.1) are presented in Table 7.1. In order to address the serial correlation that is present in the residuals in a number of cases, we have allowed for a first-order moving average in the residuals where appropriate. This moving average appears to capture the error term dynamics satisfactorily.

The empirical results in Table 7.1 are presented for the whole sample period as well as for three subperiods. Subperiod 1 covers weekly data during 01/02/1974 - 10/03/1979, subperiod 2 covers 10/10/1979 - 10/14/1987 and subperiod 3 covers $10 / 21 / 1987$ - 12/29/1993. Subdividing our total sample into these subsamples was motivated by two events during the sample period. On October 6, 1979 the Federal Reserve Board changed its operating procedures for monetary policy, as was indicated above. On October 19, 1987 the stock market crash took place. Chow-tests for structural breaks indicate that both events led to significantly different estimation results between the pre- and post-event periods.

From Table 7.1 we can infer that our results are quite robust to the choice of the interest rate variable. In all cases the results are qualitatively similar. For the whole period the standard result of negative interest rate sensitivity of bank stock returns obtains. Interestingly, analysis of the subperiod results reveals that negative interest rate sensitivity is entirely concentrated in the second subperiod (1979-1987), in which the sensitivity is very significantly present. In the 19741979 period no significant interest rate sensitivity is present and after the stock market crash of 1987, the significant interest rate sensitivity disappears again. Returns on bank stocks appear to react differently to interest rate movements in different periods. 


\section{Table 7.1}

Regression results on the interest rate sensitivity of bank stock returns, 1974 1993, using ARIMA models

$$
R_{p t}=\beta_{0}+\beta_{m} R_{m t}+\beta_{i} R_{i t}+e_{p t}+\theta e_{p t-1}
$$

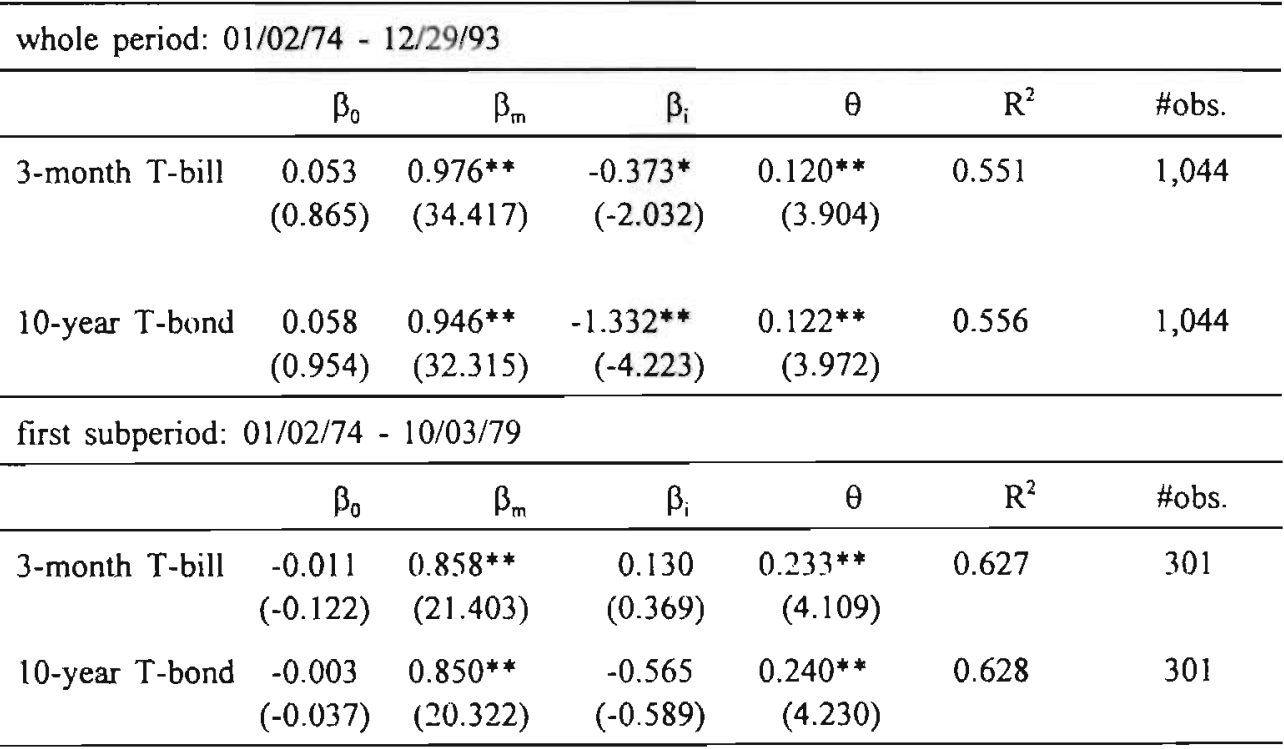

second subperiod: $10 / 10 / 79-10 / 14 / 87$

\begin{tabular}{lcrrrrr}
\hline & $\beta_{0}$ & $\beta_{\mathrm{m}}$ & $\beta_{\mathrm{i}}$ & $\theta$ & $\mathrm{R}^{2}$ & \#obs. \\
\hline 3-month T-bill & 0.103 & $0.844^{* *}$ & $-0.679^{* *}$ & $0.148^{* *}$ & 0.606 & 419 \\
& $(1.327)$ & $(22.397)$ & $(-3.940)$ & $(3.035)$ & & \\
\multirow{2}{*}{ 10-year T-bond } & 0.123 & $0.792^{* *}$ & $-1.902^{* *}$ & $0.127^{* *}$ & 0.627 & 419 \\
& $(1.631)$ & $(20.887)$ & $(-6.654)$ & $(2.065)$ & & \\
\hline
\end{tabular}

third subperiod: $10 / 21 / 87-12 / 29 / 93$

\begin{tabular}{lrrrrrrr}
\hline & $\beta_{0}$ & $\beta_{\mathrm{m}}$ & $\beta_{\mathrm{i}}$ & & $\theta$ & $\mathrm{R}^{2}$ & \#obs. \\
\hline 3-month T-bill & 0.043 & $1.258^{* *}$ & -1.010 & & 0.524 & 324 \\
& $(0.295)$ & $(18.487)$ & $(-1.037)$ & & & \\
10-year T-bond & 0.050 & $1.237^{* *}$ & -0.331 & & 0.522 & 324 \\
& $(0.348)$ & $(18.135)$ & $(-0.312)$ & & & \\
\hline
\end{tabular}

Notes: $t$ statistics are reported in parentheses; ${ }^{*}\left({ }^{* *}\right)$ indicates statistical significance at the $5 \%(1 \%)$ level. 


\subsection{The Period 1980-1993 Using Survey Data}

This section is devoted to the empirical results on the interest rate sensitivity of bank stock returns when survey data are used to determine unexpected interest rates. Because of variation in the survey methodology, as described above, in Table 7.2 we report results for two separate survey periods: 1980-1987 and 1987-1993.

\section{Table 7.2}

Regression results on the interest rate sensitivity of bank stock returns, 19801993, using interest survey data

$$
\mathrm{R}_{\mathrm{pt}}=\beta_{0}+\beta_{\mathrm{m}} \mathrm{R}_{\mathrm{mt}}+\beta_{\mathrm{i}} \mathrm{R}_{\mathrm{it}}+\mathrm{e}_{\mathrm{pt}}+\theta \mathrm{e}_{\mathrm{pt}-1}
$$

First survey period: 04/29/1980 - 10/16/87

\begin{tabular}{lcccccc}
\hline & $\beta_{0}$ & $\beta_{\mathrm{m}}$ & $\beta_{\mathrm{i}}$ & $\theta$ & $\mathrm{R}^{2}$ & \#obs. \\
\hline whole period & 0.132 & $0.885^{* *}$ & -0.228 & $0.129^{* *}$ & 0.598 & 391 \\
& $(1.547)$ & $(23.617)$ & $(-1.434)$ & $(2.541)$ & & \\
subperiod & $0.301^{* *}$ & $0.791^{* *}$ & $-0.375^{*}$ & $0.138^{* *}$ & 0.521 & 264 \\
04/29/80-05/10/85 & $(2.838)$ & $(16.204)$ & $(-2.109)$ & $(2.250)$ & & \\
subperiod & -0.249 & $1.042^{* *}$ & 0.357 & - & 0.754 & 127 \\
05/17/85-10/16/87 & $(-1.865)$ & $(19.471)$ & $(1.017)$ & & & \\
\hline Second survey period: $11 / 06 / 87$ & $-12 / 22 / 93$ & & & & \\
\hline \multicolumn{7}{c}{$\beta_{0}$} \\
\hline 8-days-ahead & 0.061 & $1.222^{* *}$ & 0.448 & - & 0.459 & 160 \\
expectations & $(0.223)$ & $(11.451)$ & $(1.020)$ & & & \\
3-days-ahead & -0.181 & $1.160^{* *}$ & 0.502 & - & 0.453 & 160 \\
expectations & $(-1.133)$ & $(11.333)$ & $(1.777)$ & & & \\
\hline
\end{tabular}

Notes: $t$ statistics are reported in parentheses; ${ }^{*}\left({ }^{* *}\right)$ indicates statistical significance at the $5 \%(1 \%)$ level. 
Results for the first survey period are reported in the top panel of Table 7.2. The results for the entire 1980-1987 period indicate that no significant interest rate sensitivity is present. When the period is subdivided, however, it becomes apparent that interest rate sensitivity is significantly present in the subperiod 1980-1985, but not in the subperiod 1985-1987. Below, we will elaborate on this change of interest rate sensitivity.

Our results for the second survey period, 1987-1993, are reported in the bottom panel of Table 7.2. The results for the two subsamples based on eighttrading-days-ahead expectations and three-trading-days-ahead expectations are reported separately ${ }^{3}$. No significant interest rate sensitivity is present. Overall we conclude, as in section 7.2 , that returns on bank stocks appear to react differently to interest rate movements in different periods.

\subsection{Interpretation and Conclusion}

Using weekly data for the period 1974-1993 and using the forecast errors of ARIMA processes in order to model the unexpected interest rate, we provide empirical evidence on the interest rate sensitivity of the stock returns of the twenty largest U.S. bank holding companies. As in most previous studies, we do not find statistically significant interest rate sensitivity during the 1970s and strong evidence of negative interest rate sensitivity during the 1980s. However, the statistically significant relation disappears completely during the second half of the 1980s. The latter result is also obtained when we use survey data to model the unexpected interest rate.

On October 6, 1979 the Federal Reserve Board announced a switch from interest rates to unborrowed reserves as its short-term operating target, which led to an increase in the level and variability of interest rates. In our empirical analysis we use this event as the switch date for the significant change in the interest rate sensitivity of the stock returns of the twenty largest U.S. bank holding companies. The latter is consistent with Aharony, Saunders and Swary (1986) who published a study on the October 1979 event in which they showed that after the monetary policy switch, banks started to experience significant interest rate sensitivity.

\footnotetext{
3 The estimation results for the three-trading-days-ahead expectations were generated by omitting one outlier. Hamilton (1996) notes that 'spectacular ouliers' are quite common for federal funds rate data.
} 
However, Kane and Unal (1988) have serious problems with this type of analysis which is focused on finding so-called switch points in the data. They argue: "Presuming a sharp causal connection between specific monetary or regulatory events and shifts in regression parameters goes beyond the inferential reach of the data actually examined". They apply this general argument to the 1978-1979 period by referring to numerous developments that might jointly or individually have supported expectations revisions large enough to induce a shift in the return-generating processes for bank stocks. The late 1970 s were characterized by the many ways in which banking regulators sought to help their regulatees to reduce burdens that deposit-rate ceilings would otherwise have imposed. Examples include the authorization by the Federal Reserve Board of Money Market Certificates and automatic transfer service (ATS) accounts in May 1978.

Our empirical results for the 1980s show a breakdown of the statistically significant interest rate sensisitivity of U.S. bank stock returns during the second half of the 1980s. This result is qualitatively independent of the methodology chosen for modelling the unexpected interest rate variable: both the ARIMA and survey data generate this result. In the ARIMA case we find as statistically significant switching point the October 1987 stock market crash while in the case of the survey data the switching point appears to be in May 1985. However, for the ARIMA case the date of May 1985 would still be a statistically significant switching point. Following Kane and Unal we observe that it is very hard to identify one switching point, even more so when we realize that the ARIMA and survey data results are related to different interest rate variables. The ARIMA results use the market-determined three-month Treasury bill and ten-year Treasury bond rates. The survey data employ the federal funds rate, which is an overnight rate and is essentially not market-determined but set by the Federal Reserve.

In our interpretation, given the previous remarks, we believe that the breakdown of interest rate sensitivity of U.S. bank stock returns should be viewed as a process which developed gradually and became significantly visible during the second half of the $1980 \mathrm{~s}^{4}$. The increase of interest rates due to the October 1979 event caused many insolvencies of savings and loan (S\&L) associations. These S\&Ls found themselves locked into negative interest margins (low fixed rates on the assets side and high floating rates on the liabilities side). The S\&L

\footnotetext{
${ }^{4}$ We would like to thank George Kaufman for suggesting this interpretation.
} 
crisis led to an increase of interest rate risk awareness on the part of bankers and regulators. A gradual process of an increasing professionalization of interest rate risk management by banks started. Moreover, hedging of interest rate risk became easier and cheaper because of the explosive growth of derivatives markets trading interest rate futures and options. All this led to a situation in which banks started to control the amount of interest rate risk they were willing to accept and to reduce their sensitivity to unexpected interest rate movements. 


\section{Chapter 8}

\section{Summary and Conclusion}

\subsection{Summary}

In the introductory chapter 1 we note that recent events of financial disorder (international debt crisis, junk bond crisis, stock market crashes, bank failures) have caused renewed interest in the subject of financial fragility. Davis (1992) defines financial fragility as a state of balance sheets offering heightened vulnerability to default in a wide variety of circumstances. A fragile financial system is more vulnerable to future outbreaks of financial disorder.

During the 1980s and beginning of the 1990s, among others, the U.S., Norway, Sweden, Finland, Japan, France, Italy, and the United Kingdom were confronted with substantial problems at large banks.

The aim of this thesis is to analyze the recent banking problems from a theoretical (chapter 2), empirical (chapters 3, 4, 5, and 7) and institutionalregulatory (chapter 6) point of view. The empirical chapters 3, 4, and 7 focus on the U.S., while chapter 5 deals with Norway, Sweden, and Finland.

Chapter 2 discusses the various theories of financial fragility and disorder. We first present theories of financial fragility characterized by a full understanding of risk, i.e. uncertainty can be reduced to the 'correct and objective' probability distribution. These theories, being the rational expectations and efficient markets literature and the literature on rational bubbles and runs, contain a postive view on periods of financial disorder. Basically, these periods of financial disruption are not causing serious damage to financial markets and the economy since agents are fully risk aware. In this context such periods are non-events. The chapter continues by discussing other theories of financial fragility, comprised of the literature on unanticipated credit rationing, irrational bubbles and euphoria, and asymmetric information. The common element of these theories is that they all analyze a financial system characterized by an incomplete understanding of risk, thereby leaving room for uncertainty. However, they differ from each other in the way they model uncertainty. The irrational bubbles and euphoria literature is extreme in the sense that uncertainty is completely untractable and invincible. The other theories take positions somewhere in between 
the polar cases of uncertainty and risk.

The central argument of chapter 2 is that globalization of financial markets, financial innovation and financial deregulation can work out in three ways:

* Imperfectly competitive or oligopolistic financial markets are opened to the forces of national and international competition and are becoming more operationally efficient, thereby generating welfare gains.

* The innovation process may increase debt ratios and volatility in asset prices and as a result financial fragility in the sense of vulnerability of the financial system to future outbreaks of financial disorder. If, however, the risks involved are known and correctly priced by market participants, then these periods of financial disorder are unlucky, but calculated events. Increased financial fragility may lead to more frequent periods of financial disorder without causing serious damage to the functioning of financial markets and the economy.

* If increased financial innovation and financial fragility go together with a lack of understanding of the risks involved, then underpricing and lack of risk awareness by financial agents will aggravate the consequences of a period of financial disorder: not fully calculated events may trigger shifts in confidence, affecting markets more than appears warranted by their significance and leading to a financial crisis.

Taking into account the remarks made above, the financial fragility debate boils down to the debate on risk and uncertainty. Based upon their subjective perception of the applicability of risk, uncertainty, or something in between, academics, regulators, and practitioners will come to different conclusions with respect to the functioning of financial markets and the desirability of regulation.

Chapter 3 deals with extreme value theory and market assessments of the riskiness of banks in the U.S. Since the 1970s the U.S. banking system has experienced major changes in terms of new financial products, deregulation, increasing competition, lower margins and changing risk attitudes.

In the literature a consensus exists that distributions of asset returns are fattailed. We use a non-parametric tail index estimator based on extreme value theory to shed light on the empirical distributions of stock returns for the twenty largest U.S. bank holding companies between January 1973 and December 
1993. Since the tail index is a good indicator of thickness of the tails, it provides an accurate measure of the degree of riskiness of the underlying bank stocks. Based on this criterion, we find that the riskiness of seven of the twenty bank holding companies has increased significantly after the start of deregulation in 1980. Moreover, for fourteen out of twenty bank holding companies we find large increases in the probabilities that the stock prices of these banks experience a one-week return of $20 \%$ or $30 \%$ (both positive and negative).

The 1980s witnessed the greatest crisis in U.S. commercial banking since the Great Depression. Boyd and Gertler (1994) show that banks with the largest total assets contributed in a significantly disproportionate way to aggregate loan losses. The intuition is that, while deregulation and financial innovation led to increased overall competition for the banking industry, the existing regulatory environment tended to subsidize risk taking by large banks more than that by small banks (too-big-to-fail policy). The study by Boyd and Gertler corresponds with our empirical findings of increased riskiness of several of the twenty largest U.S. bank holding companies.

In chapter 4, extending the analysis of Wolfson (1990), we present an empirical analysis of indicators of financial fragility in the U.S. banking sector (commercial banks and S\&Ls). For the commercial banking sector our main conclusion is that the increased variability in the assets of failed banks as a percentage of total bank assets can be explained for a substantial part by the increase of the net bank losses as a percentage of average bank loans. It is this deterioration in the loan performance of the commercial banking sector (third world loans, junk bonds, real estate loans) that led to the largest U.S. bank failures since the banking crisis of 1929-1933. This could suggest that banks' risk awareness and risk pricing were not taking account of the increased riskiness of U.S. commercial banking. Evidence of this increased riskiness was presented in chapter 3.

For the $S \& L$ sector we can conclude that the main factors accounting for the 'instability' in the S\&L sector are the decrease in the S\&L interest margin and, in particular, the decrease of the home mortgages share in total financial S\&L assets. The last variable indicates riskier investment policies of S\&Ls. Starting at the beginning of the 1980s when a lot of S\&Ls found themselves locked into negative interest margins (low fixed rates on the assets side and high floating rates on the liabilities side because of a restrictive monetary policy), they decided to take a bet on the deposit insurance system in order to try to save their heads. This was done by investing in riskier products like options, futures and 
junk bonds. Deregulation enabled S\&Ls to do this. Especially in the second half of the 1980 s the effects of the risk taking became visible in the form of S\&L insolvencies and failures.

Chapter 5 contains an empirical analysis of the Scandinavian banking crisis at the end of the 1980s and the beginning of the 1990s. In this chapter we present maximum likelihood estimates for pooled banking data of Norway, Sweden and Finland during the period 1980-1992. Our empirical analysis shows strong evidence that mounting credit losses played a significant role in the banking crises of Norway, Sweden and Finland. At the same time we observe that the bank failures and insolvencies were not caused by a significant deterioration of net interest margins. A logical interpretation could be that banks have not been able to charge adequate risk premia in order to be compensated for the higher lending risks after deregulation had taken effect. This resulted in built-up capital reserves being too small in order to be able to bear the credit losses and, consequently, in massive bank failures and insolvencies.

The focus of chapter 6 is upon the international dimension to regulation in two areas (banking and securities business) which, while they have common considerations, also raise different issues. The focus is upon two issues in internationally co-operative regulatory strategies: systemic stability and competitive neutrality. Two central themes emerge. Firstly, while in some areas there is a potential case for international co-ordination to increase the effectiveness of regulation for systemic stability reasons, issues of competitive neutrality might be dominant and, at times, in conflict with the requirements of prudential regulation for systemic stability.

Secondly, specific examples of international co-ordination (the examples chosen are the 1988 Basle Capital Convergence Arrangements with respect to banking and the 1993 European Union's Capital Adequacy Directive with respect to securities business) demonstrate that the approaches adopted may be inefficient in two respects: they do not achieve their systemic stability or competitive neutrality objectives, and the two objectives may be in conflict with the resultint compromise, being sub-optimum for both.

Chapter 7 presents an empirical analysis of the interest rate sensitivity of U.S. bank stock returns. The contribution of this chapter to the literature is twofold.

First, using weekly data for the period 1974-1993 and using the forecast errors of autoregressive integrated moving average (ARIMA) processes in order 
to model the unexpected interest rate, we provide empirical evidence on the interest rate sensitivity of the stock returns of the twenty largest U.S. bank holding companies. As in most previous studies, we do not find statistically significant interest rate sensitivity during the $1970 \mathrm{~s}$ and strong evidence of negative interest rate sensitivity during the $1980 \mathrm{~s}$. However, the statistically significant relation disappears completely during the second half of the 1980s. This result is qualitatively independent of using the three-month Treasury bill rate or the rate on ten-year Treasury bonds as input for the ARIMA modelling of the unexpected interest rate variable. Interestingly, our result indicates that. contrary to the existing literature which only covers the period until the mid$1980 \mathrm{~s}$, the interest rate sensitivity of bank stock returns varies with the subperiod considered. The only other paper incorporating recent data is Robinson (1995). Robinson employed quarterly data in contrast to the weekly data in our analysis. His results are quite mixed in the sense that the sign of the interest rate sensitivity appears to depend on the choice of the interest rate variable in his time series models.

The second contribution of this chapter is to use survey data in order to model the unexpected interest rate variable. This is an alternative approach compared to the existing literature. In this chapter we use weekly survey data on the U.S. federal funds rate for the period April 29, 1980 until December 22, 1993. The survey was conducted by Money Market Services (MMS) International (part of Standard \& Poor's) in Belmont, California. The weekly surveys generate a market expectation for the federal funds rate for a certain survey period which is then confronted with the realized value of the federal funds rate during the same survey period. This enables us to calculate an unexpected change in the federal funds rate for the relevant survey period which is then used for estimating the interest rate sensitivity. We find a statistically significant negative interest rate sensitity for the period April 1980 through May 1985. Since then, the statistically significant relation between unexpected federal fund rate changes and bank stock retums has broken down. This result is consistent with our previous findings where we used the forecast errors of ARIMA processes related to the three-month Treasury bill rate and the ten-year Treasury bond rate as a proxy for unanticipated interest rate movements. Also in the latter case we found a breakdown of the interest rate sensitivities during the second half of the $1980 \mathrm{~s}$.

In our interpretation we believe that the breakdown of interest rate sensitivity of U.S. bank stock returns should be viewed as a process which developed gradually and became significantly visible during the second half of the $1980 \mathrm{~s}$. 
The increase of interest rates due to the October 1979 event caused many insolvencies of savings and loan (S\&L) associations. These S\&Ls found themselves locked into negative interest margins (low fixed rates on the assets side and high floating rates on the liabilities side). The S\&L crisis led to an increase of interest rate risk awareness on the part of bankers and regulators. A gradual process of an increasing professionalization of interest rate risk management by banks started. Moreover, hedging of interest rate risk became easier and cheaper because of the explosive growth of derivatives markets trading interest rate futures and options. All this led to a situation in which banks started to control the amount of interest rate risk they were willing to accept and to reduce their sensitivity to unexpected interest rate movements.

\subsection{Conclusion}

Apart from the country-specific conditions, the banking crises studied in this thesis also contain a structural component which played an important role in all banking crises. This component relates to the fact that deregulation and increased competition structurally change the market environment in which banks operate. Before deregulation had come into effect, regulation acted as a protection to banks. The key elements to the underlying banking structure were: low degrees of competition, the existence of restrictive practices, cartels and anti-competitive mechanisms, high entry barriers into banking, and limited growth of bank assets and size of balance sheets. Restrictive regulation almost invariably creates economic rents which have the effect of enhancing the value of the banking franchise. It is also the case that non-price competition created a degree of excess capacity that would not be sustainable in a more competitive market environment. Overall, therefore, the impact of the regulatory environment was to create excess capacity, monopolistic profits and economic rents in the banking industry.

The immediate impact of deregulation is likely to be an initial stock adjustment response by banks towards new steady state sustainable balance sheet positions. Financial institutions have a desired portfolio structure for a given set of market and regulatory conditions, and if any of these conditions change, the desired portfolio changes and stock adjustments are made to achieve them. While the new portfolio equilibrium is being achieved through a finite once-forall stock adjustment, the volume of credit is substantially increased. The IMF (199.3a) argues: "The increase in borrowing was broadly based, suggesting that 
the debt accumulation reflected a backlog of unsatisfied demand for credit unleashed after financial liberalization". During such a transitional period of adjustment from a credit-constrained to a credit-liberalized market regime economic agents have to learn the new structural equilibrium relations. As long as learning is still taking place expectations errors need not satisfy any of the optimality properties usually assumed in the rational expectations literature (Pesaran 1987). This implies that in such a transitional phase of learning systematic estimations errors by bankers can be made resulting in inadequate risk premia, huge credit losses and substantial bank failures and insolvencies.

The movement from the regulated to the deregulated regime does not necessarily imply that, once the deregulated and new competitive steady-state equilibrium has been reached, the errors will be repeated. What remains to be determined in each of the case study countries is whether the precarious position of banks is transitory in nature (associated with the once-for-all shock of deregulation and increased competition) and whether, once the impact of stock adjustment effects has been unwound, banks will learn from past mistakes. What can safely be concluded from the experience in the countries studied in this thesis, is that big shocks to banking systems (such as sharp changes in regulation) can easily produce severe reactions. However, it cannot be concluded that the aftermath of such shocks indicates the characteristics of the new deregulated environment itself once the adjustment has been made and the lessons learned.

Nevertheless, the deregulated banking environment may have made banking potentially more fragile. The erosion of the economic rents induced by previous regulation is likely to have made banking a more vulnerable industry than in the past. 



\section{References}

Akerlof, G.A. (1970), "The Market for 'Lemons': Quality Uncertainty and the Market Mechanism", Quarterly Journal of Economics, Vol. 85, pp. 488-500.

Akella, S.R. and S.I. Greenbaum (1992), "Innovations in Interest Rates, Duration

Transformation, and Bank Stock Returns", Journal of Money, Credit and Banking,

Vol. 24, pp. 27-42.

Atle-Berg, S. (1993), "Banking Crises in the Scandinavian Countries", Mimeo, Norges Bank, Oslo.

Bank for International Settlements (1992), Structural Aspects of Financial Markets and Prudential Supervision, 62nd Annual Report, Basle.

Barr, D. and K. Gustavsson (1991), "Debt Consolidation in Progress", Quarterly Review, Sveriges Riksbank, Stockholm.

Basle Committee (1988), International Convergence of Capital Measurement and Capital Standards, Bank for International Settlements, Basle.

Basle Committee (1992), Minimum Standards for the Supervision of International Banking

Groups and their Cross-Border Establishments, Bank for International International Settlements, Basle.

Benink, H.A. (1993a), Financial Integration in Europe, Kluwer Academic Publishers, Dordrecht/Boston/London.

Benink, H.A. (1993b), "Theories of Financial Fragility", Giornale degli Economisti $e$ Annali di Economia, Vol. LI, pp. 539-549.

Benink, H.A. (1994), "Financial Fragility in the U.S.: An Empirical Analysis", Working Paper, Limburg Institute of Financial Economics, Maastricht.

Benink, H.A. and D.T. Llewellyn (1994a), "Deregulation and Financial Fragility: A Case

Study of the U.K. and Scandinavia", in D.E. Fair and R.J. Raymond (eds.), The

Competitiveness of Financial Institutions and Centres in Europe, Kluwer Academic Publishers, Boston/Dordrecht/London, pp. 443-463.

Benink, H.A. and D.T. Llewellyn (1994b), "Fragile Banking in Norway, Sweden and Finland: An Empirical Analysis", Journal of International Financial Markets, Institutions \& Money, Vol. 4, pp. 5-19.

Benink, H.A., C.G. Koedijk and F.G.M.C. Nieuwland (1995), "Extreme Value Theory and Market Assessments of the Riskiness of U.S. Banks", Working Paper, Limburg lnstitute of Financial Economics, Maastricht.

Benink, H.A. and D.T. Llewellyn (1995), "Systemic Stability and Competitive Neutrality Issues in the International Regulation of Banking and Securities", Journal of Financial Services Research, Vol. 9, pp. 393-407. 
Benink; H.A. and C.C.P. Wolff (1996), "Survey Data and the Interest Rate Sensitivity of

I. .S. Bank Stock Retums", Working Paper, Limburg Institute of Financial Economics, Maastricht.

Benston, G.J. (1989), "The Federal 'Safety Net' and the Repeal of the Glass-Steagall Act's Separation of Commercial and Investment Banking", Journal of Financial Services Research, Vol. 2, pp. 287-305.

Benston, G.J. (1994), "International Harmonization of Banking Regulations and Cooperation among National Regulators: An Assessment", Journal of Financial Services Research, Vol. 8, pp. 205-225.

Benston, G.J. and G.G. Kaufman (1995), "Is the Banking and Payments System Fragile?", Journal of Financial Services Research, Vol. 9, pp. 209-240.

Bernanke, B.S. (1983), "Nonmonetary Effects of the Financial Crisis in the Propagation of the Great Depression", American Economic Review, Vol. 73, pp. 257-276.

Bhattacharya, S. and A.V. Thakor, "Contemporary Banking Theory", Journal of Financial Intermediation, Vol. 3, pp. 2-50.

Blanchard, O.J. and M.W. Watson (1982), "Bubbles, Rational Expectations, and Financial Markets", in P.L. Wachtel (ed.), Crises in the Economic and Financial Structure, Lexington Books, Lexington, pp. 295-315.

Boyd, J.H. and M. Gertler (1994), "The Role of Large Banks in the Recent U.S. Banking Crisis, Quarterly Review, Federal Reserve Bank of Minneapolis, Minneapolis, Winter, pp. 2-21.

Brewer, E. and C.F. Lee (1985), "The Impact of Market, Industry, and Interest Rate Risks on Bank Stock Retums", Staff Memorandum, Federal Reserve Bank of Chicago, Chicago.

Bruni, F. and F. Paternò (1995), "Market Discipline of Banks' Riskiness: A Study of Selected Issues", Journal of Financial Services Research, Vol. 9, pp. 303-325.

Carter, M. (1989), "Financial Innovation and Financial Fragility", Journal of Economic Issues, Vol. 23, pp. 779-793.

Chance, D.M. and W.R. Lane (1980), "A Re-examination of Interest Rate Sensitivity in the Common Stocks of Financial Institutions", Journal of Financial Research. Vol. 3, pp. 49-55.

Choi, J.J., E. Elyasiani and K.J. Kopecky (1992); "The Sensitivity of Bank Stock Returns to Market, Interest and Exchange Rate Risks", Journal of Banking and Finance, Vol. 16, pp. 983-1004.

Corrigan, E.G. (1990), Reflections on the 1980s, Seventy-Fifth Annual Report, Federal Reserve Bank of New York, New York.

Corrigan, E.G. (1992), "Challenges Facing the International Community of Bank Supervisors", Quarterly Review, Federal Reserve Bank of New York, New York, Autumn.

Crockett, A.D. (1995), "Financial Fragility: Sources, Prevention, and Treatment", in H.A. Benink (ed.), Coping with Financial Fragility and Systemic Risk, Kluwer Academic Publishers, Boston/Dordrecht/London, pp. 267-277. 
Dale, R. (1993), "Bank Regulation after BCCl", Journal of International Banking Law, pp. 8-17.

Dalheim, B. et al. (1992), "Bank Results in Sweden and Other Nordic Countries", Quarterly Review, Sveriges Riksbank, Stockholm.

Davis, E.P. (1989), "Instability in the Euromarkets and the Economic Theory of Financial Crisis", Discussion Paper, Bank of England, London, No. 43.

Davis, E.P. (1990), "An Industrial Approach to Financial Instability", Discussion Paper, Bank of England, London, No. 50.

Davis, E.P. (1992), Debt, Financial Fragility, and Systemic Risk. Oxford University Press, Oxford.

Dekkers, A.L.M. and L. de Haan (1989), "A Moment Estimator for the Index of an Extreme Value Distribution", The Annals of Statistics, pp. 1833-1855.

Delors Report (1989), Report on Economic and Monetary Union in the European Community, Office of Publications of the European Communities, Luxembourg.

Dimson, E. and P. Marsh (1995), "Capital Requirements for Securities Firms", Journal of Finance, Vol. 50, pp. 821-851.

Economist, The (1992), California's Castles in the Sand, October 10-16, pp. 79-80.

Economist, The (1993), New Tricks to Learn - A Survey of International Banking. April 10-16.

Economist, The (1995), Do-It-Yourself Regulation, April 15-21, pp. 70-71.

Economist, The (1996), The Domino Effect - A Survey of International Banking, April 27May 3.

Englund, P. (1990), "Financial Deregulation in Sweden", European Economic Review, Vol. 34, pp. 385-393.

Fama, E.F. and W.G. Schwert (1977), "Asset Retums and Inflation", Journal of Financial Economics, Vol. 23, pp. 115-146.

Financial Times (1990), The Shadows over U.S. Banking, May 23.

Fisher, I. (1933), "The Debt Deflation Theory of Great Depressions", Econometrica, Vol. 1, pp. 337-357.

Flannery, M.J. and C.M. James (1984), "The Effect of Interest Rate Changes on the Common Stock Returns of Financial Institutions", Journal of Finance, Vol. 39, pp. 1141-1153.

Flood, R.P. and P.M. Garber (1982), "Bubbles, Runs, and Gold Monetization", in P.L. Wachtel (ed.), Crises in the Economic and Financial Structure, Lexington Books, Lexington, pp. 275-293.

Folger, H.R.. J. Kose and J. Tipton (1981). "Three Factors, Interest Rate Differentials and Stock Groups", Journal of Finance, Vol. 36, pp. 323-335.

Friedman, B.M. and D.I. Laibson (1989), "Economic Implications of Extraordinary Movements in Stock Prices", Brookings Papers on Economic Activity, pp. 137-189.

Friedman. M. and A.J. Schwartz (1963), A Monetary History of the United States, 18671960, Princeton University Press. Princeton. 
Galambos, J. (1978), The Asymptotic Theory of Extreme Order Statistics, John Wiley \& Sons. New York.

Gatti, delli D. and M. Gallegati (1995), "Financial Fragility and Economic Fluctuations: Keynesian Views", Economic Notes (Banca Monte dei Paschi di Siena), Vol. 24, pp. 513-554.

(iilbert, R.A. (1990), "Market Discipline of Bank Risk, Theory and Evidence", Economic R''view, Federal Reserve Bank of St. Louis, St. Louis, pp. 3-18.

Goldie, C.M. and R.L. Smith (1987), "Slow Variation with Remainder: Theory and Applications", Quarterly Journal of Mathematics, Vol. 38, pp. 45-71.

Gorton, G. and R. Rosen (1992), "Corporate Control, Portfolio Choice, and the Decline of Banking, Finance and Economic Discussion Paper, Federal Reserve Board, Washington DC. No. 215.

Grundfest, J. (1990), "Internationalization of the World's Securities Markets: Economic Causes and Regulatory Consequences", Journal of Financial Services Research, Vol. 4, pp. 349-378.

Gutt'ntag. J.M. and R.J. Herring (1984), "Credit Rationing and Financial Disorder", Journal of Finance, Vol. 39, pp. 1359-1382.

Haan, L. de (1976), "Sample Extremes: An Elementary Introduction", Statistica Neerlandica, Vol. 30, pp. 161-172

Haan, L. de, S.I. Resnick, H. Rootzen and C.G. de Vries (1989), "Extremal Behavior of Solutions to a Stochastic Difference Equation with Applications to ARCH Processes", Stochastic Processes and their Applications, pp. 213-224.

Hall, M. (1991a), "BCCI: The Issues Raised", Banking World, September.

Hall, M. (1991b), "BCCI: Yet More Questions", Banking World, October.

Hall, M. (1991c), "BCCI: Latest Developments", Banking World, December.

Hall, M. (1992), "BCCI: Spotlight on the Regulators", Banking World, July.

Hall, M. (1993), "BCCI: The Lessons for Bank Supervisors", International Journal of Regulatory Law and Practice, Vol. 3, pp. 298-313.

Hamilton, J.D. (1987), "Monetary Factors in the Great Depression", Journal of Monetary Economics, Vol. 19, pp. 145-169.

Hamilton, J.D. (1996), "The Daily Market for Federal Funds", Journal of Political Econo$m y$, Vol. 104, pp. 26-56.

Heffernan, S. (1996), Modern Banking in Theory and Practice, John Wiley \& Sons, Chichester.

Herring, R.J. (1993), "BCCI: Lessons for International Bank Supervision", Contemporary Policy Issues, Vol. 11, pp. 76-86.

Hester, D.D. (1994), "On the Theory of Financial Intermediation", De Economist, Vol. 142, pp. 133-149.

Hill, B.M. (1975), "A Simple General Approach to Inference about the Tail of a Distribution", The dnnals of Statistics, Vol. 3, pp. 1163-1173.

Hols. M. and C.G. de Vries (1991), "The Limiting Distribution of Extremal Exchange Rate Returns", Journal of Applied Econometrics, Vol. 6, pp. 287-302. 
Home, van J.C. (1985), "Of Financial Innovations and Excesses", Journal of Finance, Vol. 40, pp. 621-631.

Horvitz, P.M. (1995), "Banking Regulation as a Solution to Financial Fragility", Journal of Financial Services Research, Vol. 9, pp. 369-380.

International Monetary Fund (1992a), "Structural Changes and Related Policy Issues in Financial Markets". World Economic and Financial Surveys, Washington DC, September, pp. 2-9.

International Monetary Fund (1992b), "Asset Price Deflation, Balance Sheet Adjustment, and Financial Fragility", World Economic and Financial Surveys, Washington DC, October, pp. 57-68.

International Monetary Fund (1993a), "Deterioration of Bank Balance Sheets", World Economic and Finuncial Surveys, Washington DC, August. pp. 2-22.

International Monetary Fund (1993b), "Booms and Bust in Asset Markets in the 1980s: Causes and Consequences", World Economic and Financial Suncys, Washington DC, December, pp. 1-27.

International Monetary Fund (1995a), "Financial Supervisory and Regulatory Issues", World Economic and Financial Surveys, Washington DC, August, pp. 17-25.

International Monetary Fund (1995b), "Capital Adequacy and Internal Risk Management", World Economic and Financial Surveys, Washington DC, August, pp. 135-149.

Jansen, D.W. and C.G. de Vries (1991), "On the Frequency of Large Stock Returns: Putting Booms and Busts into Perspective", The Review of Economics and Statistics, Vol. 73, pp. 18-24.

Johnston, J. (1984), Econometric Methods, McGraw-Hill Publishing Company, New York. Jordan, J.L. (1995), "Supervision of Derivative Instruments", in H.A. Benink (ed.), Coping with Financial Fragility and Systemic Risk, Kluwer Academic Publishers, Boston/Dordrecht/London, pp. 239-250.

Judge, G.G., R.C. Hill, W.E. Griffiths, H. Lütkepohl and T.C. Lee (1988), Introduction to the Theory and Practice of Econometrics, John Wiley \& Sons, New York.

Kane, E.J. and H. Unal (1988), "Change in Market Assessments of Deposit-Institution Riskiness, Journal of Financial Services Research, Vol. 1, pp. 207-229.

Kaufman, G.G. (1992), The U.S. Financial System: Money, Markets and Institutions, Prentice Hall, Englewood Cliffs.

Kaufman, G.G. (1994), "Bank Contagion: A Review of the Theory and Evidence", Journal of Financial Services Research, Vol. 8, pp. 123-150.

Keeley, M. (1990). "Deposit Insurance, Risk and Market Power in Banking", American Economic Review. Vol. 80. pp. 1183-1200.

Keynes, J.M. (1936), The General Theory of Employment, Interest and Money, Macmillan Cambridge University Press, Cambridge.

Knight, F.K. (1921), Risk, Uncertainty and Profit, University of Chicago Press, Chicago. Koedijk, C.G. M.M.A. Schafgans and C.G. de Vries (1990), "The Tail Index of Exchange Rate Returns", Journal of International Economics, Vol. 29, pp. 93-108. 
Koedijk, C.G. and C.J.M. Kool (1994). "Tail Estimates and the EMS Target Zone", Review of International Economics, Vol. 2, pp. 153-166.

Krugman (1985), "Is the Strong Dollar Sustainable?", The U.S. Dollar - Recent Developments, Outlook, and Policy Options, Federal Reserve Bank of Kansas City, Kansas City, pp. 103-132.

Kwan, S.H. (1991), "Re-examination of Interest Rate Sensitivity of Commercial Bank Stock Returns Using a Random Coefficient Model", Journal of Financial Services Research, Vol. 5, pp. 61-76.

Lane, T.D. (1993), "Market Discipline", IMF Siaff Papers, Vol. 40, pp. 53-88.

Leadbetter, M.R., G. Lindgren and H. Rootzen (1983). Extremes and Related Properties of Random Sequences and Processes, Springer Verlag, Berlin.

Llewellyn, D.T. and M. Holmes (1992), Competition or Credit Controls?, Institute of Economic Affairs, London.

Longin, F.M. (1996), "The Asymptotic Distribution of Extreme Stock Market Retums", Journal of Business, Vol 69, pp. 383-408.

Loretan, M. and P.C.B. Philips (1994), "Testing the Covariance Stationarity of HeavyTailed Time Series: An Overview of the Theory with Applications to Several Financial Datasets", Journal of Empirical Finance, Vol. 1, pp. 211-248.

Marcus, A.J. (1984), "Deregulation and Bank Financial Policy", Journal of Banking and Finance, Vol. 8, pp. 557-565.

Mason, D.M. (1982), "Laws of Large Numbers for Sums of Extreme Values", Annals of Probability, pp. 754-764.

Mayer, C. (1993), "The Regulation of Financial Services: Lessons from the United Kingdom", in J. Dermine (ed.), European Banking in the 1990s, Blackwell Publishers, Oxford.

McCulloch, J.H. (1981), "Interest Rate Risk and Capital Adequacy for Traditional Banks and Financial Intermediaries", in S.J. Maisel (ed.), Risk and Capital Adequacy in Commercial Banks, University of Chicago Press, Chicago.

Meltzer, A.H. (1982), "Rational Expectations, Risk, Uncertainty and Market Responses", in P.L. Wachtel (ed.), Crises in the Economic and Financial Structure, Lexington Books, Lexington, pp. 3-22.

Merton, R.C. (1977), "An Analytic Derivation of the Cost of Deposit Insurance and Loan Guarantees", Journal of Banking and Finance, Vol. 1, pp. 3-11.

Merton, R.C. and Z. Bodie (1992), "On the Management of Financial Guarantees", Financial Management, Winter, pp. 87-109.

Miller, M.H. (1986), "Financial Innovation: The Last Twenty Years and the Next", Journal of Financial and Quantitative Analysis, Vol. 21, pp. 459-471.

Miller, M.H. (1988), "The Modigliani-Miller Propositions after Thirty Years", Journal of Economic Perspectives, Vol. 2, pp. 99-120.

Miller, M.H. (1991), "Leverage", Journal of Finance, Vol. 46, pp. 479-488.

Minsky, H.P. (1975), John Maynard Keynes, Columbia University Press, New York. 
Minsky, H.P. (1977), "A Theory of Systemic Fragility", in E.I. Altman and A.W. Sametz (eds.), Financial Crises: Institutions and Markets in a Fragile Environment, John Wiley \& Sons, New York, pp. 138-152.

Minsky, H.P. (1980), "Capitalist Financial Processes and the Instability of Capitalism", Journal of Economic Issues, Vol. 14, pp. 505-523.

Minsky, H.P. (1982), Inflation, Recession and Economic Policy, M.E. Sharpe, Armonk. Minsky, H.P. (1986), Stabilizing an Unstable Economy, Yale University Press, New Haven and London.

Mishkin, F.S. (1982), "Monetary Policy and Short-Term Interest Rates: An Efficient Markets-Rational Expectations Approach, Journal of Finance, Vol. 37, pp. 63-72.

Modigliani, F. (1988), "MM - Past, Present, Future", Journal of Economic Perspectives, Vol. 2, pp. 149-158.

Mood, A.M., T.A. Graybill and D.C. Boes (1974), Introduction to the Theory of Statistics, McGraw Hill, New York.

Mullineux, A.W. (1990), Business Cycles \& Financial Crises, Harvester Wheatsheaf, Hemel Hempstead.

Muth. J.F. (1961), "Rational Expectations and the Theory of Price Movements", Econometrica, Vol. 29, pp. 315-335.

Norwegian Official Report (1992), Report by the Commission on the Banking Crisis, Government Administration Services, Oslo.

Nyberg, P. and V. Vihriala (1993), "Finnish Banking Crisis and its Handling", Discussion Paper, Bank of Finland, Helsinki. August.

Organization for Economic Co-operation and Development (1989), Competition in Banking, Paris.

Organization for Economic Co-operation and Development (1993), Systemic Risks in Securities Markets, Paris.

Park, S. (1994), "Explanations for the Increased Riskiness of Banks in the 1980s", Economic Review, Federal Reserve Bank of St. Louis, St. Louis, July/August, pp. 3-23.

Parkinson (1980), "The Extreme Value Method for Estimating the Variance of the Rate of Returns", Journal of Business, Vol. 53, pp. 61-65.

Pesaran, M.H. (1987), The Limits to Rational Expectations, Basil Blackwell, Oxford.

Priestley, M.B. (1981), Spectral Analysis and Time Series, Academic Press, London/New York.

Robinson, K.J. (1995), "Interesting Times for Banks since Basle", Financial Industry Study, Federal Reserve Bank of Dallas, Dallas. July, pp. 9-16.

Rothschild, M. and J.E. Stiglitz (1970). "Increasing Risk I: A Definition", Journal of Economic Theory, Vol. 2, pp. 225-243.

Ruding, H.O. (1995), "Fragility in the Banking World", in H.A. Benink (ed.), Coping with Financial Fragility and Systemic Risk, Kluwer Academic Publishers, Boston/Dordrecht/London, pp. 279-285. 
Saunders, A. and P. Yourougou (1990), "Are Banks Special? The Separation of Banking from Commerce and Interest Rate Risk", Journal of Economics and Business, Vol. 42, pp. 171-182.

Schwartz, A.J. (1995), "Coping with Financial Fragility: A Global Perspective", in H.A. Benink (ed.), Coping with Financial Fragility and Systemic Risk, Kluwer Academic Publishers, Boston/Dordrecht/London, pp. 251-257.

Scott, H. and S. Iwahara (1994), "In Search of a Level Playing Field", Occasional Paper, Group of Thirty, Washington DC, No. 46.

Scott, W.L. and R.L. Peterson (1986), "Interest Rate Risk and Equity Values of Hedged and Unhedged Financial Intermediaries, Journal of Financial Research, Vol. 9, pp. 325-329.

Skanland, H. (1992), "Norway's Banking Sector and Economy: Current Situation and Outlook", Economic Bulletin, Norges Bank, Oslo, No. 2.

Solheim, J. (1994), "Norwegian Experience with Financial Liberalization and Banking Problems", in D. Vittas (ed.), Financial Regulation: Changing the Rules of the Game, World Bank, Washington DC.

Steil, B. (1992), "Regulatory Foundations for Global Capital Markets", in R. O'Brien (ed.), Finance and the International Economy, Oxford University Press, Oxford, No. 6.

Stiglitz, J.E. and A. Weiss (1981), "Credit Rationing in Markets with Imperfect Information", American Economic Review, Vol. 71, pp. 393-410.

Stone, B.K. (1974), "Systematic Interest-Rate Risk in a Two-Index Model of Returns", Journal of Financial and Quantitative Analysis, Vol. 9, pp. 709-721.

Sweeney R.J. and A.D. Warga (1986), "The Pricing of Interest Rate Risk: Evidence from the Stock Market", Journal of Finance, Vol. 41, pp. 393-410.

Sijben, J.J. (1993), "Credit Markets, Financial Fragility, and the Real Economy", Kredit und Kapital, Vol. 26, pp. 481-515.

Sijben, J.J. (1994), "Financial Fragility and Macroeconomic Performance: An Overview", in D.E. Fair and R.J. Raymond (eds.), The Competitiveness of Financial Institutions and Centres in Europe, Kluwer Academic Publishers, Boston/Dordrecht/London, pp. 353-379.

Sijben, J.J. (1995), "Comment on Minsky and Calomiris", Journal of Financial Services Research, Vol. 9, pp. 291-297.

Taylor, C.R. (1994), A New Approach to Capital Adequacy Regulation for Banks, Centre for the Study of Financial Innovation, London.

Taylor, C.R. (1995), "Global Financial Fragility and the Private Sector", Journal of Financial Services Research, Vol. 9, pp. 363-368.

Vikkula, K. (1992), "Competitiveness of Finnish Banks in the 1990s", Kansallis Economic Review, No. 1.

White, L.J. (1991), The S\&L Debacle, Oxford University Press, New York/Oxford.

Wolfson, M.H. (1990), "The Causes of Financial Instability", Journal of Post Keynesian Economics, Vol. 12, No. 3, pp. 333-355. 
Yourougou, P. (1990), "Interest-Rate Risk and the Pricing of Depository Financial Intermediary Common Stock", Journal of Banking and Finance, Vol. 14, pp. 803-820. 



\section{Nederlandse Samenvatting}

In het introductie-hoofdstuk 1 werd gesteld dat recente episoden van financiële turbulentie (internationale schuldencrisis, crisis op de markt voor junk bonds, koersval op aandelenmarkten, bankfaillissementen) hernieuwde belangstelling hebben opgewekt voor het onderwerp financiële fragiliteit. Davis (1992) definieert financiële fragiliteit als een staat van zodanige balansverhoudingen dat er een toegenomen kwetsbaarheid ontstaat om in een breed spectrum van omstandigheden aan de financiële verplichtingen te kunnen voldoen. Een fragiel financieel systeem is kwetsbaarder voor het uitbreken van toekomstige perioden van financiële turbulentie.

Gedurende de jaren ' 80 en het begin van de jaren ' 90 werden, onder andere, de Verenigde Staten, Noorwegen, Zweden, Finland, Japan, Frankrijk, Italië en het Verenigd Koninkrijk geconfronteerd met substantiële problemen bij hun grote banken.

Het doel van dit proefschrift is om de recente bankproblemen te analyseren vanuit een theoretisch (hoofdstuk 2), empirisch (hoofdstukken 3, 4, 5 en 7) en een institutioneel/regelgevings-gezichtspunt (hoofdstuk 6). De empirische hoofdstukken 3, 4 en 7 richten zich op de Verenigde Staten, terwijl hoofdstuk 5 zich concentreert op Noorwegen, Zweden en Finland.

Hoofdstuk 2 gaat in op de diverse theorieën van financiële fragiliteit en turbulentie. Allereerst worden er de theorieën gepresenteerd die zich kenmerken door een volledig begrip van risico. Dat wil zeggen dat onzekerheid kan worden gereduceerd tot de 'correcte en objectieve' kansverdeling. Deze theorieën, zijnde de literatuur aangaande rationele verwachtingen en efficiënte markten enerzijds en de literatuur inzake rationele 'bubbles' en 'runs' anderzijds, impliceren een positieve visie wat betreft perioden van financiële turbulentie. Vanwege het uitgangspunt dat economische agenten volledig risicobewust zijn, veroorzaken zulke perioden van financiële disruptie geen serieuze schade voor de financiële markten en de economie. In het vervolg van hoofdstuk 2 worden andere theorieën van financiële fragiliteit aan de orde gesteld, namelijk de literatuur inzake onverwachte kredietrantsoenering, irrationele 'bubbles' en euforie, en de literatuur die uitgaat van asymmetrische informatie. Het gemeenschappelijke element van genoemde theorieën is dat zij allen een financieel systeem analyseren dat wordt gekenmerkt door een onvolledig begrip van risico. 
Het gevolg is dat er ruimte is voor onzekerheid die niet kan worden gekwantificeerd in de vorm van kansverdelingen. Echter, bedoelde theorieën verschillen van elkaar in de wijze waarop zij deze onzekerheid modelleren. De literatuur aangaande irrationele 'bubbles' en euforie is extreem daar zij ervan uitgaat dat onzekerheid geheel niet te traceren en te overwinnen valt. De overige theorieën plaatsen zich ergens tussen de polen van risico en onzekerheid in.

De centrale boodschap van hoofdstuk 2 is dat de processen van globalisering van tinanciële markten, financiële innovaties en financiële deregulering op drie manieren kunnen uitwerken:

* Niet volledig concurrerende of oligopolistische markten worden geopend voor de krachten van nationale en internationale concurrentie en worden daardoor efficiënter in operationele zin. Het gevolg is dat er welvaartswinsten worden gegenereerd.

* Het innovatieproces kan ertoe leiden dat schuldratio's en de volatiliteit van activaprijzen toenemen met als gevolg een toename van financiële fragiliteit in de zin van kwetsbaarheid van het financiële systeem voor het uitbreken van toekomstige perioden van financiële turbulentie. Indien, echter, de hiermee gepaard gaande risico's door de economische agenten volledig worden gekend en geprijsd, dan zijn zulke perioden van financiële turbulentie ongelukkige, maar volledig ingecalculeerde gebeurtenissen. Een toegenomen financiële fragiliteit kan op deze wijze samengaan met een grotere frequentie van perioden van turbulentie zonder dat er sprake is van serieuze schade voor de financiële markten en de economie.

* Indien toegenomen financiële innovaties en fragiliteit samengaan met een gebrek aan begrip van de risico's, dan kan het niet correct prijzen en het gebrek aan risicobewustheid de gevolgen van een periode van financiële turbulentie verergeren: niet volledig ingecalculeerde gebeurtenissen kunnen vertrouwensschokken genereren, markten sterker beïnvloeden dan gerechtvaardigd lijkt door de omvang van de gebeurtenissen en daarmee tot een financiële crisis leiden.

Het voorgaande samenvattende kan worden gesteld dat het debat inzake financiële fragiliteit nauw samenhangt met het debat aangaande risico en onzekerheid. Gebaseerd op de eigen subjectieve belevingswereld met betrekking tot het spectrum van risico aan de ene kant en onzekerheid aan de andere kant, zullen 
wetenschappers, toezichthouders en professionele dienstverleners tot verschillende conclusies komen aangaande de werking van financiële markten en de wenselijkheid van regulering.

Hoofstuk 3 gaat in op de theorie van extreme waarden en de marktperceptie van de risicograad van banken in de Verenigde Staten (VS). Sinds de zeventiger jaren heeft het Amerikaanse bankwezen grote veranderingen doorgemaakt in termen van nieuwe financiële producten, deregulering, toegenomen concurrentic, lagere marges en veranderende risicohoudingen.

In de literatuur bestaat er een consensus dat de kansverdelingen die de rendementen van activa beschrijven een dikstaartig karakter hebben. In dit hoofdstuk wordt gebruik gemaakt van een non-parametrische schatter van een index die de mate van dikstaartigheid weergeeft. Deze schatter komt voort uit de theorie van extreme waarden. Het doel van de schattingen is om inzicht te verkrijgen in de empirische verdelingen van de aandelenrendementen van de twintig grootste houdstermaatschappijen van bankaandelen in de VS gedurende de periode januari 1973 tot en met december 1993. Daar de 'staart-index' een goede indicator is van de mate van dikstaartigheid van de verdelingen, kan deze index tevens worden beschouwd als een accurate maatstaf van de risicograad van de onderliggende bankaandelen. Uit de schattingen blijkt dat de risicograad van zeven van de twintig houdstermaatschappijen van bankaandelen significant is toegenomen na de start van deregulering in 1980. Bovendien blijkt dat veertien van de twintig banken een grote stijging vertonen van de kans dat hun aandelen in één week een rendement hebben van $20 \%$ of $30 \%$ (zowel positief als negatief).

De jaren ' 80 werden gekenmerkt door de grootste crisis bij de Amerikaanse handelsbanken sinds de Grote Depressie. Boyd en Gertler (1994) laten zien dat juist de banken met de grootste balanstotalen op significant disproportionele wijze hebben bijgedragen aan de totale verliezen in het Amerikaanse bankwezen. De intuïtie hierbij is dat, hoewel deregulering en financiële innovaties leidden tot een toename van de concurrentie in de Amerikaanse bankensector in zijn geheel, de bestaande structuur van regelgeving neigde tot het stimuleren van riskant gedrag bij vooral de grote banken ('too-big-to-fail policy'). In dit opzicht correspondeert de studie van Boyd en Gertler met de in hoofdstuk 3 gepresenteerde resultaten die een toegenomen risicograad laten zien bij een aantal van de twintig grootste houdstermaatschappijen van bankaandelen in de VS. 
Gebaseerd op het werk van Wolfson (1990) wordt in hoofdstuk 4 een empirische analyse gepresenteerd van indicatoren van financiële fragiliteit in de Amerikaanse bancaire sector (handelsbanken en spaarbanken). Voor de sector van handelsbanken is de belangrijkste conclusie dat de toegenomen variabiliteit in de ratio van de activa van banken die failliet zijn gegaan als percentage van de activa van alle banken voor een groot deel kan worden verklaard uit de stijging van de netto kredietverliezen als percentage van de gemiddeld uitstaande leningen. Het was deze verslechtering in de 'performance' van de kredietuitzettingen (leningen aan Derde Wereld-landen, junk bond-leningen, onroerend goed-leningen) die heeft geleid tot de grootste Amerikaanse bankfaillissementen sinds de bankencrisis van de periode 1929-1933. Het voorgaande zou kunnen betekenen dat het gedrag van banken inzake de risicobewustheid en het prijzen van risico niet in voldoende mate rekening heeft gehouden met de toegenomen risicograad van de Amerikaanse handelsbanken. Empirisch bewijs aangaande deze toegenomen risicograad werd gepresenteerd in hoofdstuk 3 .

Voor de sector van spaarbanken kan worden geconcludeerd dat de belangrijkste factoren die hebben bijgedragen aan de problemen in deze sector zijn enerzijds de daling van de rentemarge en anderzijds, en in het bijzonder, de daling van de woninghypotheken als percentage van de totale uitzettingen van de spaarbanken. De ontwikkeling van deze laatste variable duidt op een riskanter uitzettingenbeleid van spaarbanken. Aan het begin van de jaren ' 80 werden vele spaarbanken geconfronteerd met een negatieve rentemarge als gevolg van een restrictief monetair beleid in een situatie dat de spaarbanken zich kortlopend gefinancierd hadden en de toevertrouwde middelen tegen een lage rente voor lange tijd hadden uitgezet. Om uit deze impasse te geraken besloten vele spaarbanken in riskante produkten zoals opties, futures en junk bonds te beleggen. Het proces van deregulering vanaf 1980 stelde hen hiertoe in staat. In het bijzonder gedurende de tweede helft van de jaren ' 80 werden de gevolgen van de genomen risico's zichtbaar in de vorm van een groot aantal faillissementen en insolventies van spaarbanken.

Hoofdstuk 5 bevat een empirische analyse van de Scandinavische bankencrisis aan het einde van de jaren ' 80 en het begin van de jaren ' 90 . In dit hoofdstuk worden 'maximum likelihood' schattingen gepresenteerd voor in één dataset gecombineerde bancaire data van Noorwegen, Zweden en Finland. Uit de empirische analyse komt sterk naar voren dat massale kredietverliezen een significante rol hebben gespeeld in de bancaire crises van Noorwegen, Zweden en Finland. Tegelijkertijd blijkt dat de bancaire faillissementen en insolventies niet 
zijn veroorzaakt door een significante verslechtering van de rentemarges. Een logische interpretatie van het voorgaande zou kunnen zijn dat de banken niet in staat zijn geweest om adequate risicopremies door te berekenen als compensatic voor de toegenomen kredietrisico's nadat deregulering in gang was gezet. Hierdoor ontstond bij de banken een situatie waarin de opgebouwde reserves te gering waren om de grote kredietverliezen te kunnen dragen met als consequentie massale faillissementen en insolventies van banken.

In hoofdstuk 6 wordt aandacht besteed aan de internationale dimensie van regulering met betrekking tot bancaire en effecteninstellingen. De analyse richt zich in het bijzonder op twee punten waarop internationale coördinatie van regelgeving zich kan richten: coördinatie ten behoeve van het handhaven en bevorderen van de stabiliteit van het financiële systeem ('systemic stability') en coördinatie ten behoeve van het versterken van de competitieve neutraliteit ('competitive neutrality'). Twee hoofdthema's komen aan bod in dit hoofdstuk.

Ten eerste, alhoewel er deelgebieden zijn waar sprake is van een behoette aan internationale coördinatie teneinde de effectiviteit van regelgeving te vergroten uit hoofde van 'systemic stability'-redenen, kunnen kwesties van 'competitive neutrality' dominant zijn en soms in conflict met de gewenste regelgeving ter bevordering van 'systemic stability'.

Ten tweede, er zijn specifieke voorbeelden van internationale coördinatie te geven, zoals het Bazelse Akkoord van 1988 met betrekking tot bancaire instellingen en de Richtlijn Kapitaaltoereikendheid van de Europese Unie uit 1993 inzake effecteninstellingen, die aangeven dat de gekozen benaderingen inefficiënt zijn op twee manieren: enerzijds realiseren zij niet de doelstellingen van 'systemic stability' en 'competitive neutrality' en anderzijds zijn de twee doelstellingen vaak met elkaar in conflict met als gevolg een compromis dat suboptimaal is vanuit het gezichtspunt van beide doelstellingen.

Hoofdstuk 7 bevat een empirische analyse van de rentegevoeligheid van de bancaire aandelenrendementen in de VS. De bijdrage van dit hoofdstuk aan de literatuur is tweeledig.

Ten eerste, uitgaande van wekelijkse data voor de periode 1974-1993 en gebruik makende van de voorspelfouten van zogeheten 'autoregressive integrated moving average' (ARIMA) processen teneinde de onverwachte rente te modelleren, wordt empirisch bewijs gepresenteerd aangaande de rentegevoeligheid van de aandelenrendementen van de twintig grootste Amerikaanse houdstermaatschappijen van bankaandelen. Zoals in de meeste voor- 
gaande studies is er geen statistisch significante rentegevoeligheid gedurende de jaren ' 70 en is er een sterk significante negatieve rentegevoeligheid in de eerste helft van de tachtiger jaren. Echter, deze statistisch significante rentegevoeligheid verdwijnt geheel tijdens de tweede helft van de jaren '80. Dit resultaat wordt kwalitatief niet beïnvloed door de keuze voor het driemaands rendement op schatkistpapier of voor het tienjaars rendement op staatsobligaties als inputvariabele ter berekening van de onverwachte rente.

Een tweede bijdrage van dit hoofdstuk is dat er gebruik wordt gemaakt van survey data teneinde de onverwachte rente te modelleren. Dit is een alternatieve benadering ten opzichte van de bestaande literatuur. In dit hoofdstuk wordt gebruik gemaakt van survey data betreffende de Amerikaanse 'federal funds rate' voor de periode 29 april 1980 tot en met 22 december 1993. De survey werd georganiseerd door Money Market Services (MMS) International (deel uitmakend van Standard \& Poor's) in Belmont, Californië. De wekelijkse surveys genereren een marktverwachting voor de federal funds rate gedurende een bepaalde periode, welke wordt geconfronteerd met de feitelijk gerealiseerde wairde van de federal funds rate gedurende dezelfde survey-periode. Dit creëert de mogelijkheid om de onverwachte verandering in de federal funds rate te berekenen voor de relevante survey-periode, welke vervolgens wordt gebruikt om de rentegevoeligheid te schatten. Het resultaat van de schatting is een statistisch significante negatieve rentegevoeligheid gedurende de periode april 1980 tot en met mei 1985. Sindsdien is de statistisch significante relatie tussen onverwachte veranderingen in de federal funds rate en bancaire aandelenrendementen verdwenen. Dit resultaat is consistent met het resultaat dat werd gegenereerd door middel van de ARIMA-processen ter modellering van de onverwachte rente. Ook in dat geval was er sprake van een verdwijnen van de rentegevoeligheid gedurende de tweede helft van de jaren ' 80 .

Het voorgaande resultaat van het verdwijnen van de rentegevoeligheid is waarschijnlijk het gevolg van een proces dat zich geleidelijk ontwikkelde en pas significant zichtbaar werd gedurende de tweede helft van de de jaren ' 80 . Ten gevolge van de rentestijging samenhangende met de keuze voor een restrictief monetair beleid in oktober 1979 zijn veel Amerikaanse spaarbanken in de problemen geraakt. De spaarbankcrisis leidde tot een toegenomen aandacht voor de problematiek van het renterisico bij bankiers en toezichthouders. Dit zette een geleidelijk proces in gang van een professionalisering van het management van renterisico door banken. Tegelijkertijd werd het afdekken van renterisico goedkoper door de explosieve groei van derivatenmarkten waarop onder andere rentefutures en rente-opties worden verhandeld. Dit alles leidde tot een situatie 
waarin banken in toenemende mate hun renterisico gingen beheersen en hun gevoeligheid voor onverwachte rente-ontwikkelingen gingen reduceren. 



\section{Curriculum Vitae}

Harald A. Benink was born on August 31, 1964 in Geldrop, The Netherlands. In 1988 he obtained with distinction a Master's degree in Economics from Tilburg University and in 1991 he received with distinction a Master's degree in Financial Economics at the Tilburg Institute for Advanced Studies in Management.

In 1988 Harald Benink worked as assistant professor of monetary economics at the Department of Economics of Tilburg University. Since 1989 he has been working as assistant professor of finance at the Faculty of Economics and Business Administration of Maastricht University (previously called University of Limburg). He was also adviser of the Banking and Financial Services Group of Moret Ernst \& Young during the period 1989-1996.

In 1990 Harald Benink participated in the summer intern program of the International Monetary Fund in Washington DC, working at the European Department. In September 1994 he was the organizer of the conference "Coping with Financial Fragility: A Global Perspective" in co-operation with the editors of the Journal of Financial Services Research and Ernst \& Young Europe.

Harald A. Benink werd op 31 augustus 1964 geboren in Geldrop. In 1988 behaalde hij cum laude het doctoraal examen Economie aan de Katholieke Universiteit Brabant en in 1991 studeerde hij cum laude af aan de postdoctorale managementopleiding FinancieelEconomisch Management van het Tilburgs Instituut voor Academische Studies.

In 1988 werkte Harald Benink als toegevoegd docent bij de sectie Geld-, Krediet- en Bankwezen van de Faculteit der Economische Wetenschappen van de Katholieke Universiteit Brabant. Sinds 1989 is hij als universitair docent werkzaam bij de sectie Financieel Management en Financiële Markten van de Faculteit der Economische Wetenschappen en Bedrijfskunde van de Universiteit Maastricht (voorheen genoemd Rijksuniversiteit Limburg). Gedurende de periode 1989-1996 was hij tevens als adviseur verbonden aan de sector Bancaire Instellingen van Moret Emst \& Young.

In 1990 participeerde Harald Benink in het zomerprogramma van het Internationaal Monetair Fonds in Washington DC, waar hij werkzaam was op het European Department. In september 1994 was hij de organisator van de conferentie "Coping with Financial Fragility: A Global Perspective" in samenwerking met de editors van de Journal of Financial Services Research en Ernst \& Young Europe. 
